\title{
Development Of Safety Analysis Codes And Experimental Validation For A Very High Temperature Gas-Cooled Reactor
}

Nuclear Energy Research Initiative Report January 2005 to September 2005

Chang Oh Cliff Davis

Richard Moore

Hee C. No

Jong Kim

Goon C. Park

John Lee

W. Martin

James Holloway

September 2005

The INL is a U.S. Department of Energy National Laboratory operated by Battelle Energy Alliance 


\section{Development of Safety Analysis Codes and Experimental Validation for a Very High Temperature Gas-Cooled Reactor}

Chang Oh, Cliff Davis, and Richard Moore, Idaho National Laboratory (INL)

Hee C. NO and Jong Kim, KAIST

Goon C. Park, SNU

John Lee and W. Martin, U. Michigan

September 2005

Idaho National Laboratory

Idaho Falls, Idaho 83415

Prepared for the

U.S. Department of Energy

Office of Nuclear Energy

Under DOE Idaho Operations Office

Contract DE-AC07-05ID14517 


\section{CONTENTS}

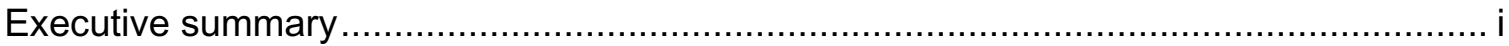

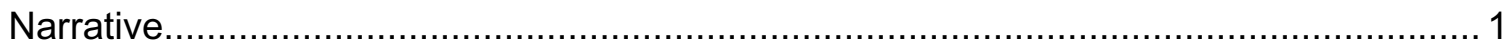

Task 1. CFD Thermal Hydraulics Benchmark Code Development (KAIST) .............. 1

Task 1-1. V\&V Simulation of GAMMA Code ................................................. 1

Task 1-2. Air Ingress Analysis for PBR and PMR .................................... 1

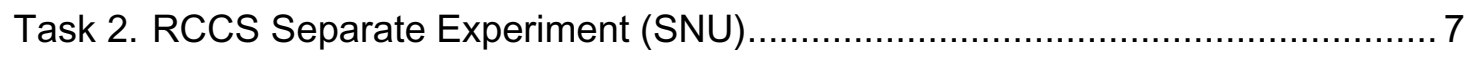

Task 2-1. Upper Pool Cooling Trip Test.................................................... 7

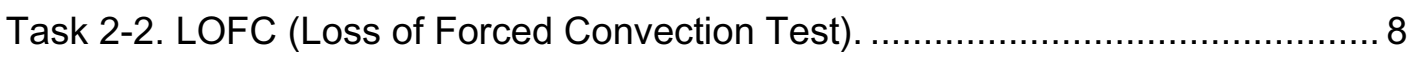

Task 2-3. Emissivity Measurement test. .............................................. 10

Task 2-4. New Separate Effect Tests for the Water Pool of the SNU-RCCS. ....... 12

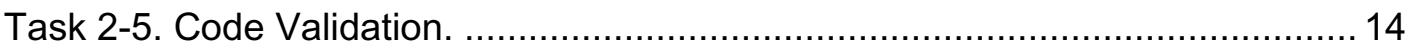

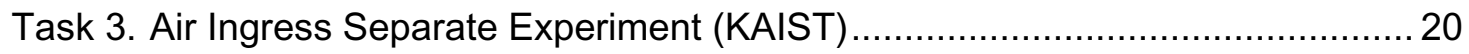

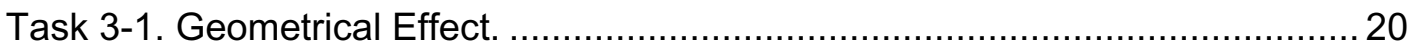

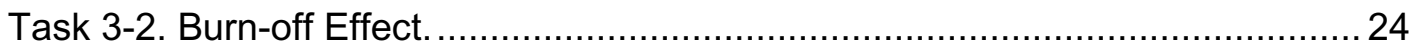

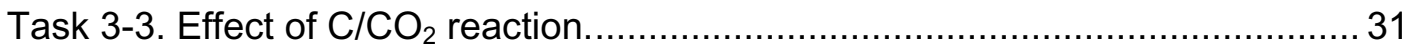

Task 4. Improvement of System Codes (INL) ............................................. 34

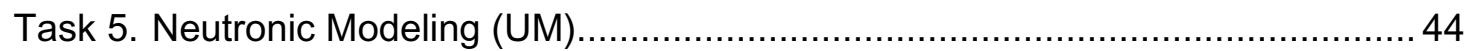

Task 6. Verification and Validation (INL \& KAIST) ….................................... 51

APPENDIX-A. References

APPENDIX-B. Project Milestone/Deliverable Summary 


\title{
INTERNATIONAL NUCLEAR ENERGY RESEARCH INITIATIVE
}

\section{Development of Safety Analysis Codes and Experimental Validation for a Very-High- Temperature Gas-Cooled Reactor}

\author{
PI: \\ Chang Oh, Idaho National Laboratory (INL) \\ Collaborators: $\quad$ Cliff Davis and Richard Moore, INL \\ Hee C. NO and Jong Kim, KAIST \\ Goon C. Park, SNU \\ John Lee, W. Martin, and James Holloway, U. Michigan \\ Project Start Date: October $2003 \quad$ Project Number: 2003-013-K
}

Projected End Date: September 2005

\section{Research Objective:}

The very high temperature gas-cooled reactors (VHTGRs) are those concepts that have average coolant temperatures above $900^{\circ} \mathrm{C}$ or operational fuel temperatures above $1250^{\circ} \mathrm{C}$. These concepts provide the potential for increased energy conversion efficiency and for high-temperature process heat application in addition to power generation and nuclear hydrogen generation. While all the High Temperature Gas Cooled Reactor (HTGR) concepts have sufficiently high temperatures to support process heat applications, such as desalination and cogeneration, the VHTGR's higher temperatures are suitable for particular applications such as thermochemical hydrogen production. However, the high temperature operation can be detrimental to safety following a loss-of-coolant accident (LOCA) initiated by pipe breaks caused by seismic or other events. Following the loss of coolant through the break and coolant depressurization, air from the containment will enter the core by molecular diffusion and ultimately by natural convection, leading to oxidation of the in-core graphite structures and fuel. The oxidation will release heat and accelerate the heatup of the reactor core.

Thus, without any effective countermeasures, a pipe break may lead to significant fuel damage and fission product release. The Idaho National Laboratory (INL) has investigated this event for the past three years for the HTGR. However, the computer codes used, and in fact none of the world's computer codes, have been sufficiently developed and validated to reliably predict this event. New code development, improvement of the existing codes, and experimental validation are imperative to narrow the uncertainty in the predictions of this type of accident.

The objectives of this Korean/United States collaboration are to develop advanced computational methods for VHTGR safety analysis codes and to validate these computer codes.

\section{Research Progress:}

The collaborators for this research project are the INL, the Korea Advanced Institute of Science and Technology (KAIST), Seoul National University (SNU), and the University of Michigan (UM).

This project consists of six tasks for developing, improving, and validating computer codes for analysis of the VHGTR. These tasks are: (1) develop a computational fluid dynamics code for benchmarking, (2) perform a reactor cavity cooling system (RCCS) experiment, (3) perform an air ingress experiment, (4) improve the system analysis codes RELAP5/ATHENA and MELCOR, (5) develop an advanced neutronic model, and 
(6) verify and validate the computer codes. The primary activities and key accomplishments for each task are summarized below.

Task 1 - CFD thermal hydraulic benchmark code development (KAIST). Prof. NO developed a multidimensional gas multi-component mixture analysis code (GAMMA) to predict the thermo-fluid and chemical reaction behaviors in a multi-component mixture system related to an air/water ingress accident in a HTGR. The multi-dimensional governing equations consist of the basic equations for continuity, momentum conservation, energy conservation of the gas mixture, and the mass conservation of each species. GAMMA has the capability to handle the multi-dimensional convection and conduction behaviors as well as heat transfer within the solid components, free and forced convection between a solid and a fluid, and radiative heat transfer between the solid surfaces. Also, the basic equations are formulated with a porous media model to consider a pebble bed-type HTGR. We performed the code V\&V simulations for the various experiments and benchmark tests ranging from the basic simple problems to the integral test problems on the molecular diffusion, graphite oxidation, air ingress, heat transport in a pebble-bed and the reactor cavity cooling system, etc. As a final step, we applied the GAMMA code to assess the system behaviors during the air ingress accident following the complete break of main pipes. We first performed the chemical reaction test for the VELUNA pebble oxidation experiment in order to select proper reaction models and then the analysis of the air ingress accident for PBMR 268MWt. In the GAMMA analysis, significant rise in pebble temperature was observed at the bottom of the core due to graphite oxidation. Since the air ingress process depends on the vault conditions, further analysis coupled with more detailed vault or containment modeling would be necessary as a future study. As a further plant application of GAMMA code, we conducted two analyses: IAEA GT-MHR benchmark calculation for LPCC and air ingress analysis for PMR 600MWt. The GAMMA code shows comparable peak fuel temperature trend to those of other country codes. The analysis result for air ingress shows much different trend from that of previous PBR analysis: later onset of natural circulation and less significant rise in graphite temperature.

Task 2 - RCCS experiment (SNU). Prof. Park performed experiments for SNU-RCCS to provide the experimental data for the validation of the thermal hydraulic code being developed at KAIST and to evaluate the performance of the system. The three categories of experiments were performed in the SNU-RCCS facility; 1) upper pool cooling trip test, 2) LOFC (Loss of Forced Convection) experiment, 3) emissivity measurement experiment. In addition new separate effect test device was designed having same heat transfer area but different diameter and total number of U-bands of air cooling pipe. New design has smaller pressure drop in the air cooling pipe than previous one as designed with larger diameter and less number of U-bands. With the device, additional experiments have been performed to obtain temperature distributions in the water pool, and on the surface and the center of cooling pipe on axis.

Calculations for new separated effect test were conducted using CFX code and MARS 3.0a code for code-toexperiment validation and code-to-code benchmark respectively. The results will be used to optimize the design of SNU-RCCS.

Task 3 - Air ingress experiment (KAIST). Prof. NO experimentally investigated the geometrical effect, burn-off effect and minor chemical reactions. To investigate the geometrical effects on nuclear graphite oxidation in the regime where the chemical effect is the rate-controlling process, the concept of internal surface density was introduced into the Arrhenius-type reaction model. Using the 16 different samples of IG110 graphite, which have different ratios of external surface to volume, the value of internal surface density was obtained as $17260 \mathrm{~m}^{-1}$. It was revealed that the external surface reaction is very small compared to the total reaction for the IG-110 graphite.

The burn-off effect on the rate of reaction was experimentally investigated and the modeling was performed. As a result, the time variation of the reaction rate was well predicted by the suggested numerical simulation. 
The chemical characteristics of $\mathrm{C} / \mathrm{CO}_{2}$ reaction were investigated. As a result, its activation energy was $295 \pm 8 \mathrm{~kJ} / \mathrm{mol}$ and the order of reaction was 0.9 . It turns out that the rate of $\mathrm{C} / \mathrm{CO}_{2}$ reaction is much smaller than the rate of the $\mathrm{C} / \mathrm{O}_{2}$ reaction, which is dominant in HTGR air-ingress below 1400 . A correlation of the reaction rate was developed.

Task 4 - Improvement of system codes (INL). The RELAP5/ATHENA code was extended to model the molecular diffusion of several species of gas through a system represented by a general network of control volumes wherein any control volume can be connected to several other control volumes on its inlet and outlet sides. Previously, the molecular diffusion modeling was applicable only to a gas mixture with two species of gas and only to gas mixture in a pipe wherein each control volume was connected only to one other control volume at each of its two ends. In the extended modeling, the molecular diffusion modeling can be applied to gas mixtures containing up to five species of gas ( $\mathrm{He}, \mathrm{N}_{2}, \mathrm{O}_{2}, \mathrm{CO}_{2}$, and $\mathrm{CO}$ ) and any individual control volume may be connected up to twelve other control volumes on either its inlet or outlet sides. Assessment of the updated RELAP5/ATHENA code was performed and the assessment of the diffusion modeling in the RELAP5/ATHENA code indicates correct modeling for a general system containing several species of gases. The Multiple Junction Test Problem showed correct modeling of diffusion in a network of control volumes with multiple inlet and outlet junctions. The Bulb Experiment Test Problem showed calculated and measured results to be in fair to good agreement for diffusion in a system with three species of gas and involving for a period of time the special case of diffusion against the concentration gradient.

Task 5 - Neutronic modeling (UM). The UM team has also made substantial progress in completing a full-core model of the VHTR, and have made substantial progress in several areas. A neutronic model for particle fuel has been created and tested that accounts for the double heterogeneity posed by the particle fuel and is valid at all levels of analysis, from a microsphere cell to full core. We have demonstrated that a two-region model of the six-region microsphere cell is an excellent model. We have also examined the effect of "clipping" fuel particles on the surface of the compact cell and developed two approaches to eliminate clipped cells, which are artificial and have a substantial effect on the neutronic results. Our preferred model preserves the packing fraction of the particle fuel, results in no clipped particles, and maintains a simple cubic lattice within the compact fuel region. In addition, the thermal/hydraulic feedback model has been completed and we have used it to obtain a converged flux-power distribution for a full-core configuration at beginning of life. This will soon be extended to depletion with temperature feedback. Finally, we have made substantial progress toward the goal of performing full-core depletion calculations with Monte Carlo, a necessary step to predicting the decay heat production source in the reactor. A preliminary full-core MONTEBURNS depletion with a constant temperature $(900 \mathrm{~K})$ throughout the core has been completed using our parallel version of MONTEBURNS. This was used to predict the decay heat production source in the core as a function of burnup. 


\section{Narrative:}

\section{Task 1: CFD TH Code Development (KAIST)}

\section{Task Status and Significant Results}

The objective of this task is to develop a multidimensional system analysis tool for the thermo-fluid transport processes in VHTGRs. Following the code V\&V for the 14 test items, the GAMMA code is applied to analyze the air ingress accident for the typical pebble-bed and prismatic core gas-cooled reactors, PBMR268MWt and PMR600MWt.

\section{Task 1-1: V\&V simulation of GAMMA code}

The V\&V simulations for GAMMA are summarized in the following Table 1-1. The 14 simulation cases have been finished.

Table 1-1 Assessment matrix for the GAMMA code

\begin{tabular}{|c|c|c|c|}
\hline Test & ID & Test Facility & Phenomena \\
\hline \multirow[t]{2}{*}{ Basic Test } & B1 & NWU pipe network & Flow balancing in a complex pipe network \\
\hline & $\mathrm{B} 2$ & NWU blowdown & Pressure transient and critical flow \\
\hline Natural Circulation & N1 & $\begin{array}{l}\text { NACOK natural convection } \\
\text { test }\end{array}$ & Natural convection in a pebble bed \\
\hline \multirow{3}{*}{$\begin{array}{l}\text { Molecular } \\
\text { Diffusion }\end{array}$} & M1 & Duncan \& Toor's experiment & Multicomponent molecular diffusion \\
\hline & M2 & $\begin{array}{l}\text { Inverse U-tube single/multiple } \\
\text { channel tests }\end{array}$ & $\begin{array}{l}\text { Binary molecular diffusion and natural } \\
\text { convection }\end{array}$ \\
\hline & M3 & Vertical slot exp. & $\begin{array}{l}\text { Local circulation effect on molecular } \\
\text { diffusion }\end{array}$ \\
\hline \multirow[t]{3}{*}{ Chemical Reaction } & $\mathrm{C} 1$ & Ogawa's circular tube test & Chemical reactions in a IG-110 \\
\hline & $\mathrm{C} 2$ & Takahashi's annular tube test & Chemical reactions in a IG-110 \\
\hline & $\mathrm{C} 3$ & VELUNA pebble bed test & Chemical reactions in a pebble bed \\
\hline \multirow[t]{2}{*}{ Air Ingress } & A1 & Inverse U-tube air ingress exp. & $\begin{array}{l}\text { Molecular diffusion (MD), natural } \\
\text { convection (NC), and chemical reactions } \\
(\mathrm{CR})\end{array}$ \\
\hline & A2 & $\begin{array}{l}\text { HTTR-simulated air ingress } \\
\text { exp. }\end{array}$ & $\begin{array}{l}\text { MD, NC, and CR } \\
\text { Multi-D effect on air ingress process }\end{array}$ \\
\hline \multirow[t]{3}{*}{ Heat Removal } & H1 & SANA-1 afterheat removal test & $\begin{array}{l}\text { Pebble temperature distributions: steady } \\
\text { power tests and power ramp up/down tests }\end{array}$ \\
\hline & $\mathrm{H} 2$ & HTTR RCCS mockup test & $\begin{array}{l}\text { Air convection and radiation in a reactor } \\
\text { cavity }\end{array}$ \\
\hline & $\mathrm{H} 3$ & SNU RCCS test & $\begin{array}{l}\text { Air convection and radiation in a reactor } \\
\text { cavity }\end{array}$ \\
\hline
\end{tabular}

\section{Task 1-2: Air Ingress Analysis for PBR and PMR}

For the analysis of an air ingress accident for a pebble-bed gas-cooled reactor, we selected PBMR 268MWt as a reference reactor because of well-described design information and performed the sensitivity analyses on air volumes in a vault. In order to simulate the chemical reactions during air ingress process, the following 
chemical reaction models were selected and well tested with the pebble oxidation experiment conducted in the VELUNA test facility [1] as shown at Figure 1-1:

A. $\mathrm{CO}-\mathrm{O}_{2}$ exothermic bulk reaction: [Dryer \& Glassmann]

$$
R_{C O}\left(k g / m^{3}-s\right)=-2.24 \times 10^{12} \exp (-167400 / \bar{R} T) \rho\left(\rho / W_{O_{2}}\right)^{1 / 4}(\rho / W)^{1 / 2} Y_{C O} Y_{O_{2}}^{1 / 4} X_{H_{2} O}^{1 / 2}
$$

B. $\mathrm{C}-\mathrm{O}_{2}$ exothermic surface reaction: [VELUNA]

$$
R_{C}{ }^{w}\left(\mathrm{~kg} / \mathrm{m}^{2}-\mathrm{hr}\right)=720 \exp (-16140 / T) P_{O_{2}}
$$

C. $\mathrm{CO}_{2}-\mathrm{C}$ endothermic surface reaction: [Moormann]

$$
R_{C}{ }^{w}\left(\mathrm{~kg} / \mathrm{m}^{2}-\mathrm{s}\right)=\frac{0.145 \exp (-25000 / T) P_{\mathrm{CO}_{2}}}{1+3.4 \times 10^{-5} \exp (7000 / T) P_{\mathrm{CO}_{2}}{ }^{0.5}}
$$

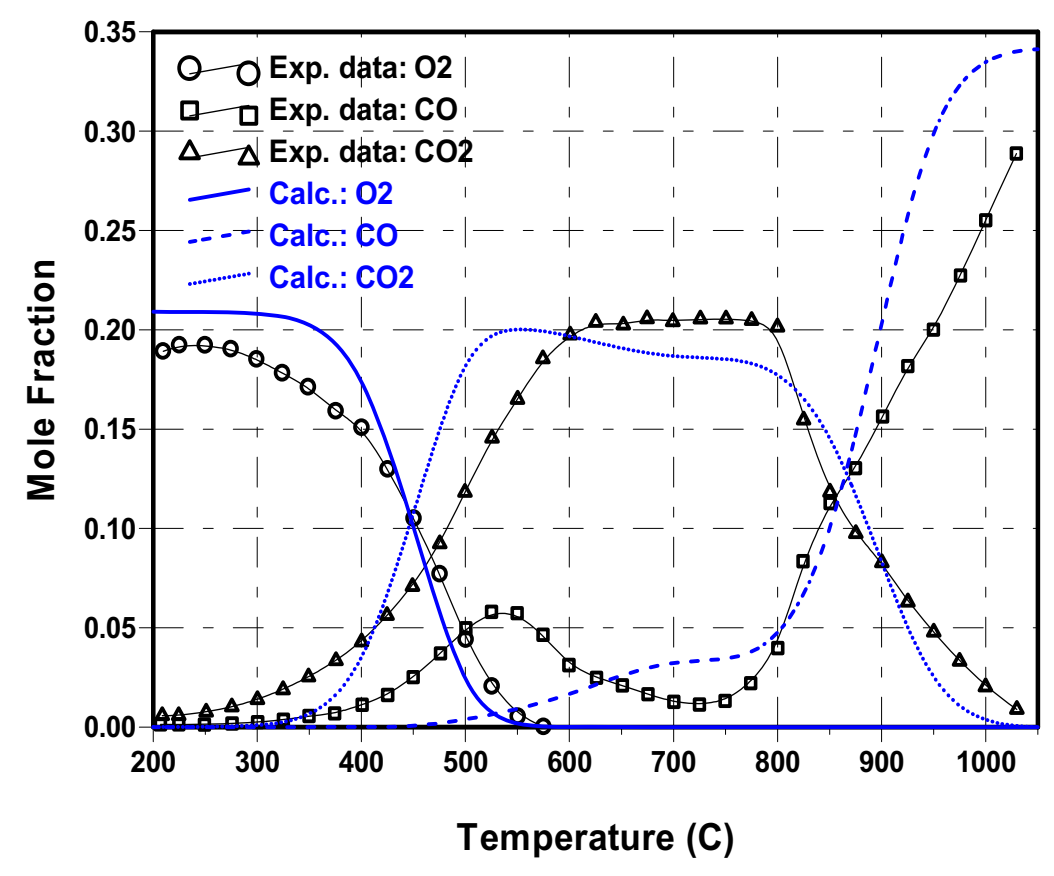

Figure 1-1. Graphite oxidation test for the VELUNA pebble-bed experiment.

As pebble temperature increases, more oxygen is consumed, producing the heavy gases, $\mathrm{CO}$ and $\mathrm{CO}_{2}$. At middle temperature, the produced $\mathrm{CO}_{2}$ is balanced with the depleted $\mathrm{CO}_{2}$ due to the depletion reaction $(\mathrm{C})$. At high temperature larger than $800^{\circ} \mathrm{C}$, the $\mathrm{CO}$ production reactions $(\mathrm{A}, \mathrm{C})$ become dominant.

In PBMR 268MWt [2], helium at $500^{\circ} \mathrm{C}$ enters the pebble core through the riser holes and exits at $900^{\circ} \mathrm{C}$, at a flow rate of $129 \mathrm{~kg} / \mathrm{s}$. Figure 1-2 shows the GAMMA modeling of PBMR and the helium flow paths at the right figure. The pebble core and reactor cavity are modeled by 2-D geometry, and all the solid structures are modeled by 2-D geometry. For all the cavities or plenums, the radiation heat exchanges are considered. 

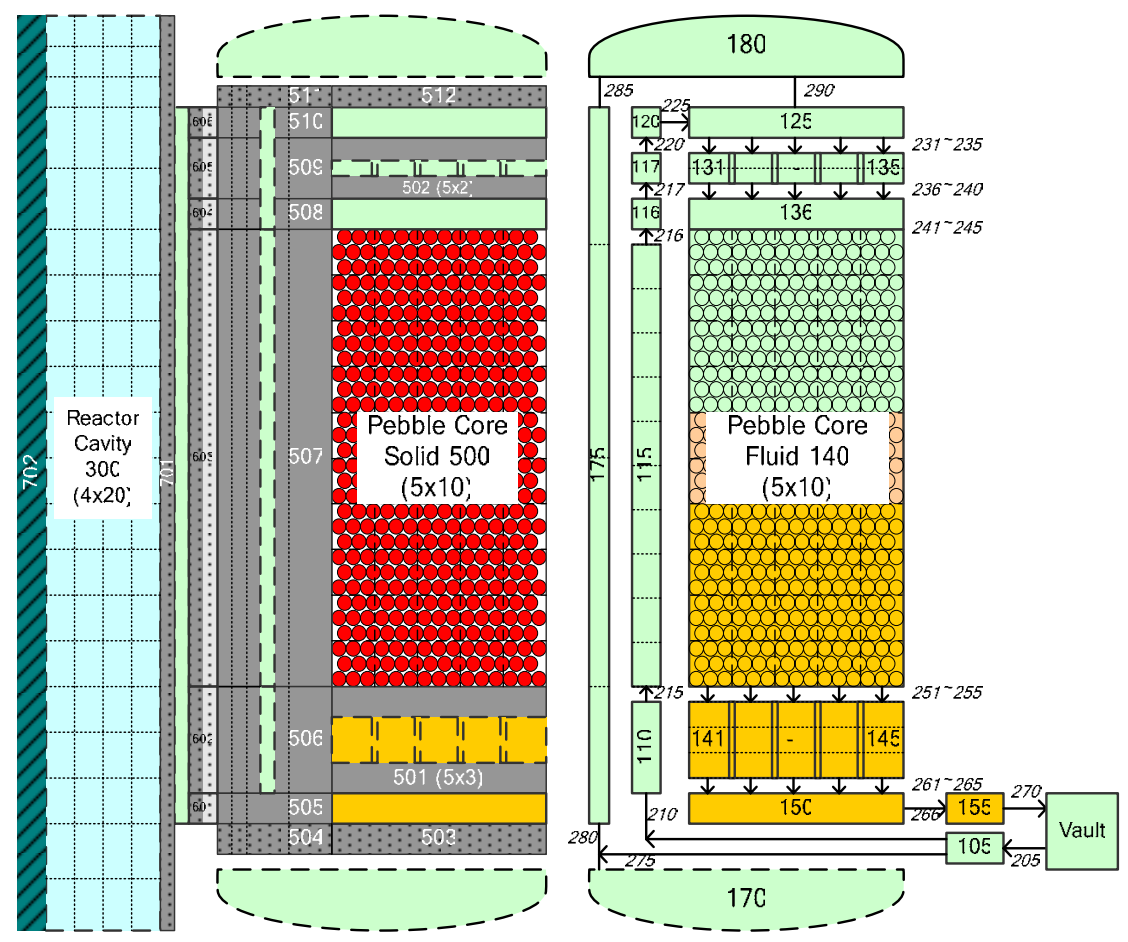

Figure 1-2. GAMMA nodalization for PBMR 268MWt: solid and reactor cavity (left) and fluid component connection (right).

As shown at Figure 1-3, a significant rise in pebble temperature was observed at the bottom of the core due to graphite oxidation when the natural convection occurs at about $230 \mathrm{hrs}$. The sensitivity analyses on air volumes, as shown at Figure 1-4, show that, as air volume decreases, the onset time of natural convection is delayed gradually. However, the peak fuel temperature is not a simple function of air volume but depends on the combination of the bottom reflector temperature and air ingress flow. When the bottom reflector temperature is low, more oxygen survives through the bottom reflector.

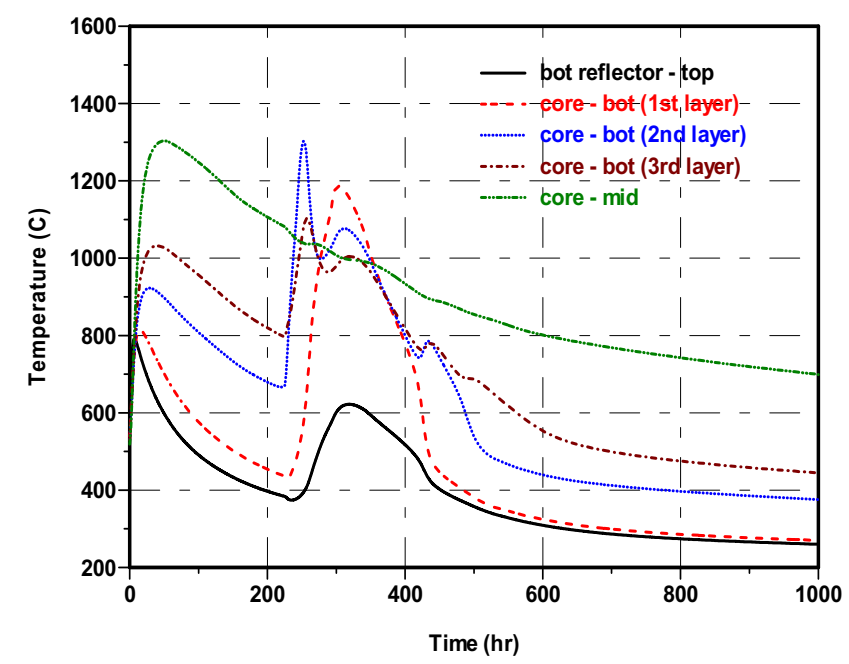

Figure 1-3. Predicted axial temperatures in the center $\operatorname{ring}\left(\mathrm{V}_{\text {air }}=50,000 \mathrm{~m}^{3}\right)$. 


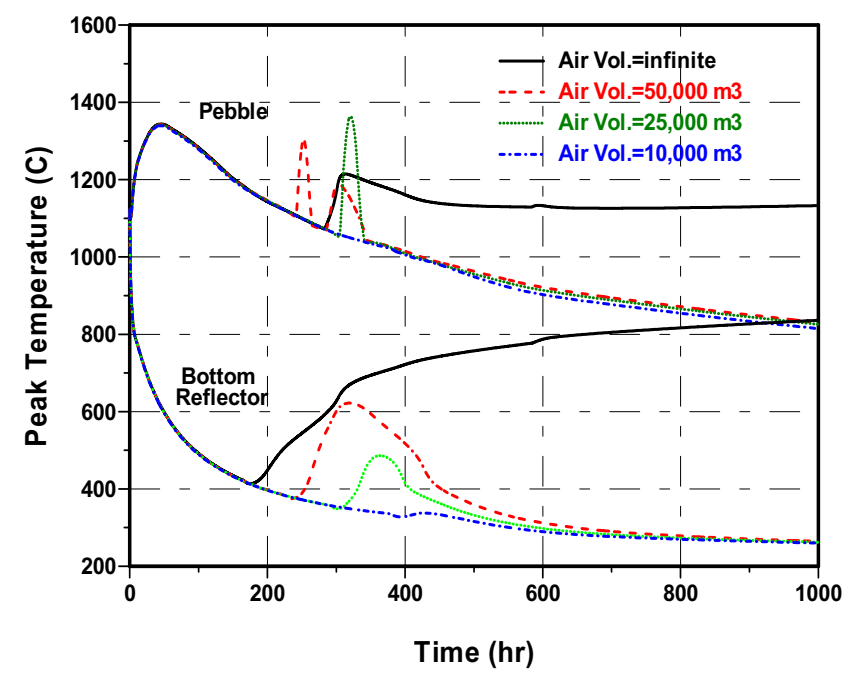

Figure 1-4. Predicted peak fuel temperatures for various air volumes in a vault.

In PMR 600MWt [3], helium at $490^{\circ} \mathrm{C}$ enters the prismatic core through the inlet riser and exits at $850^{\circ} \mathrm{C}$, at a flow rate of $320 \mathrm{~kg} / \mathrm{s}$. Figure 1-5 shows the GAMMA modeling of PMR and the helium flow paths at the right figure. The prismatic core and reactor cavity are modeled by 2-D geometry, and all the solid structures are modeled by 2-D geometry. For all the cavities or plenums, the radiation heat exchanges are considered. The air-cooling RCCS system is modeled using the 1-D pipe network for the air flow loop and the 3-D tube model for the cooling tubes.
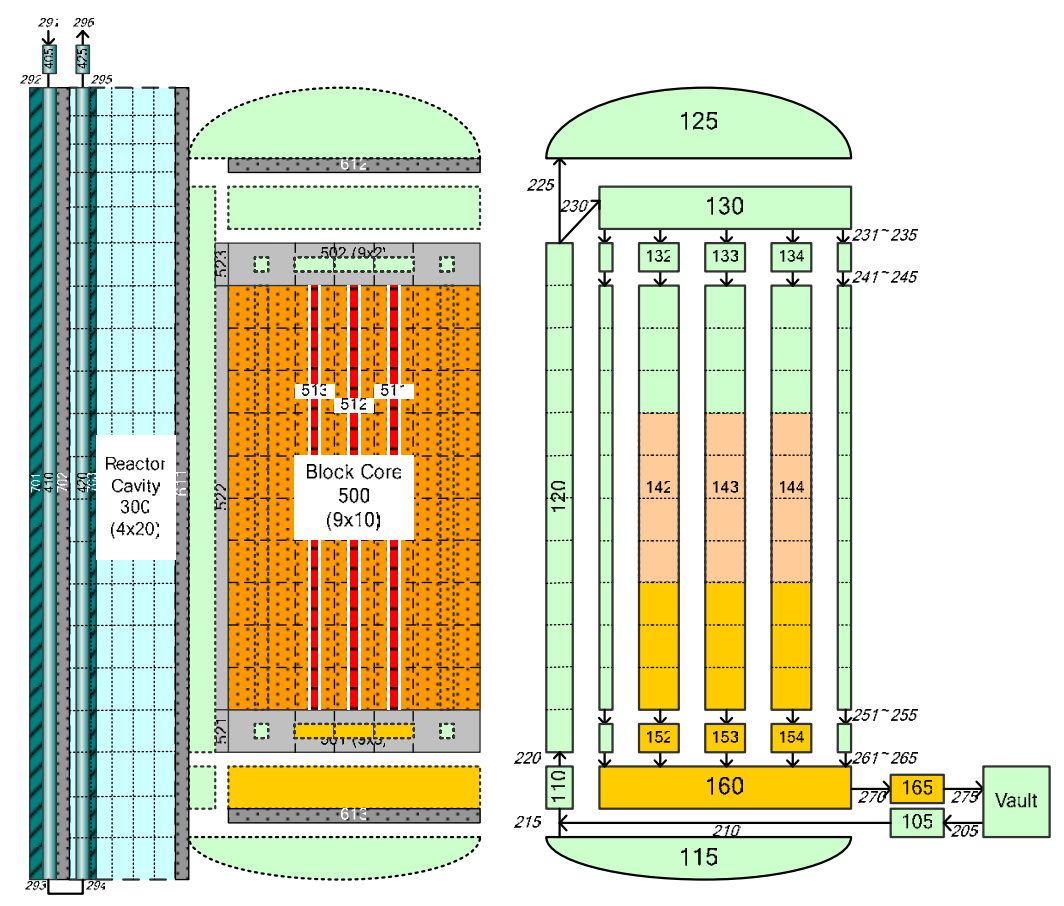

Figure 1-5. GAMMA nodalization for PMR 600MWt: solid and reactor cavity (left) and fluid component connection (right). 
First, in order to verify the GAMMA predictability for the system transient behavior, we performed the benchmark exercise [4] for the low pressure conduction cooldown (LPCC) accident. Figures 1-6 show the calculated fuel peak temperature and the results from other countries. The GAMMA code shows comparable temperature trend to those of other codes. Much difference in the predicted results is remarkable.

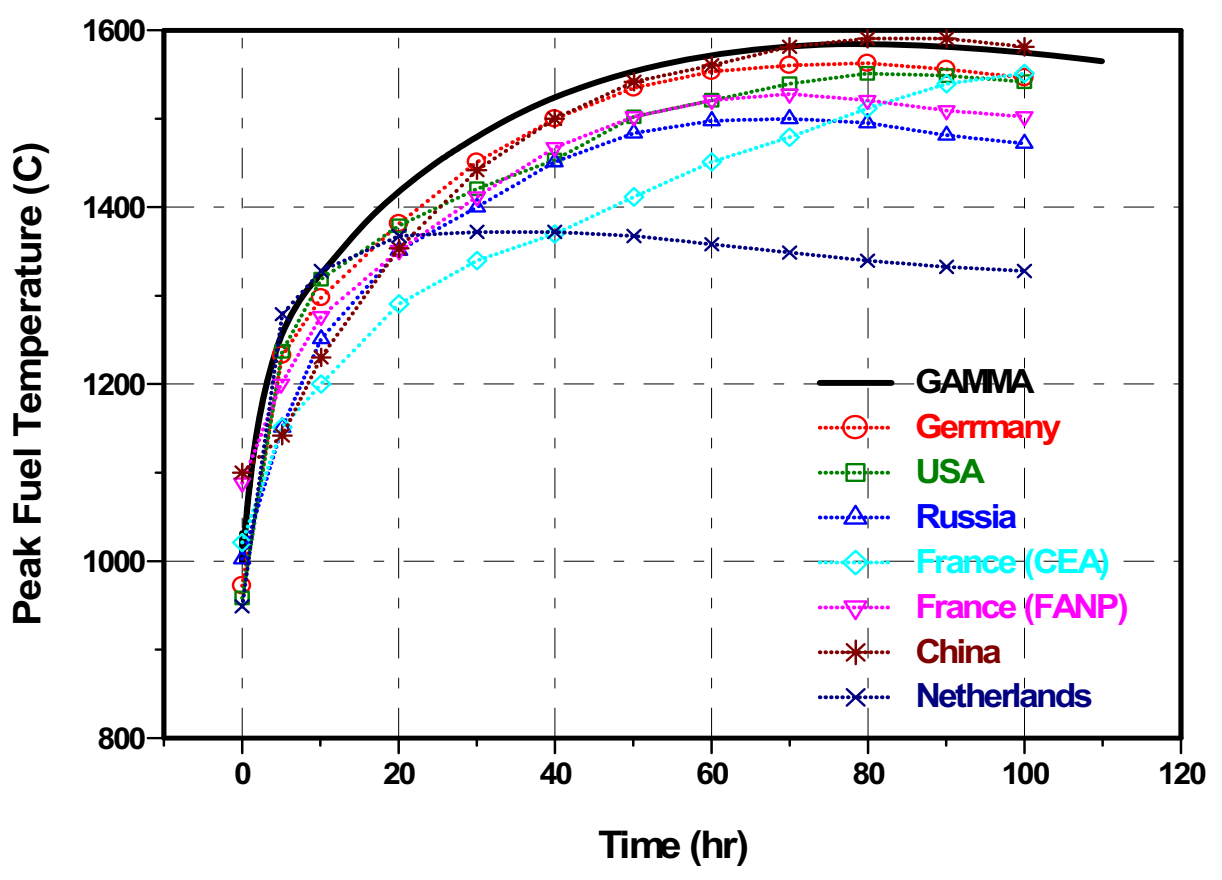

Figure 1-6. IAEA GT-MHR benchmark calculation for the LPCC accident.

For the air ingress analysis of PMR $600 \mathrm{MWt}$, the air volume of $50,000 \mathrm{~m}^{3}$ in a vault has been assumed. As shown in Figure 1-7, the onset time of natural convection occurs at 570 hours, much delayed compared to that of previous PBR analysis. It is because of the lower equilibrium air concentration at the end of blowdown caused by the larger fluid volume ratio of the reactor coolant system to the vault. In addition, due to the large fluid volume inside the reactor vessel, the molecular diffusion process proceeds slowly and therefore the density of a gas mixture increases slowly, by delaying the onset time of a natural convection. As well, there is no significant rise in the core and reflector temperatures. It is mainly due to the higher ratio of the graphite volume to the surface area contacting with the oxygen. 


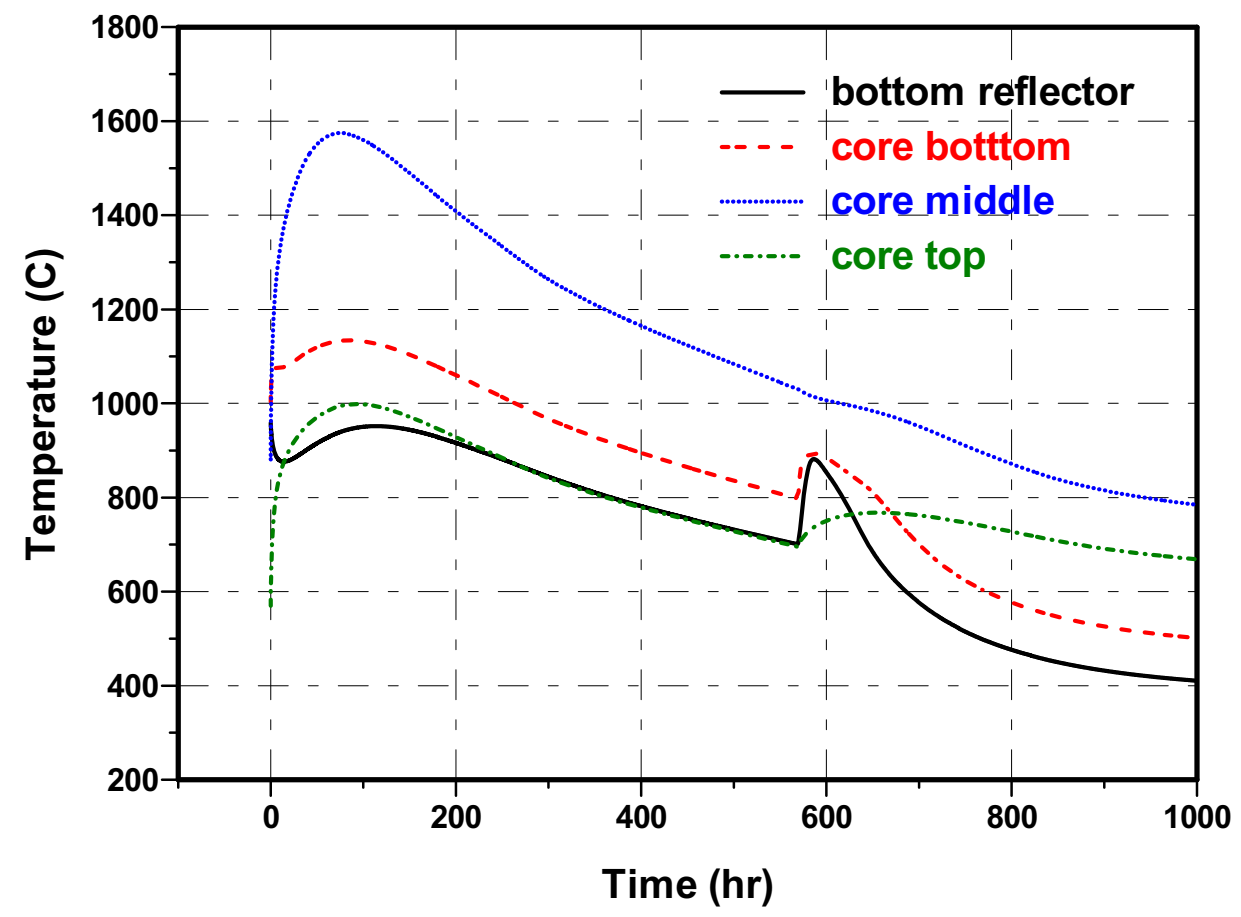

Figure 1-7. Predicted axial temperatures in the fuel ring $1\left(\mathrm{~V}_{\text {air }}=50,000 \mathrm{~m}^{3}\right)$.

\section{Publication in 2005:}

Hong Sik Lim and Hee Cheon NO, "GAMMA Multi-Dimensional Multicomponent Mixture Analysis to Predict Air Ingress Phenomena in an HTGR," Nuclear Science \& Engineering, to be published, January 2006. 


\section{Task 2: RCCS Separate Experiment (SNU)}

\section{Task Status and Significant Results}

The experiments for SNU-RCCS were continued with tests for upper pool cooling trip, LOFC and emissivity measurement. The test device for separate effect was designed with different diameter of cooling pipe and number of u-band. Experiment results were compared with the calculation results of CFX code and MARS 3.0a code for code-to-experiment validation and code-to-code benchmark.

\section{Task 2-1 Upper Pool Cooling Trip Test}

The pressure in the upper pool was maintained at the atmospheric pressure. Figure 2-1 shows the temperature transient of the cavity wall and water in the upper pool. When the active cooling was stopped, the temperature of the upper pool increased but it kept constant at the saturation temperature $100^{\circ} \mathrm{C}$ until the entire inventory was depleted. The temperature measured at the top part of the cavity near the free surface showed the same trend with the upper pool temperature and it maintained constantly after the water in the upper pool reached the saturation temperature. The temperature below the free surface elevation did not change during the experiment. The transient of the axial temperature distribution of the reactor vessel wall is presented in Figure 2-2. The temperature near the top of the reactor vessel wall increased after the upper cooling was terminated. However, it did not increase further after the cavity wall temperature reached steady state.

From this experiment, it was found that the passive cooling capability of the upper pool is sufficient to remove the heat released from the reactor vessel during normal operation unless the entire inventory is depleted and then this experimental result could be used to determine the optimized capacity of the water pool.

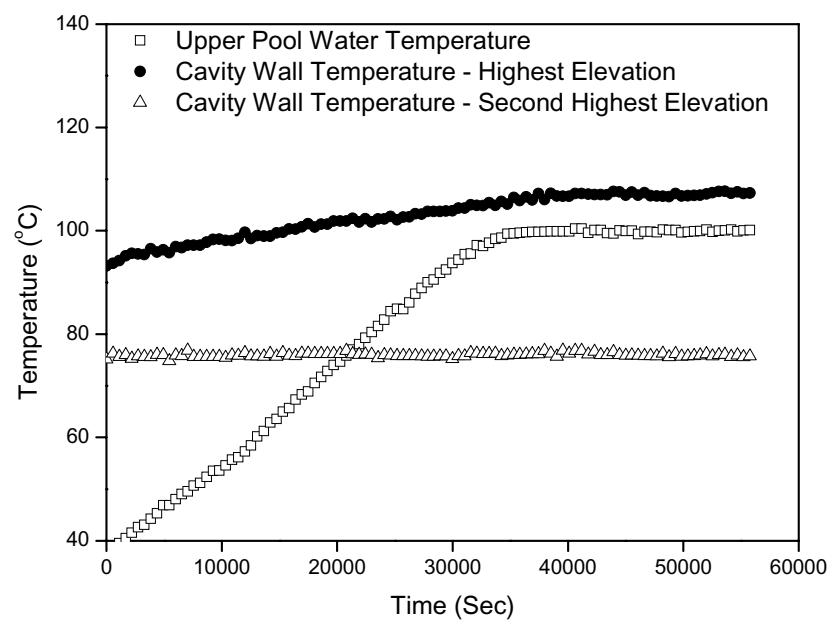

Figure 2-1. Temperature transients during the upper cooling trip test. 


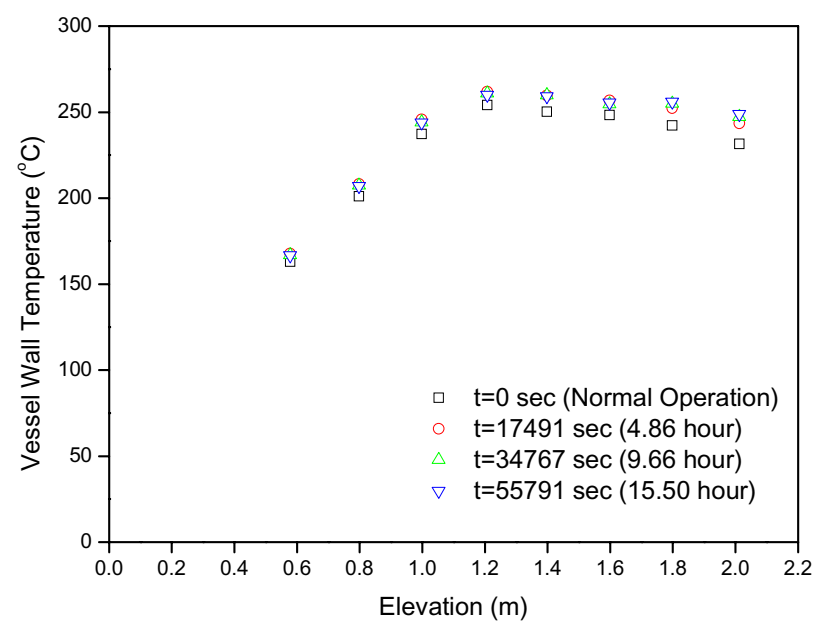

Figure 2-2. Vessel wall temperature transients during upper cooling trip test.

\section{Task 2-2 LOFC (Loss of Forced Convection) Test}

An experiment was carried simulating the LOFC accident, which is the case that the forced convection from the main cooling system of the reactor is failed including the RCCS air coolers. According to the design criteria suggested in the study, the RCCS should be able to remove the core after heat passively for three days which is equivalent to 7.2 hours of the 1/10 time-reduced test facility. The present LOFC experiment, however, was continued for 25 hours to investigate the phenomena when the water inventory was so depleted that the heat released from the reactor vessel could not be removed. The stuck-open of the relief valve was assumed to accentuate the depletion of the side and upper pools in the experiment and then, the relief valve was opened when the water of the side pool reached saturation temperature. The initial steady state temperature of the water pool was $50^{\circ} \mathrm{C}$ with $0.38 \%$ of heat loss.

The temperature transient in the water pool is shown in Figure 2-3. During the normal operation, the water pool temperatures were nearly constant along the vertical axis. However, the thermal stratification occurred within the water pool and the temperature of the upper part of the water pool increased rapidly with the failure of the RCCS active cooling and increases of the heat released from the reactor vessel. After the relief valves were opened at 25,000 second, the upper part temperature in the water pool decreased toward $100^{\circ} \mathrm{C}$ and then kept constant at $100^{\circ} \mathrm{C}$. A lot of steam was generated in the water pool after the opening of the relief valve and the water level was decreased as shown in Figure 2-4. Swelling of the water caused the slight increase of the water level before the relief valve open. When the thermocouple was uncovered with the decrease of the water level, the temperature increased sharply because of the existence of the superheated steam.

Figure 2-5 shows the results of the cavity wall temperature during the LOFC experiment. The temperature of the cavity wall during normal operation increased slightly along the axis except the top part of the cavity. With the beginning of the LOFC accident, it was affected by the thermal stratification of the water pool and then the temperature of each elevation increased with different inclination. Since the temperature of the heat sink remained at the saturation point, the cavity wall temperature also held constant except the dry out region. At the uncovered region by water, the cavity wall temperature increased rapidly because incoming heat could not be removed sufficiently.

Figure 2-6 shows the temperature transient of the reactor vessel wall. The temperature increased gradually with the increase of the heat released from the heater. After 40,000 second, the heating power was fixed until 
the end of the experiment and therefore, most of the region except the upper parts of the reactor vessel had nearly constant wall temperature. The sharp increase of the temperature at the dry out region does not seem to affect the reactor vessel temperature before 60,000 second due to the small view factor of the region. After 60,000 second, however, the increasing uncovered area of the cavity wall began to affect the radiative heat transfer from the upper part of the reactor vessel. At the moment, the water level was reduced by about $10 \%$, and about $12 \%$ of total cavity wall length was uncovered by water. From this experimental result, we can conclude that $10 \%$ of water level reduction by boiling off would be allowed in the water pool type RCCS and this criterion will be applied for the optimization of the system

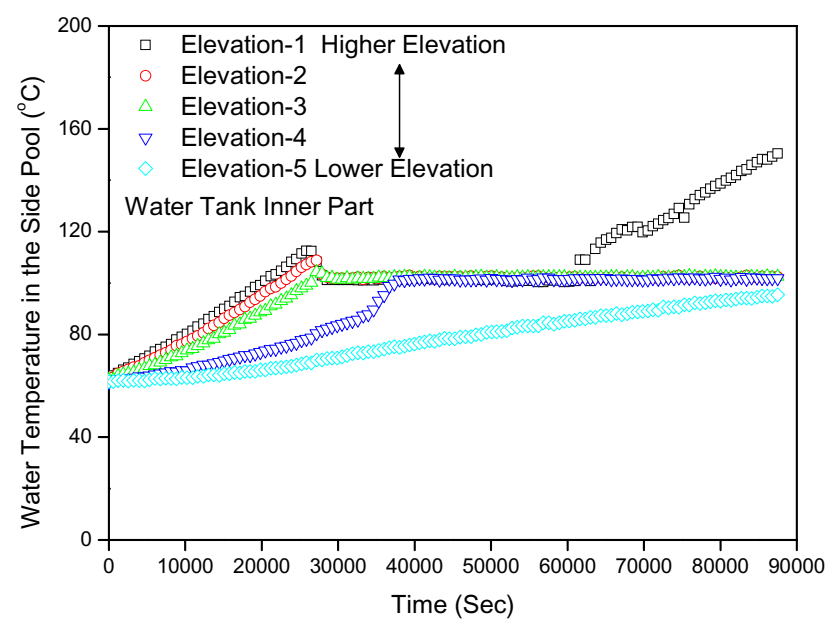

Figure 2-3. Temperature transients of the water during the LOFC Experiment.

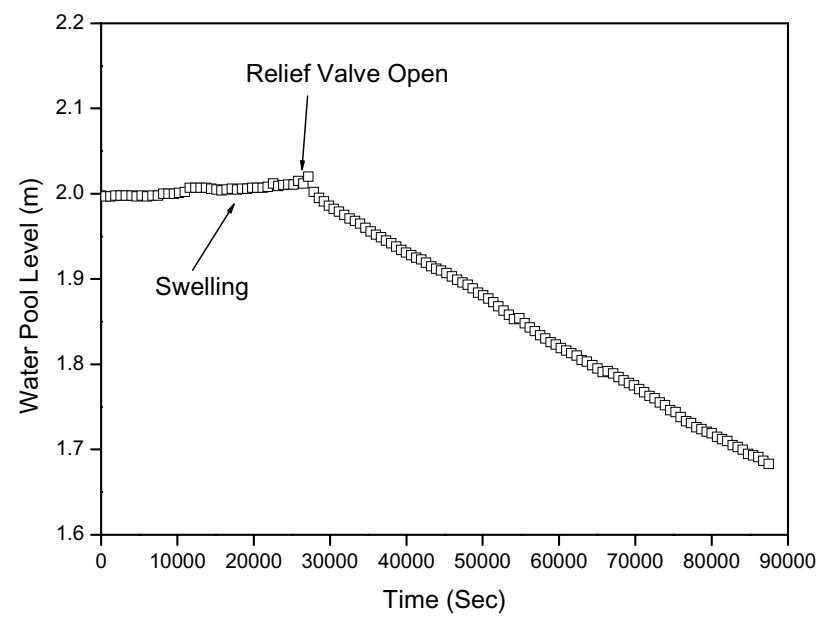

Figure 2-4. Water level transients in the side pool during the LOFC experiment. 


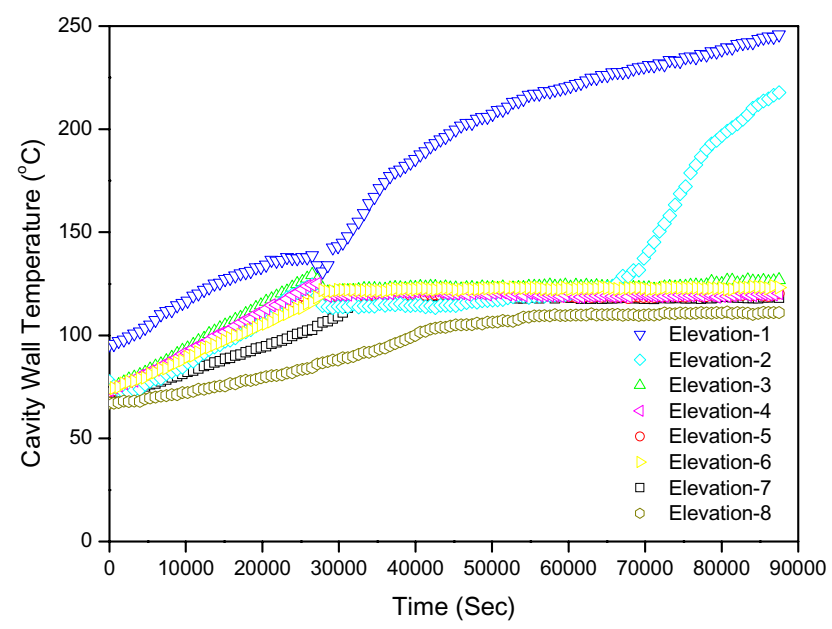

Figure 2-5. Temperature transients of the cavity wall during the LOFC experiment.

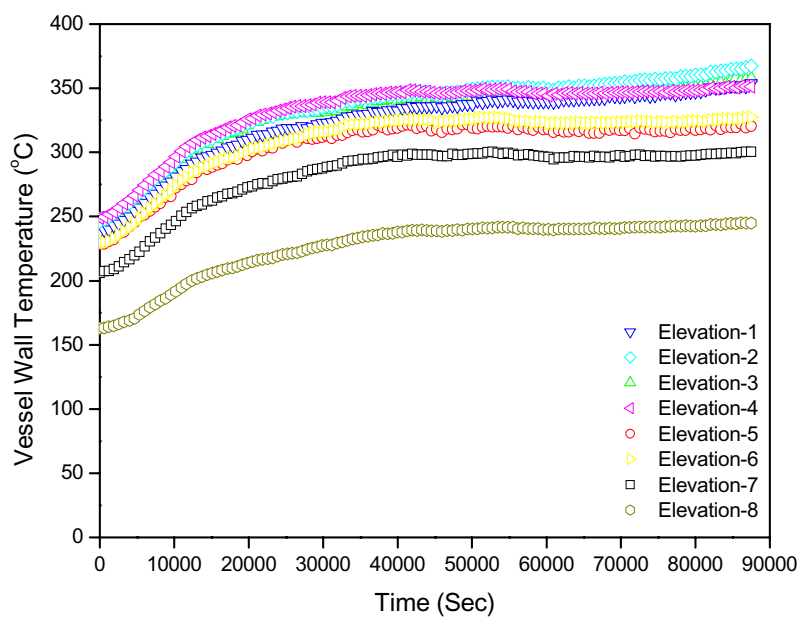

Figure 2-6. Temperature transients of the vessel wall during the LOFC experiment.

\section{Task 2-3 Emissivity Measurement Test}

The emissivity of the vessel surface of SNU-RCCS was measured via sight tube by the infrared thermometer. The sight tube was installed through the water pool and cavity to simplify geometry and facilitate temperature measurement for the calculation. Figure 2-7 depicts the process of emissivity measurement and calculation. First, the measured emissivity was compensated by the transmittance of window and the effect of air concentration was ignored from the result of SET device. Then the effect of background radiation was removed via solving a series of radiative heat transfer equations. This result was compared with the emissivity of the same material with the reactor vessel of the SNU-RCCS, named true-emissivity in this study, which was measured without any surrounding-surface near the target material in the SET device.

As shown in Figure 2-8, the calculated emissivity and the true emissivity gradually increased with temperature over the low temperature range. After all, both emissivities reached the almost constant value as 0.83 around $400{ }^{\circ} \mathrm{C}$. In addition, the calculated emissivity was in good agreement with the true emissivity and its tendency within the uncertainty band of $3 \%$ as shown in Figure 2-9. The result means that the evaluation process is appropriate to predict the effect of background radiation. 


\section{Schematic Diagram of Experiments}

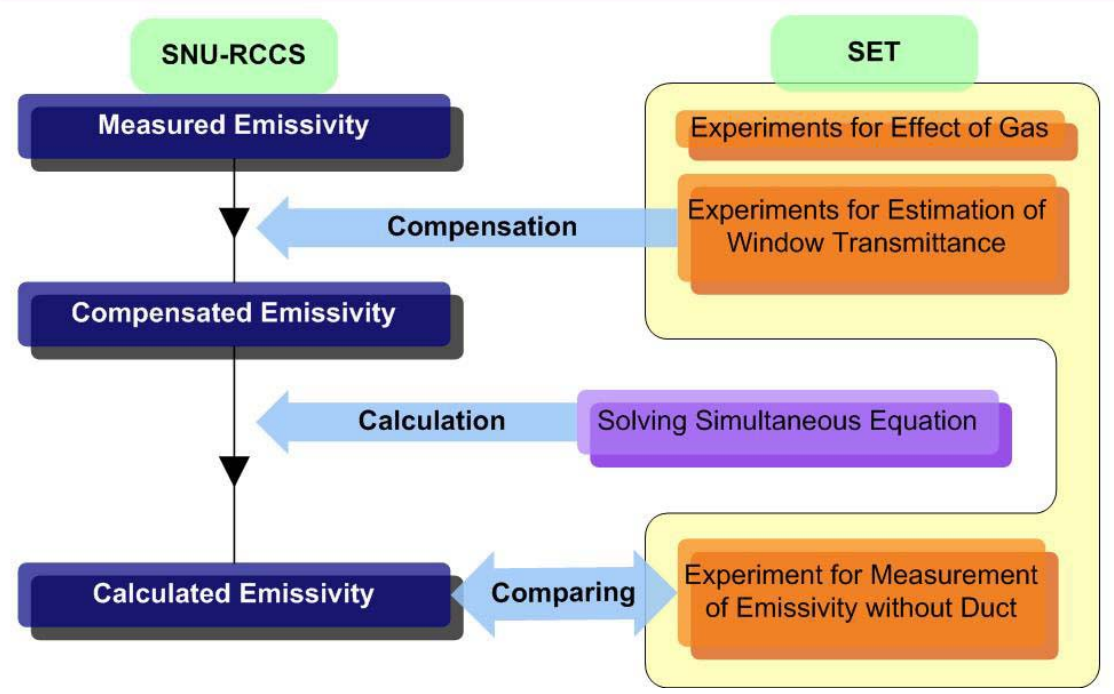

Figure 2-7. Process of emissivity measurement and calculation.

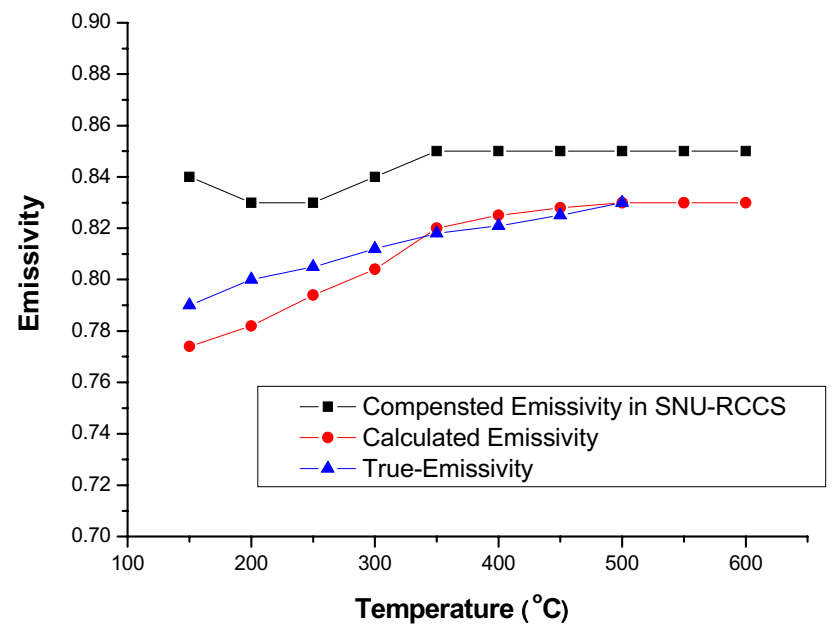

Figure 2-8. Comparison of emissivity. 


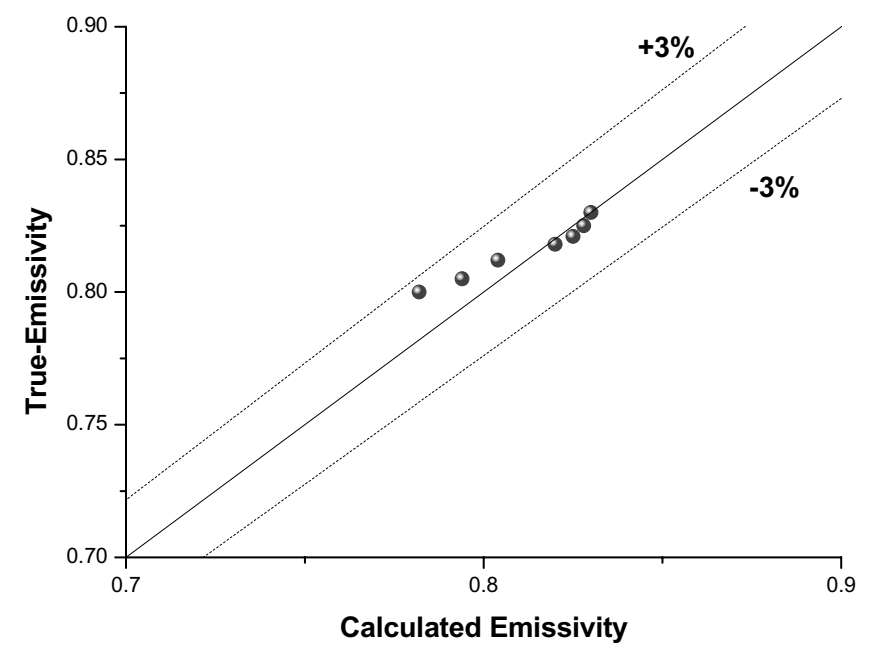

Figure 2-9. Validation of calculated emissivity.

Task 2-4 New Separate Effect Tests for the Water Pool of the SNU-RCCS

New separate effect test device simulated a quarter of the water pool in azimuthal direction and one third in radius direction as shown in Figure 2-10. Compared to previous device, the total number of U-bands of air cooling pipe was decreased from 16 to 11. In addition the diameter of air-cooling pipe was enlarged from $63.5 \mathrm{~mm}$ to $76.6 \mathrm{~mm}$ in order to reduce the pressure drop. Other geometry such as height and width of water pool was preserved.

Figures 2-11 shows temperature distributions measured in the center of water pool, cooling pipe and on the surface of cooling pipe. The center temperature of the cooling pipe gradually increased from atmosphere temperature up to near the bulk temperature as air flows through the cooling pipe. Bulk temperature of upper part of water pool was higher than bottom part about $3 \sim 4{ }^{\circ} \mathrm{C}$. The surface temperature of cooling pipe was lower than the bulk temperature at inlet by $6 \sim 8{ }^{\circ} \mathrm{C}$, and it closed to bulk temperature near the outlet. These results show good agreement with previous experimental results for separated effect test.

The power for operating air blower was reduced more than $30 \%$ because the pressure drop was decreased due to the enlarged diameter of cooling pipe. It means if the diameter of cooling pipe increase, we can get more advantage in aspect of active cooling power. In this case, however, the capacity of water in the water pool was decreased and it can influence passive long term cooling of RCCS. Thus, the diameter and total number of U-bands of cooling pipe and water capacity should be considered synthetically for design optimization. 


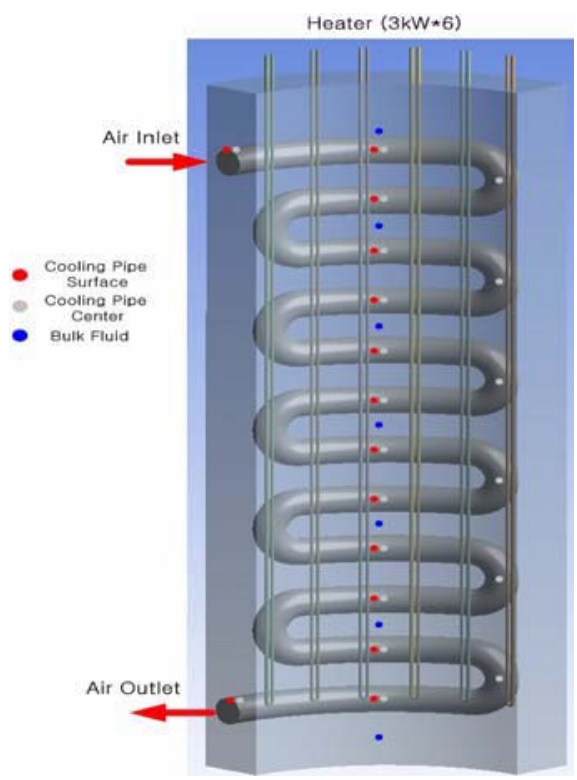

Figure 2-10. Schematic diagram of the new separate effect test device.

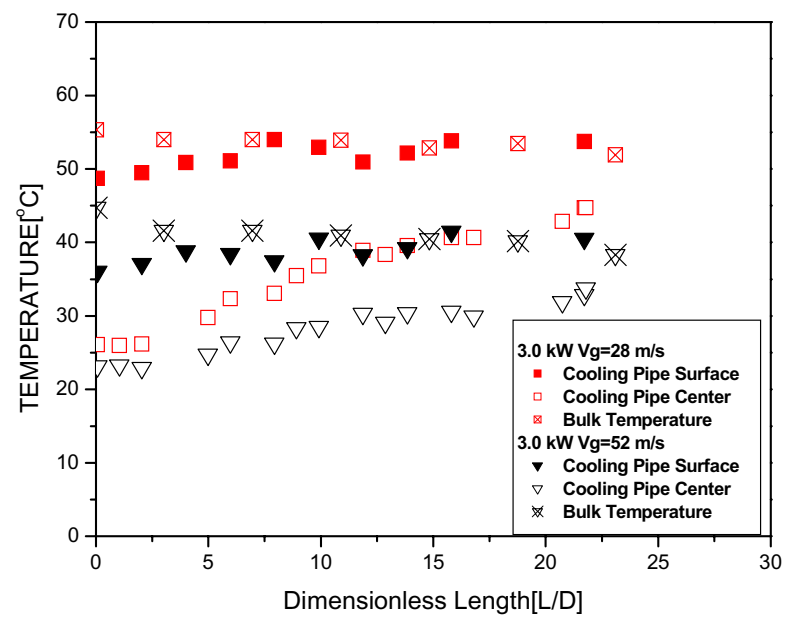

Figure 2-11. Temperature distribution.

Table 1-1 Test Matrix

\begin{tabular}{|l|l|}
\hline Gas Velocity & Total Heat Power $(\mathrm{kW})$ \\
\hline $28 \mathrm{~m} / \mathrm{s}$ & $3.0,4.0,5.0$ \\
\hline $33 \mathrm{~m} / \mathrm{s}$ & $3.0,4.0,5.0,6.0$ \\
\hline $40 \mathrm{~m} / \mathrm{s}$ & $3.0,4.0,5.0,6.0,7.0$ \\
\hline $48 \mathrm{~m} / \mathrm{s}$ & $3.0,4.0,5.0,6.0,7.0$ \\
\hline $52 \mathrm{~m} / \mathrm{s}$ & $3.0,4.0,5.0,6.0,7.0$ \\
\hline
\end{tabular}




\section{Task 2-5 Code Validation}

Numerical analysis for separate effect test was performed with MARS 3.0a code and CFX code.

\section{MARS Calculation}

The nodalization for the analysis using MARS 3.0a for the new separate effect test is shown in Figure 2-12. The water pool was modeled using multi-dimensional component and consists of 63 volumes and 138 junctions. Air-cooling pipe consisted of 18 volumes and heat structures, and 17 junctions. Heat flux was supplied constantly through inner wall having 21 heat structures on it.

Figures 2-13 and 2-14 compares the experimental data and code calculation results of the air temperature in cooling pipe and bulk temperature in water pool, respectively. Total heat power was $4.0 \mathrm{~kW}$ and inlet air mass flow was $0.2 \mathrm{~kg} / \mathrm{sec}$ at $25^{\circ} \mathrm{C}$ in this case. Although the air temperatures show good agreement with the experimental data, the bulk temperature differences according to height were smaller than the experiment data. Because the MARS code did not consider cooling pipe in the water pool as obstacle to prevent natural convection, the calculation showed more active natural calculation and uniform temperature distribution than experiment. Figure 2-15 shows thermal stratification and natural convection inside water pool. Upward flow near the heated wall and downward flow at unheated node was observed. Maximum liquid velocity was about $4 \mathrm{~cm} / \mathrm{sec}$ near the heated wall.

Temperature difference between experiment data and calculation results of MARS at the center of water pool is shown in Figure 2-16. MARS code slightly under-predicted bulk temperature in most case. This result was caused by the excessive cooling due to the larger natural circulation than the experiment.
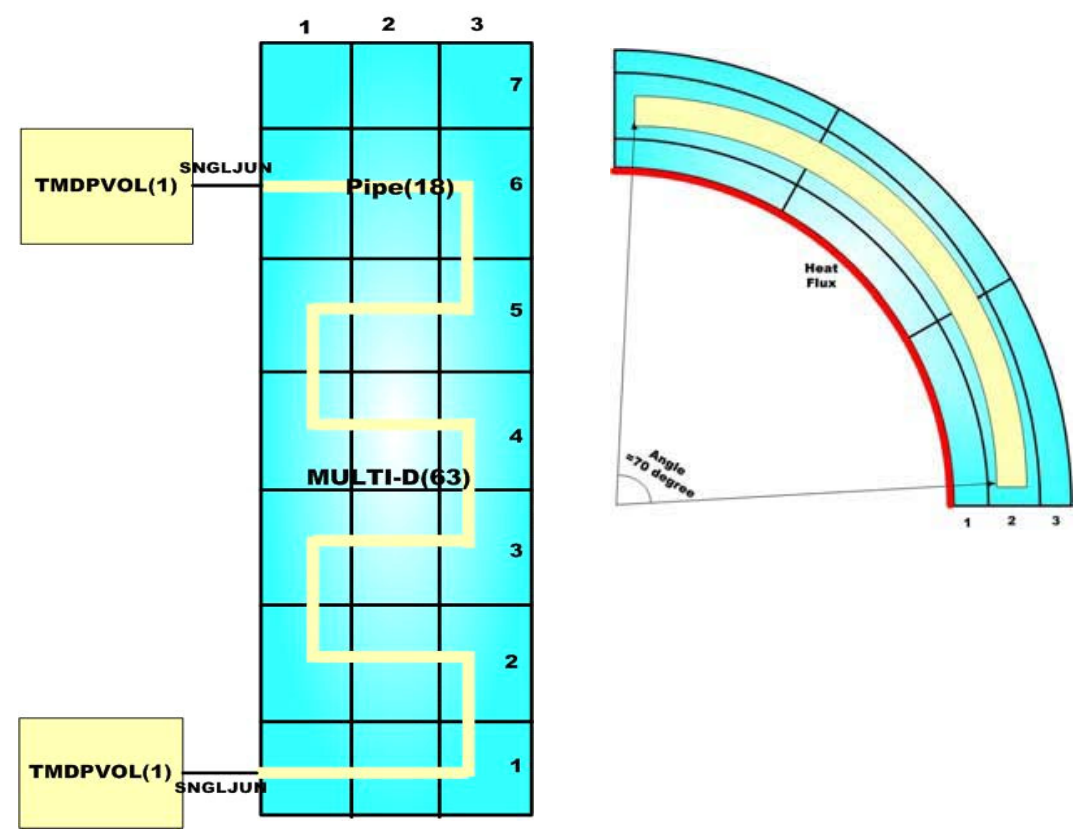

Figure 2-12. Nodalization of MARS calculation. 


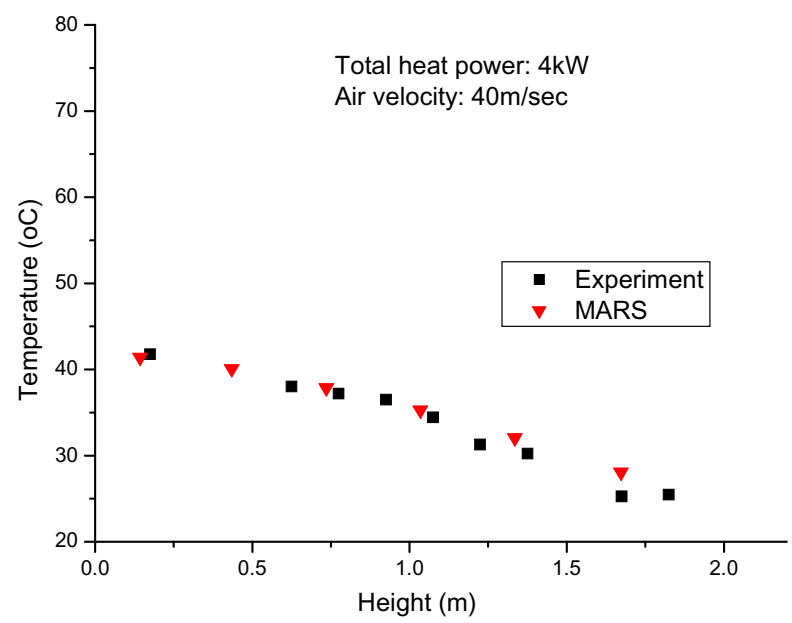

Figure 2-13. Temperature transients of air in cooling pipe.

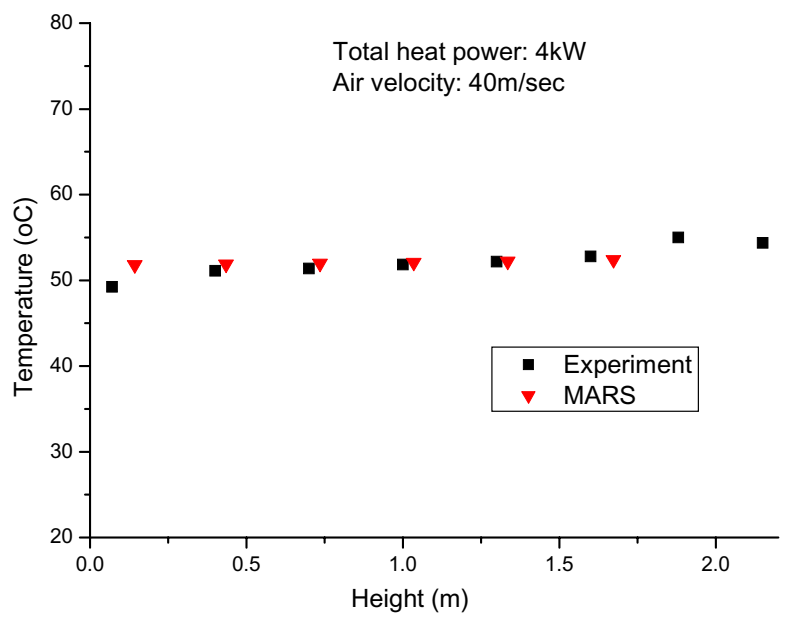

- Experiment

$\nabla$ MARS

Figure 2-14. Temperature transients of water in water pool. 


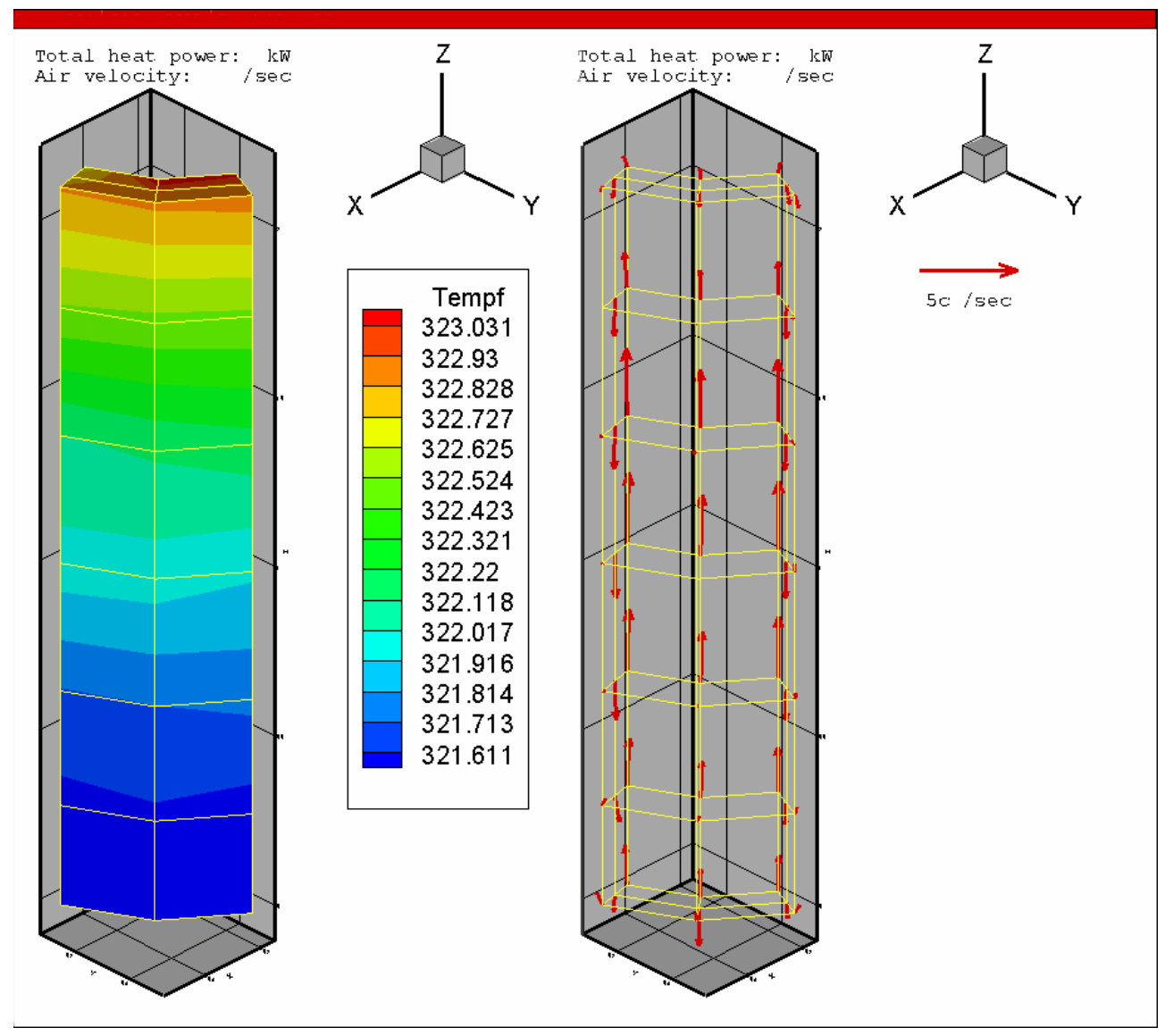

Figure 2-15. Thermal stratification and natural circulation.

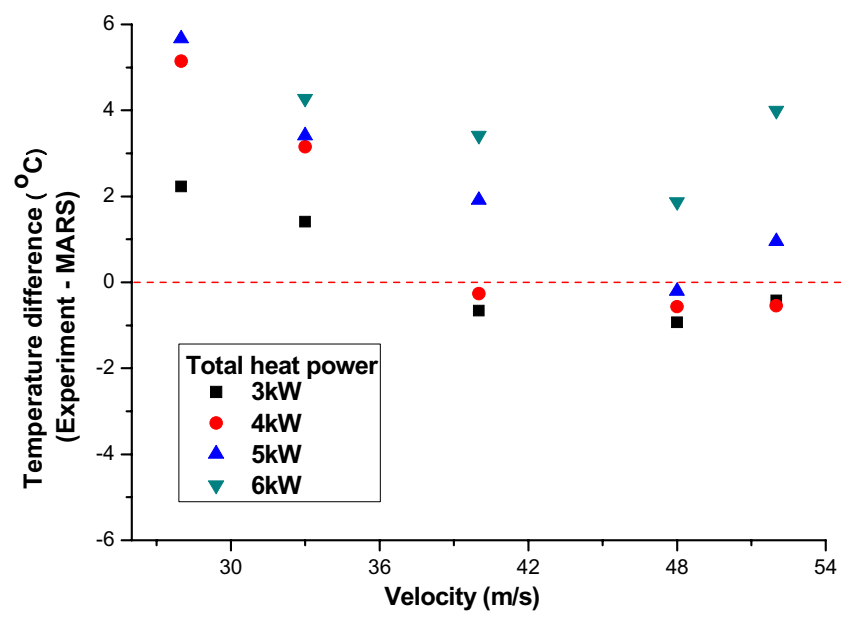

Figure 2-16. Temperature comparison at center of water pool. 


\section{CFX Calculation}

CFX calculation was carried out to investigate the heat transfer phenomena for the new separate effect test. The experimental results of the cooling pipe surface temperature were implemented as boundary conditions of the calculation. The k- $\varepsilon$ model was used for turbulent modeling. Heat power was implemented as heat flux at the inner wall. A hexahedral mesh was formed in this geometry as shown Figure 2-17.

The calculation simulated the cooling pipe and the water pool respectively to save calculation time. The calculation results of air temperature at the pipe center were compared with the experimental results in Figure 2-18. Although the CFX code slightly under-predicted the experimental data, the calculated temperatures showed good agreement with the experimental data. However, the bulk temperature of water pool slightly over-predicted by 3 4 ${ }^{\circ} \mathrm{C}$ as shown in Figure 2-19 than those of experimental data due to the lower velocity of natural convection. Figure 2-20 shows natural convection in water pool.

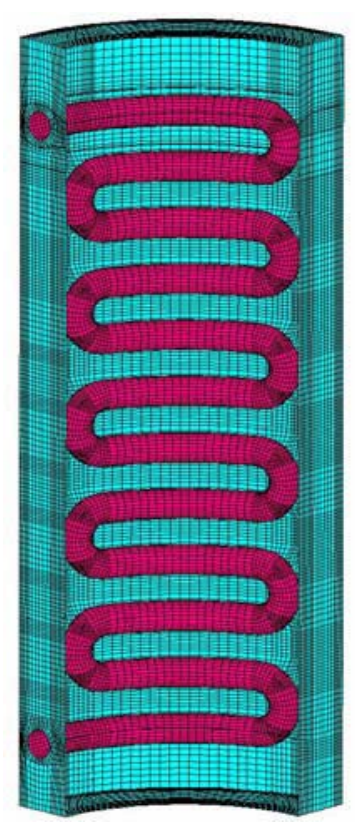

Figure 2-17. Nodalization of CFX calculation. 


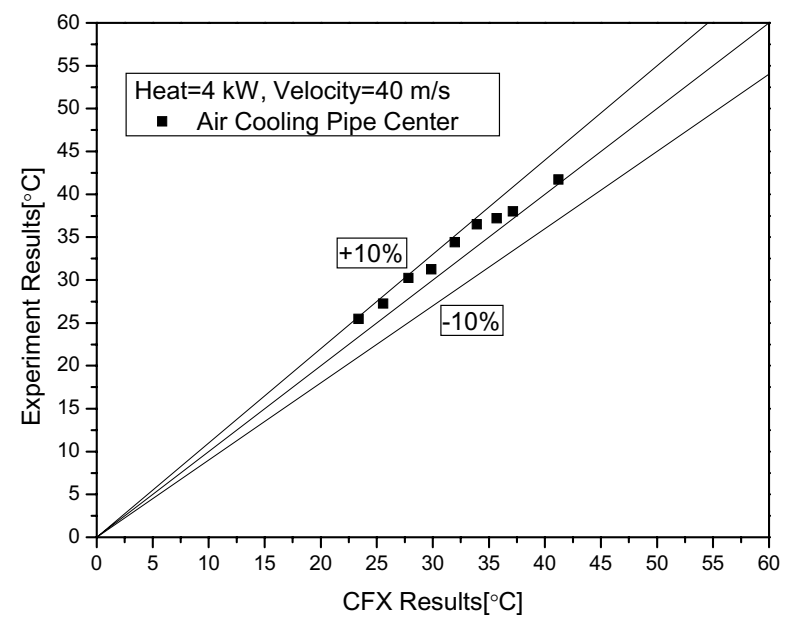

Figure 2-18. Temperature comparison at cooling pipe center.

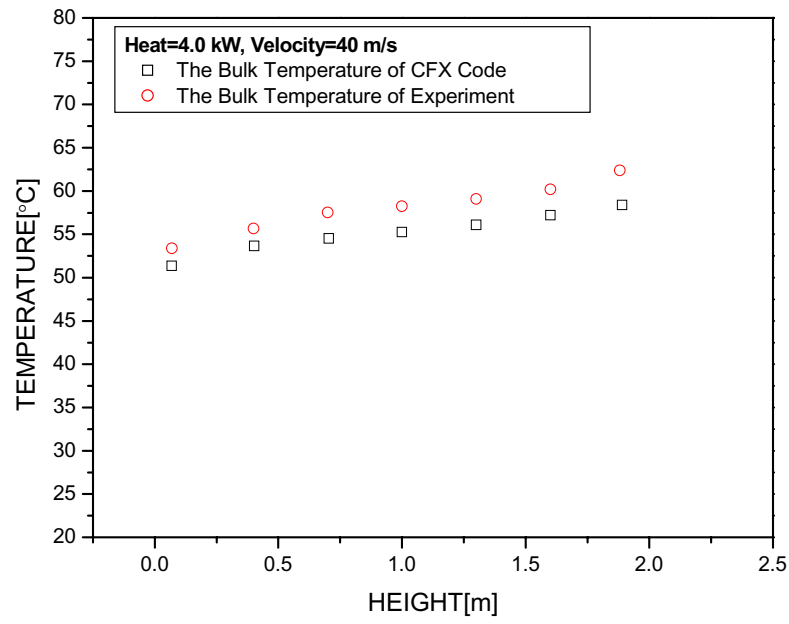

Figure 2-19. Temperature comparison at water pool. 

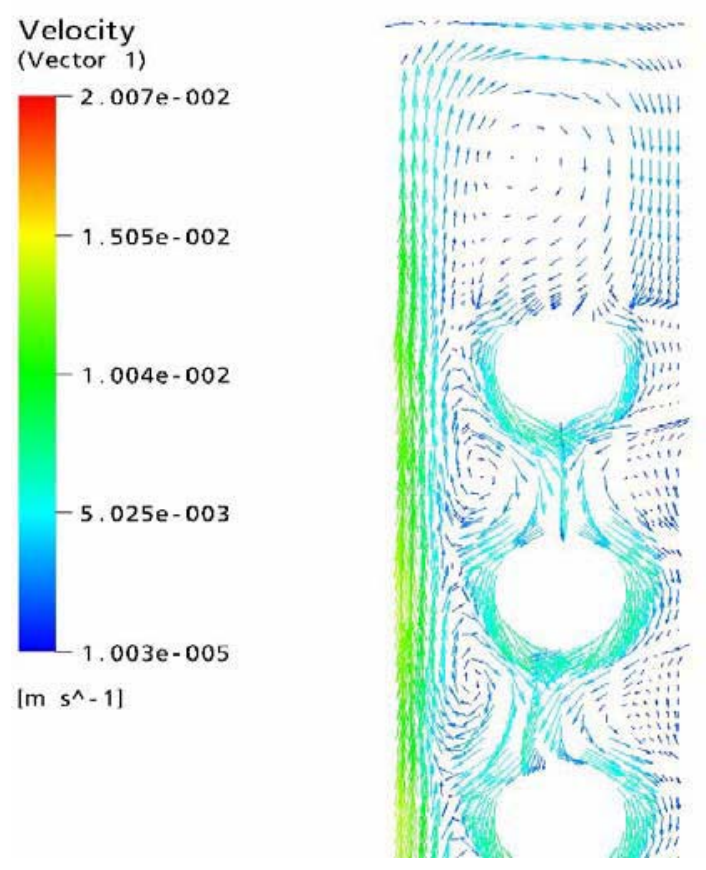

Figure 2-20. Velocity distribution of water pool.

\section{Publication in 2005:}

D.U. Seo, M.O. Kim, H.K. Cho, T.W. Kim, G.C. Park, "Numerical Study on the Heat Transfer Phenomena in Water Pool Type-Reactor Cavity Cooling System of Very High Temperature Gascooled Reactor ", $18^{\text {th }}$ International Conference on Structural Mechanics in Reactor Technology (SMiRT-18), Beijing, China, Aug. 7-12, 2005.

H.K.Cho, M.O.Kim, H.K.Ahn, G.C.Park, "Experimental Study for the Water Pool Type Reactor Cavity Cooling System in the Very High Temperature Gas Cooled Reactor", $5^{\text {th }}$ International Symposium on Multiphase Flow, Heat Mass Transfer and Energy Conversion, 3-6 July, 2005, Xi'an, China

H.K.Cho, D.U.Seo, M.O.Kim, G.C.Park, "Study on the Heat Transfer in the Water Pool Type Reactor Cavity Cooling System of the Very High Temperature Gas Cooled Reactor", 2005 ASEM Summer Heat Transfer Conference, July 17-22, 2005, San Francisco, California, USA Following paper is under review.

Y.J. Cho, M. O. Kim and G. C. Park, "Experimental Study on Measurement of Emissivity for Analysis of SNU-RCCS," 


\section{Task 3: Air Ingress Separate Experiment (KAIST)}

\section{Task Status and Significant Results}

The objective of this task is to carry out the graphite oxidation experiment to determine the oxidation-limited model (chemical kinetics-limited, diffusion-limited or in-pore diffusion-limited model), and to develop measurement techniques of the concentration of each species.

The present study investigates the graphite oxidation reaction, which is one of the most serious problems during an air-ingress accident in a high temperature gas-cooled reactor (HTGR). The chemical effects and fluid dynamic effects have been investigated in the past 2 years, and many good results were obtained. However, there are many other effects concerned with the rate of graphite oxidation besides the chemical or fluid dynamic effects. Geometrical effect, burn-off effect and effect of $\mathrm{C} / \mathrm{CO} 2$ reaction are among those neglected ones. In this year, we focused on these effects and the results are summarized as follows.

\section{Task 3-1: Geometrical effect}

To investigate the geometrical effect on the graphite oxidation, we developed a new method of analysis. The details are as follows. Since graphite is a porous material, the oxidation reaction occurs not only on the external surface but also in the internal pores. Therefore, the reaction rate of graphite oxidation $\left(\mathrm{R}_{\mathrm{g}}\right)$ can be expressed as follows:

$$
R_{g}=A_{0} \cdot \exp \left(-\frac{E a}{R \cdot T}\right) \cdot P_{O 2}{ }^{n} \cdot\left(A_{s}+A_{v}\right),
$$

where $\mathrm{A}_{0}$ is a pre-exponent factor, $\mathrm{Ea}$ is an activation energy, $\mathrm{R}$ is a gas constant, $\mathrm{T}$ is the temperature, $\mathrm{P}_{\mathrm{O} 2}$ is the partial pressure of the oxygen, $n$ is the order of reaction, $A_{s}$ is the external surface area, and $A_{v}$ is the internal surface area available for reaction. In order to determine $A_{v}$, we assume that $A_{v}$ is proportional to the volume $(\mathrm{V})$ of the graphite because the internal pores are uniformly distributed:

$$
A_{v}=\theta \cdot V
$$

where $\theta$ is an internal surface density, which physically means an internal surface area in unit volume. If we put Eq. (3-2) into Eq. (3-1), we can obtain the following equation:

$$
\frac{R_{g}}{A_{s}}=A_{0} \cdot \exp \left(-\frac{E a}{R \cdot T}\right) \cdot P_{O 2}{ }^{n} \cdot\left(1+\frac{\theta \cdot V}{A_{s}}\right) .
$$

If the temperature and oxygen pressure are fixed in Eq. (3-3), the value of $A_{0} \cdot \exp \left(-\frac{E a}{R \cdot T}\right) \cdot P_{O 2}{ }^{n}$ is also fixed. Therefore, we can rewrite Eq. (3-3) as

$$
\frac{R_{g}}{A_{s}}=C \cdot\left(1+\theta \cdot \frac{V}{A_{s}}\right)
$$


where

$$
C=A_{0} \cdot \exp \left(-\frac{E a}{R \cdot T}\right) \cdot P_{O 2}{ }^{n}
$$

In Eq. (3-5), $\mathrm{R}_{\mathrm{g}} / \mathrm{A}_{\mathrm{s}}$ is linearly related to $\mathrm{V} / \mathrm{A}_{\mathrm{s}}$ under constant temperature and oxygen pressure conditions. As illustrated in Figure 3-1, $C \cdot \theta$ represents a slope and $C$ represents a y-axis intercept of the linear graph.

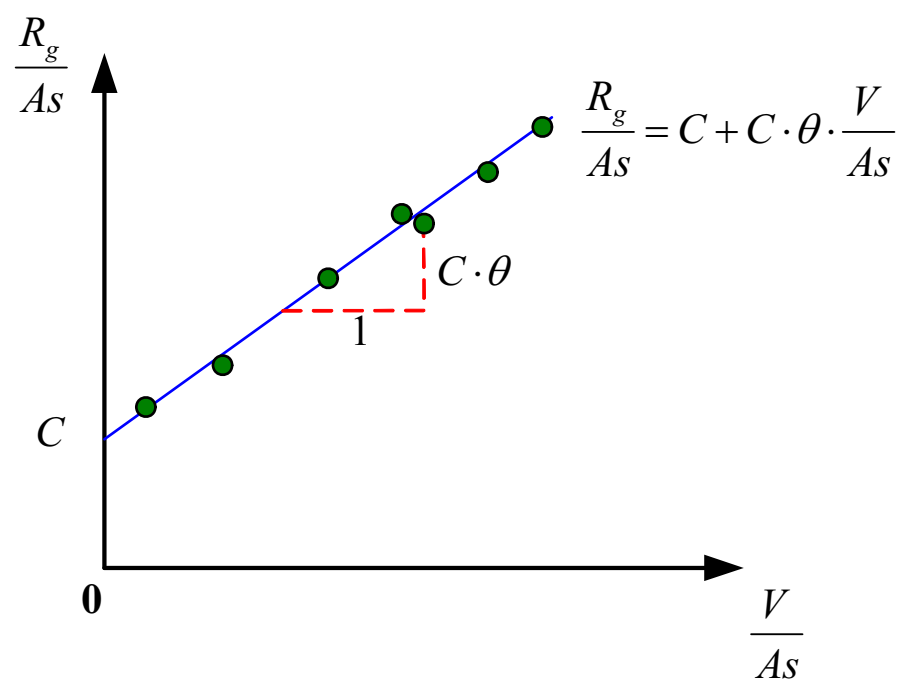

Figure 3-1. Analysis method for geometrical effect.

In this study, to determine the value of $\theta$, we measured the reaction rates for various graphite samples with different surface-to-volume ratios, and obtained the relation graph shown in Figure 3-1. We then calculated $\theta$ by analyzing its gradient and y-interception.

To measure the graphite oxidation velocity, we manufactured the experimental facility, as shown in Figure 32. We injected dehumidified natural air into the test section through a damping tank, and controlled the flow rate with a mass flow controller within $\pm 1 \%$ accuracy. In our experiment, the temperature was constantly maintained at $600{ }^{\circ} \mathrm{C}$ within $\pm 1{ }^{\circ} \mathrm{C}$ accuracy. The test was carried out under the condition, where the chemical reaction is a rate-controlling process. We placed graphite samples on the beam at the center of the furnace, and connected the support beam to the balance. Weights were measured with a precision of $\pm 1 \mathrm{mg}$.

Figure 3-3 illustrates the graphite specimens used in the geometrical effect test and Table 3-1 summarizes the shapes and sizes. 


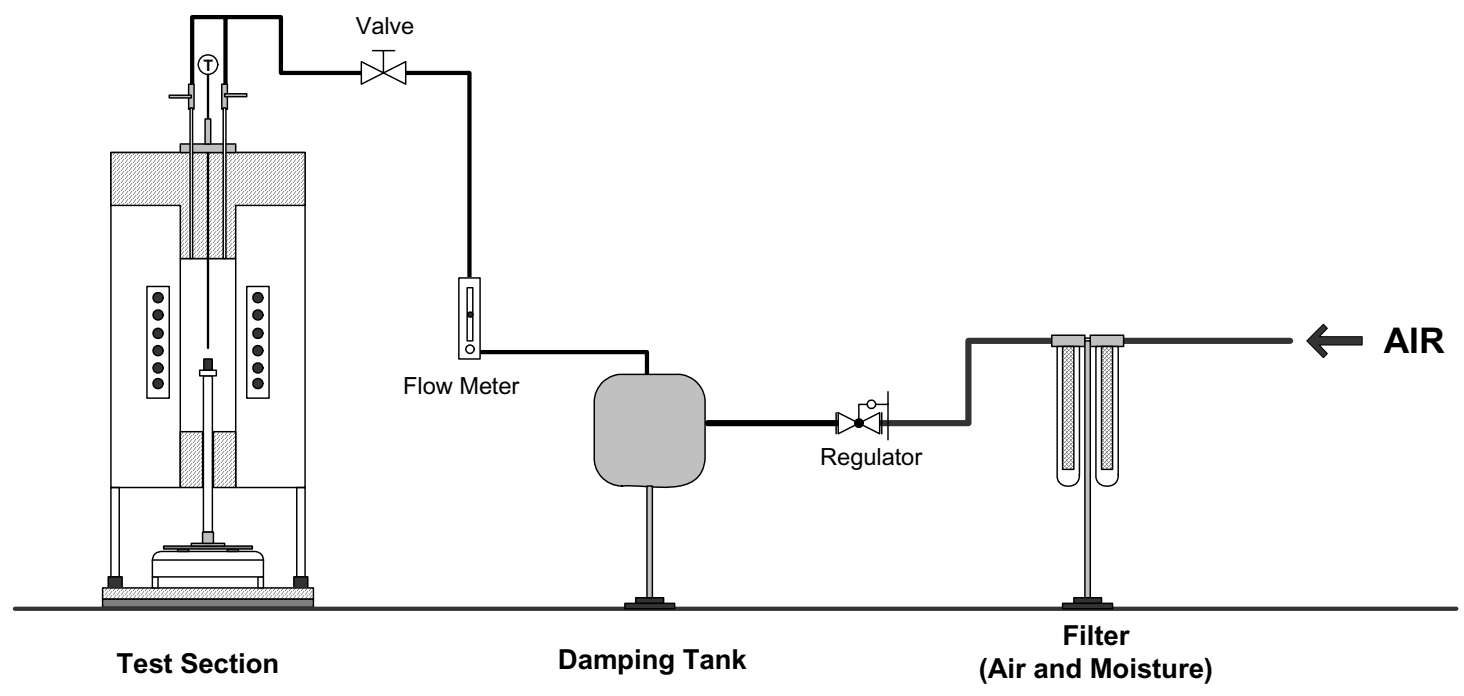

Figure 3-2. Experimental facility for geometrical effect.

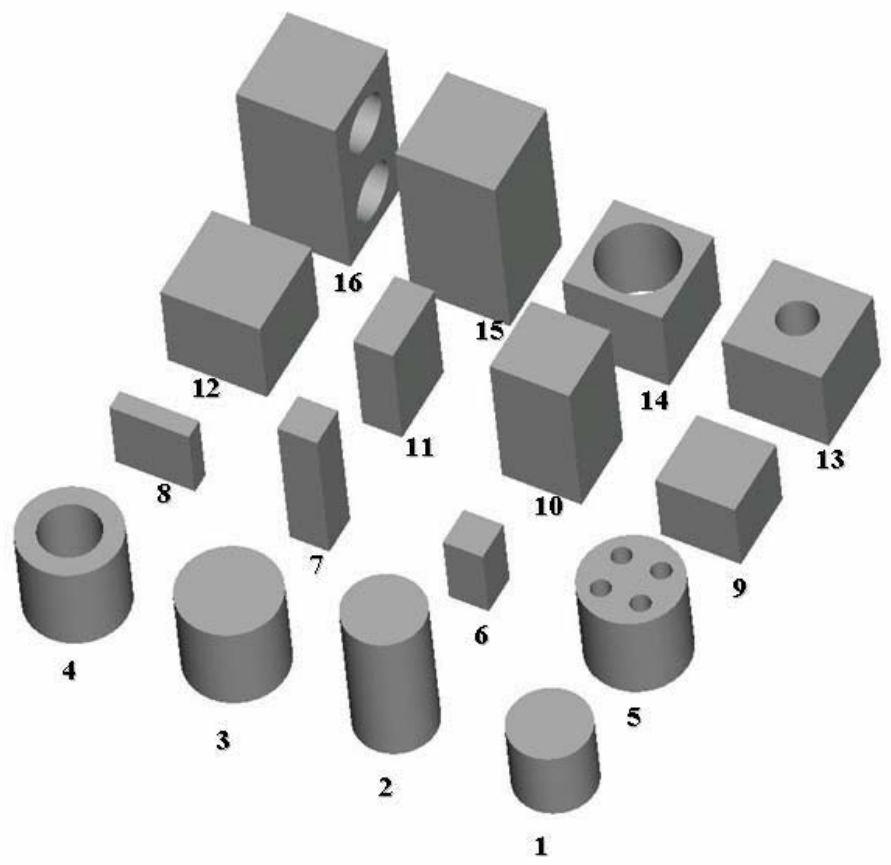

Figure 3-3. Graphite specimens used in the geometrical effect test. 
Table 3-1 Specifications of the graphite specimens used in the geometrical effect test

\begin{tabular}{|c|c|c|c|c|c|}
\hline & Type & Size (mm) & Volume $\left(\mathrm{mm}^{3}\right)$ & Area $\left(\mathrm{mm}^{2}\right)$ & $\mathrm{V} / \mathrm{A}_{\mathrm{s}}(\mathrm{m})$ \\
\hline 1 & Cylinder & $\mathrm{D} 20 \times \mathrm{L} 20$ & 6283 & 1885 & 0.0033 \\
\hline 2 & Cylinder & $\mathrm{D} 20 \times \mathrm{L} 40$ & 12566 & 3142 & 0.0040 \\
\hline 3 & Cylinder & $\mathrm{D} 25 \times \mathrm{L} 25$ & 12272 & 2945 & 0.0042 \\
\hline 4 & Cylinder & D25 $\times$ L25 (15mm 1hole $)$ & 7854 & 3770 & 0.0021 \\
\hline 5 & Cylinder & $\mathrm{D} 25 \times \mathrm{L} 25$ (5mm 4holes) & 10308 & 4359 & 0.0024 \\
\hline 6 & Rectangular & $10 \times 10 \times 20$ & 2000 & 1000 & 0.002 \\
\hline 7 & Rectangular & $10 \times 10 \times 40$ & 4000 & 1800 & 0.0022 \\
\hline 8 & Rectangular & $5 \times 20 \times 20$ & 2000 & 1200 & 0.0017 \\
\hline 9 & Rectangular & $20 \times 20 \times 20$ & 8000 & 2400 & 0.0033 \\
\hline 10 & Rectangular & $20 \times 20 \times 40$ & 16000 & 4000 & 0.004 \\
\hline 11 & Rectangular & $10 \times 20 \times 30$ & 6000 & 2200 & 0.0027 \\
\hline 12 & Rectangular & $25 \times 25 \times 25$ & 15625 & 3750 & 0.0042 \\
\hline 13 & Rectangular & $25 \times 25 \times 25(10 \mathrm{~mm}$ 1hole $)$ & 13662 & 4278 & 0.0031 \\
\hline 14 & Rectangular & $25 \times 25 \times 25(20 \mathrm{~mm} 1 \mathrm{hole})$ & 7771 & 4693 & 0.0017 \\
\hline 15 & Rectangular & $25 \times 25 \times 50$ & 31250 & 6250 & 0.005 \\
\hline 16 & Rectangular & $25 \times 25 \times 50$ ( $15 \mathrm{~mm}$ 2holes $)$ & 22414 & 7899 & 0.0028 \\
\hline
\end{tabular}

Figure 3-4 shows the relation between $R / A_{s}$ and $V / A_{s}$. By analyzing the slope and y-axis intercept of this graph, we deduced the internal surface density as follows:

$$
\theta=12760 \mathrm{~m}^{-1} .
$$

Physically, it means that a unit volume of graphite includes a $12760 \mathrm{~m}^{2}$ internal surface area. 


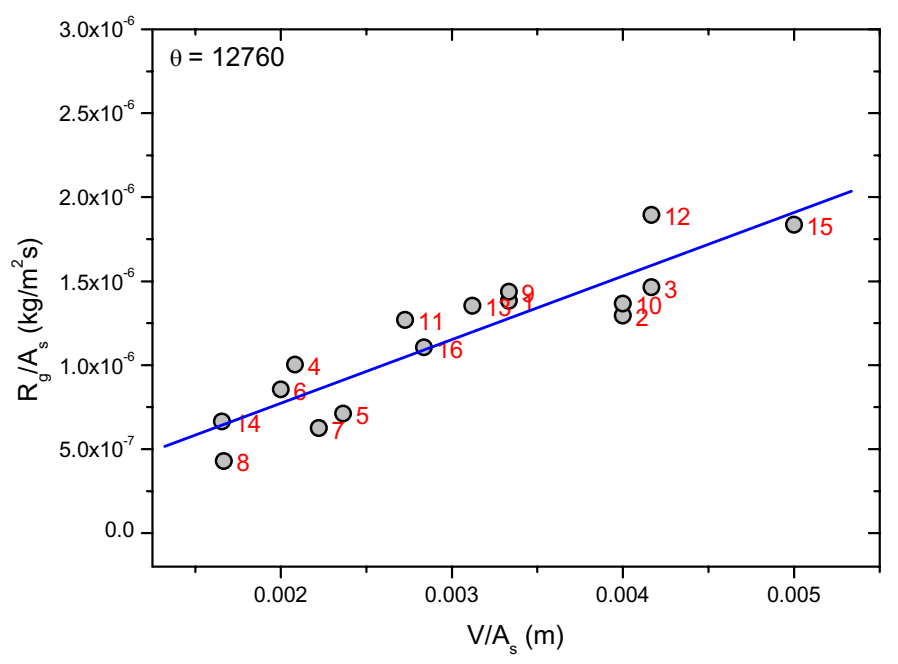

Figure 3-3. Relation between $\mathrm{V} / \mathrm{A}_{\mathrm{s}} \mathrm{Vs} . \mathrm{R}_{\mathrm{g}} / \mathrm{A}_{\mathrm{s}}$.

With this result, we calculated the proportion (I) of the external surface reaction among the total reaction for each sample. Since the reaction rate is proportional to the surface area, the proportion of external reaction can be calculated by the following equation:

$$
I(\%)=\frac{A_{s}}{A_{s}+A_{v}} \times 100=\frac{A_{s}}{A_{s}+\theta \cdot V} \times 100,
$$

where $\mathrm{I}(\%)$ means the percentage of the external surface reaction in the total reaction. As a result, the proportion of the external reaction was below 5 percent of the total reaction, which means that the external surface reaction is negligible.

Finally, we propose the following reaction equation for this material:

$$
r^{\prime \prime \prime}\left(\mathrm{kg} / \mathrm{m}^{3} \mathrm{~s}\right) \approx 2552000 \cdot \exp \left(-\frac{218000}{R \cdot T}\right) \cdot P_{O 2}{ }^{0.75}
$$

\section{Task 3-2: Burn-off effect}

The rate of reaction between graphite and oxygen is dependent on the level of burn-off although it looks constant in a small time scale. In this study, the effect of burn-off was experimentally investigated and the modeling was performed. The same facility and specimens used in Task 3-1 were also used here.

At first, we measured the rates of reaction for various geometries at the same temperature $600{ }^{\circ} \mathrm{C}$ where the chemical reaction is the rate-controlling process. At this temperature, we can assume that the reaction is uniform inside of the graphite since the rate of reaction is very slow. Figure 3-4 shows the results of burn-off variation with time. As shown in this figure, the geometries and sizes do not affects the reaction history, and it confirms that the internal reaction occurred uniformly in the graphite. Therefore, we expect that the same pattern of the reaction history will happen irrespective of the geometries or sizes. 


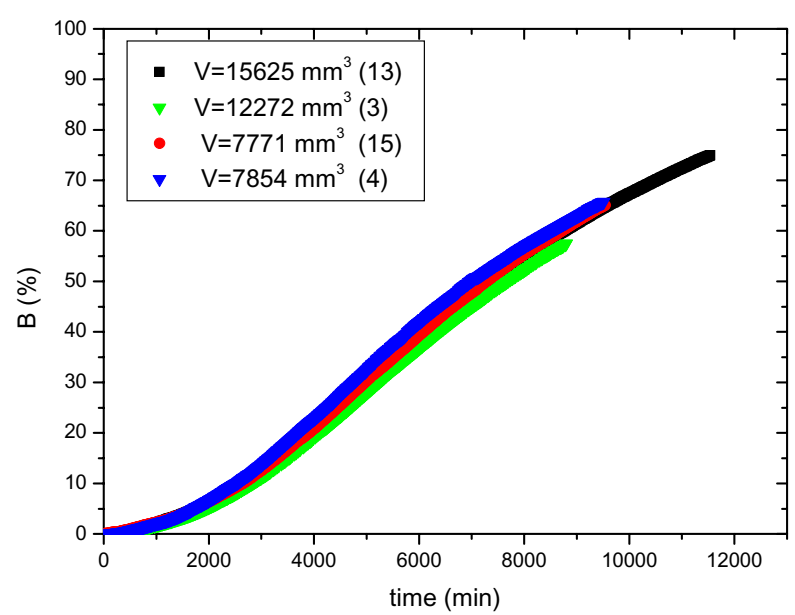

Figure 3-4. Rate of reaction for various geometries.

From Fig 3-4, we obtained the relation between the burn-off and the relative reaction rate as shown in Figure 3-5.

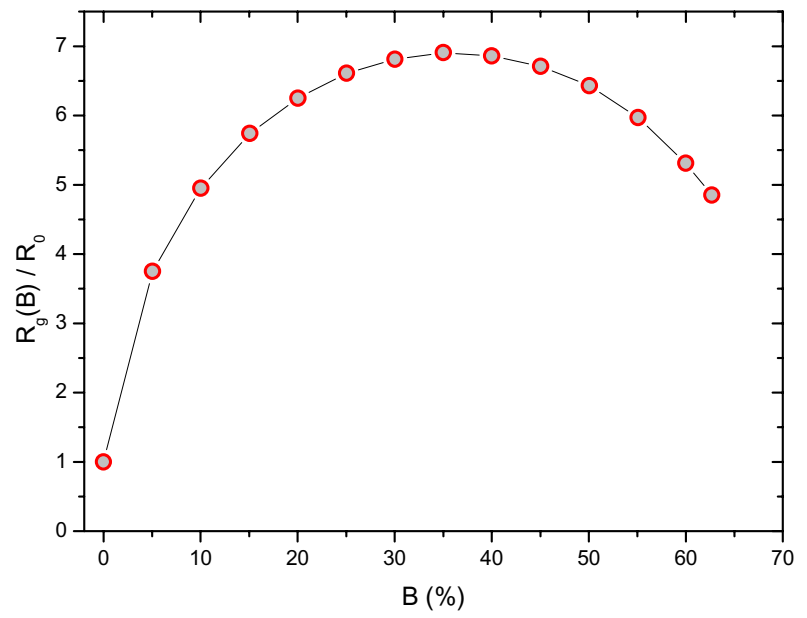

Figure 3-5. Relation between burn-off and oxidation rate.

We estimated the change of shape and size during the test for sample 4. Figure 3-6 shows the graphite sample tested up to $65 \%$ of burn-off level. As shown in this figure, the shape and size changes are negligible compared to the mass variation. 

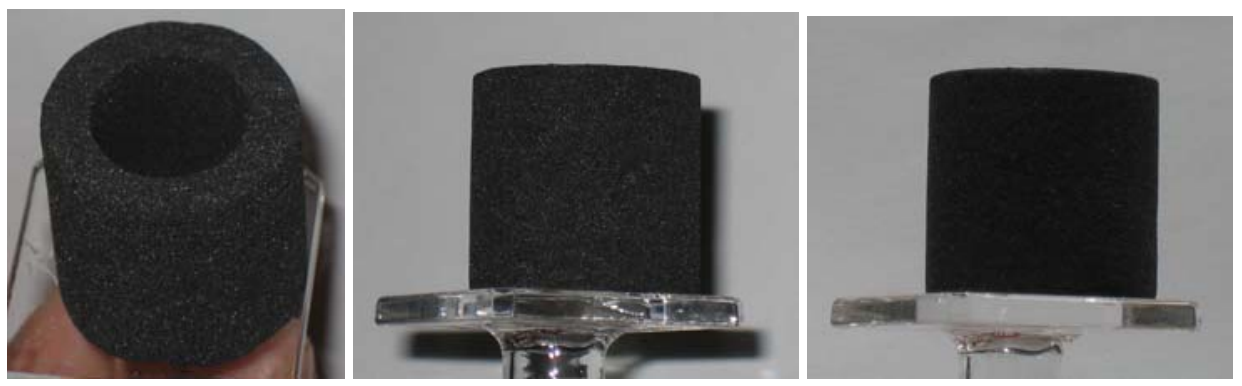

Figure 3-6. shape of the tested graphite sample (sample 4).

We also carried out the same test at different temperatures where the diffusion effect can not be ignored any more. Figure 3-7 shows the results of mass variation with time at different temperatures and it shows that the trends are different for different temperatures. At low temperature, since the internal reaction increases the pore size inside, the reaction increases with time. On the other hand, at high temperature, since the reaction is concentrated on the external surface, it changes the bulk shapes and sizes with time and, as a result, the reaction decreases with time.

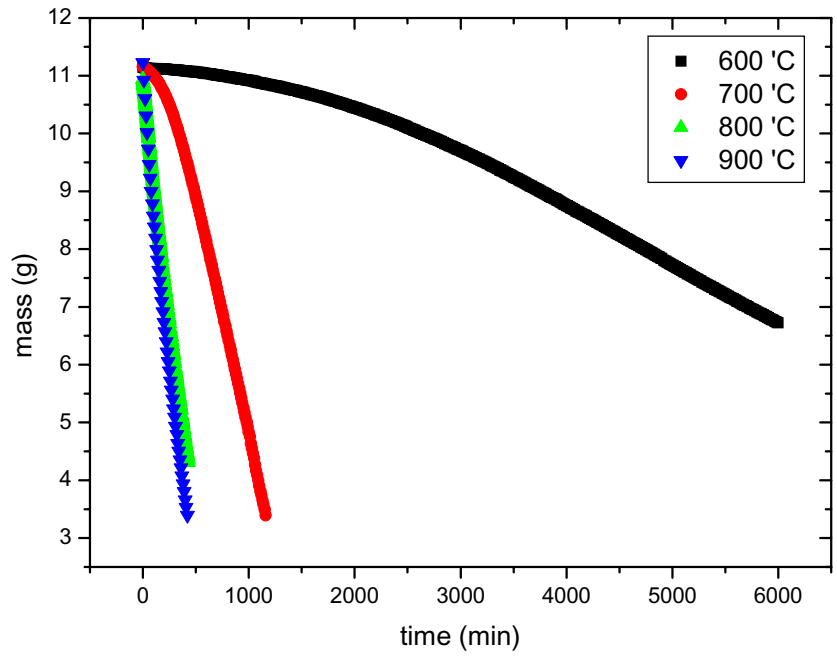

Figure 3-7. shape of the tested graphite sample (sample 4).

To predict the variation of the graphite reaction with time, a modeling and simulation were performed. The following assumptions were used in this modeling.

- The variation of the external surface roughness with time is negligible.

- The variation of the diffusion coefficient with time is negligible.

- The level of burn-off does not affect the chemical characteristics of the graphite.

- The variation of the internal structure of the graphite is only dependent on the level of burn-off. 
The following equations were selected for modeling.

- 2 dimensional diffusion equation (cylindrical coordinate)

$$
\frac{\partial C_{O 2}}{\partial t}=\frac{1}{r} \frac{\partial}{\partial r}\left(r D_{e} \frac{\partial C_{O 2}}{\partial r}\right)+\frac{\partial}{\partial z}\left(D_{e} \frac{\partial C_{O 2}}{\partial z}\right)+S_{O 2}
$$

- mass change

$$
\frac{\partial \rho_{g}}{\partial t}=-r^{\prime \prime \prime}(B)
$$

- burn-off

$$
B=\frac{\rho_{\text {initial }}-\rho}{\rho_{\text {initial }}} \times 100
$$

- graphite oxidation

Bulk reaction: $r^{\prime \prime \prime}(B)=200 \cdot \exp (-218000 / R \cdot T) \cdot p_{O 2}{ }^{0.75} \cdot \theta(B)$

Surface reaction: $r^{\prime \prime}=200 \cdot \exp (-218000 / R \cdot T) \cdot p_{O 2}{ }^{0.75}$

- diffusion coefficient

$$
\begin{aligned}
& D_{e}=D_{T} \times(\text { void fraction }) /(\text { tortousity }) \\
& 1 / D_{T}=1 / D_{\text {binary }}+1 / D_{\text {knussent }}
\end{aligned}
$$

The finite volume method was used as a discretization method. And implicit scheme and Gauss-Siedal method were applied here. Figure 3-8 shows the calculation procedure for this simulation. 


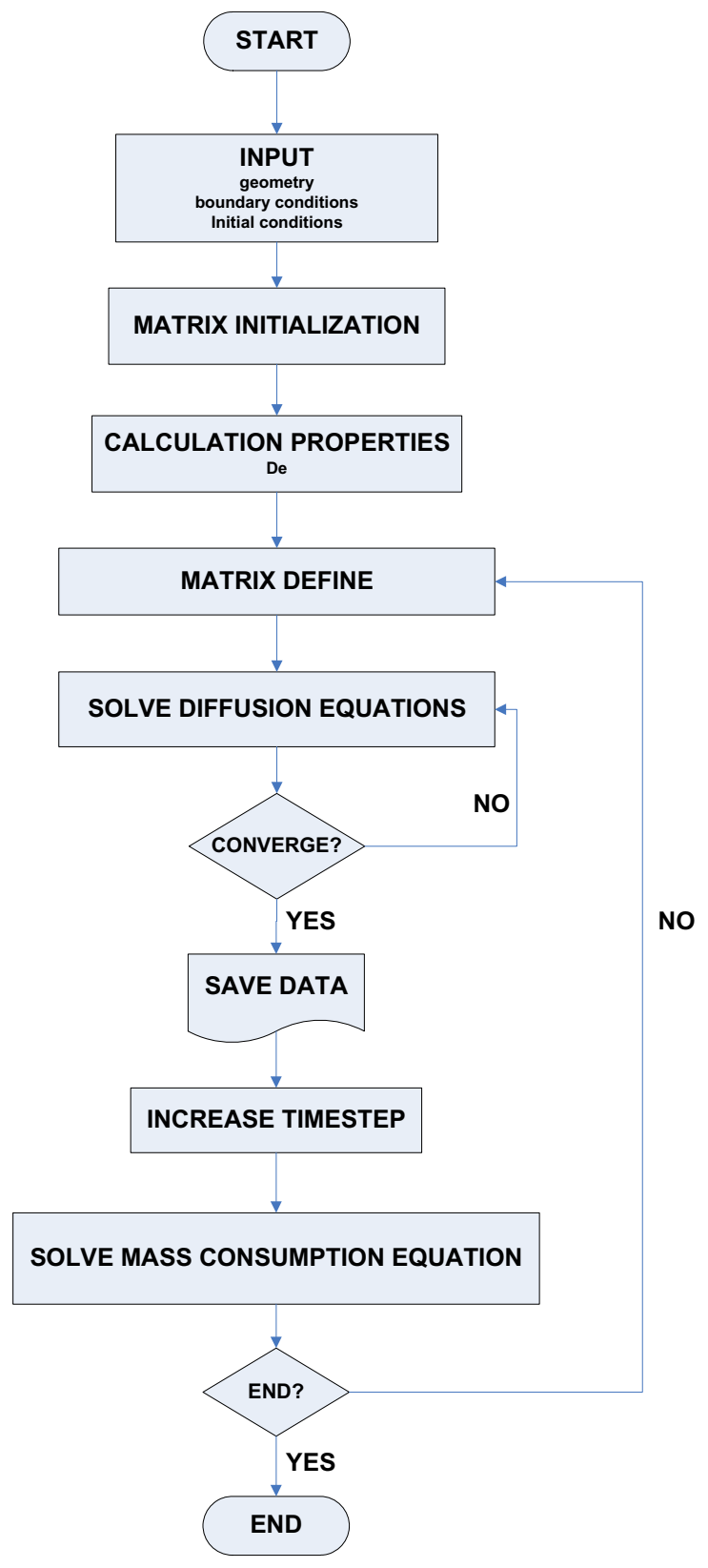

Figure 3-8. Calculation procedure for burn-off effect modeling.

Figure 3-9 shows the comparison results between the calculation and the experimental results. As shown in this figure, the simulation results are in good agreement with the experimental data. Figures 3-10 through 313 illustrate the simulation results for the density variation of the graphite with time. At low temperatures, the internal density change is main reaction mechanism. However, at high temperatures, internal density changes are very small and the size change is the main reaction mechanism. 


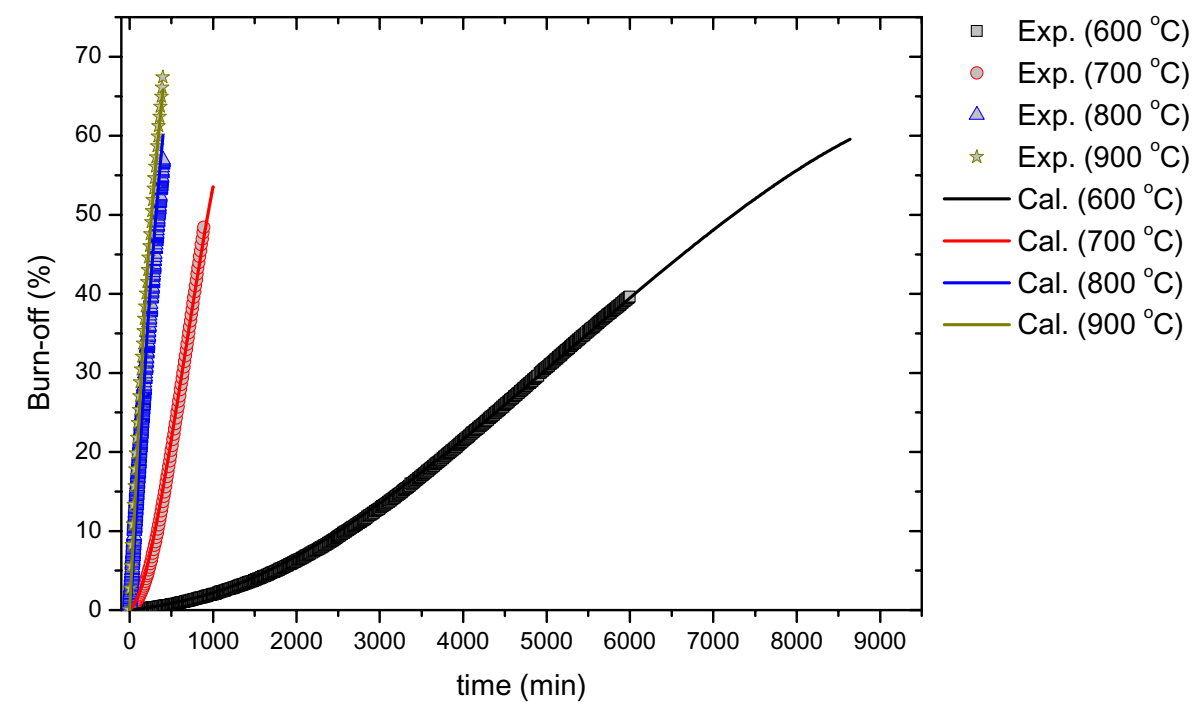

Figure 3-9. Comparisons between experimental data and calculation results.
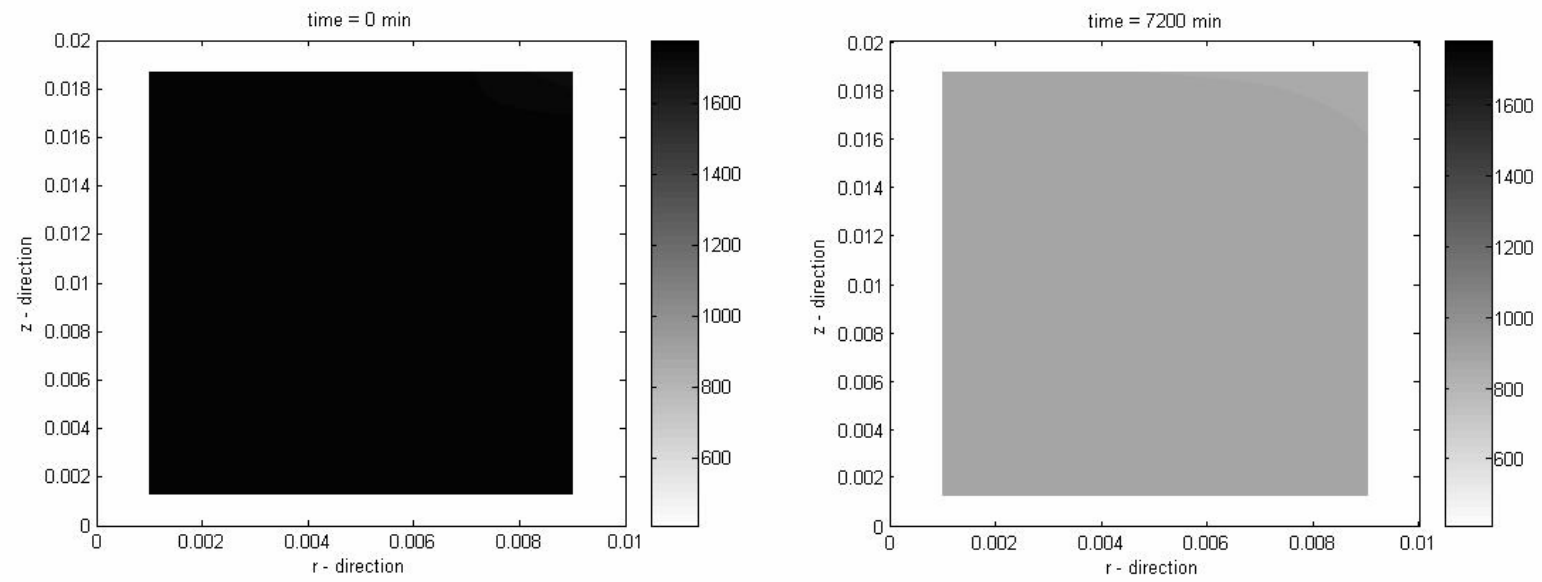

Figure 3-10. Simulation results at $600{ }^{\circ} \mathrm{C}$ (density). 

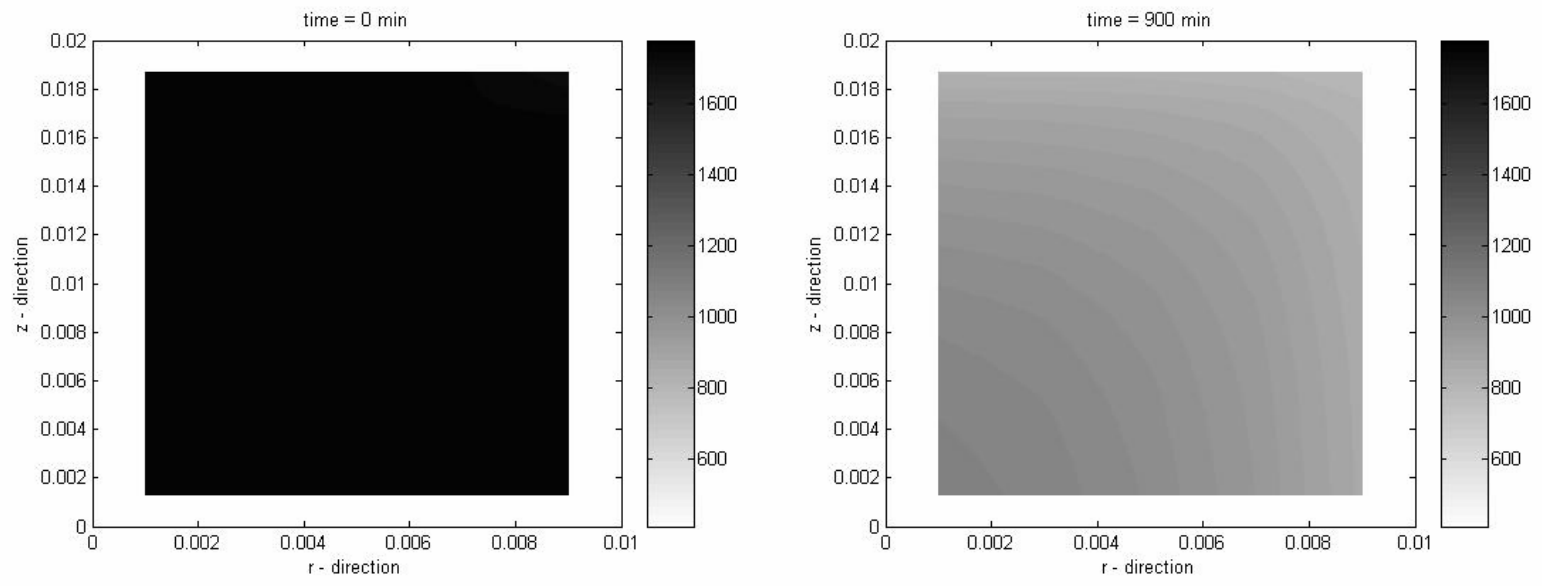

Figure 3-11. Simulation results at $700{ }^{\circ} \mathrm{C}$ (density).
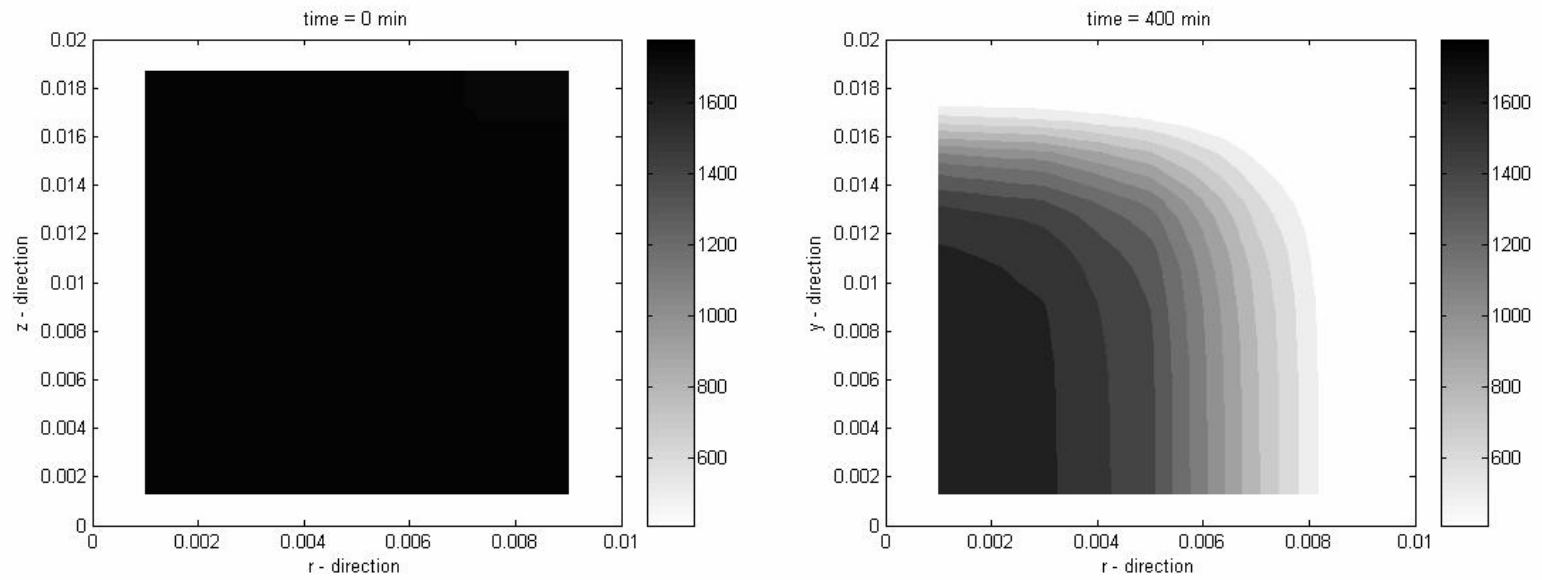

Figure 3-12. Simulation results at $800{ }^{\circ} \mathrm{C}$ (density).
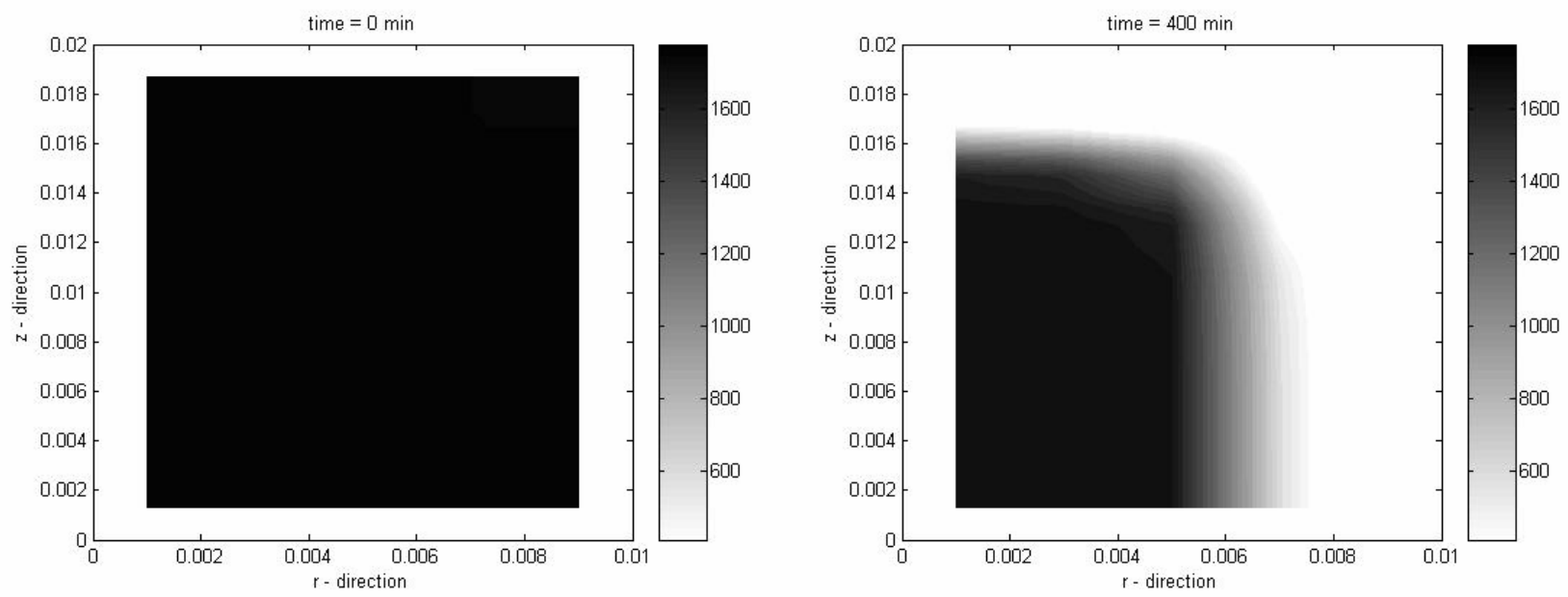

Figure 3-13. Simulation results at $900{ }^{\circ} \mathrm{C}$ (density). 


\section{Task 3-3:Effect of $\mathrm{C} / \mathrm{CO}_{2}$ reaction}

Until recently, many researchers have studied the reaction of $\mathrm{C} / \mathrm{O}_{2}$ and obtained excellent results. However, relatively, little attention has been given to other reactions. The reaction of graphite and $\mathrm{CO}_{2}$ gas $\left(\mathrm{C} / \mathrm{CO}_{2}\right.$ reaction) is among those neglected reactions. The reaction of the $\mathrm{C} / \mathrm{CO}_{2}$ is written as follows:

$$
\mathrm{C}+\mathrm{CO}_{2} \rightarrow 2 \mathrm{CO}
$$

This equation shows that the $\mathrm{C} / \mathrm{CO}_{2}$ reaction produces $\mathrm{CO}$ gas as a main product, which is known toxic and explosive. Furthermore, since this reaction can damage the structural integrity, investigation on this reaction is necessary for better analysis of the air-ingress.

Figure 3-14 shows our experimental facility. First, we obtained the reaction rate by analysis on the concentrations of $\mathrm{O}_{2}, \mathrm{CO}$ and $\mathrm{CO}_{2}$ species. Figure 3-15 shows the test section. The specimen was supported by a ceramic rod and heated by a induction heater. We then measured its surface temperature with an infrared thermometer. The test specimens made of IG-110 graphite, which is an isostatically molded, isotropic finegrained and halogen purified, were machined to $2.1 \mathrm{~cm}$ in diameter and $3 \mathrm{~cm}$ in length. The mixture gas of Helium and $\mathrm{CO}_{2}$ was used as a reacting gas and injected at the bottom of the test section, which was made of a quartz tube. This experiment was conducted in the temperature range between $600{ }^{\circ} \mathrm{C}$ and $1400{ }^{\circ} \mathrm{C}$, and in the mole fraction of $\mathrm{CO}_{2}$ between 5 percent and 20 percent.

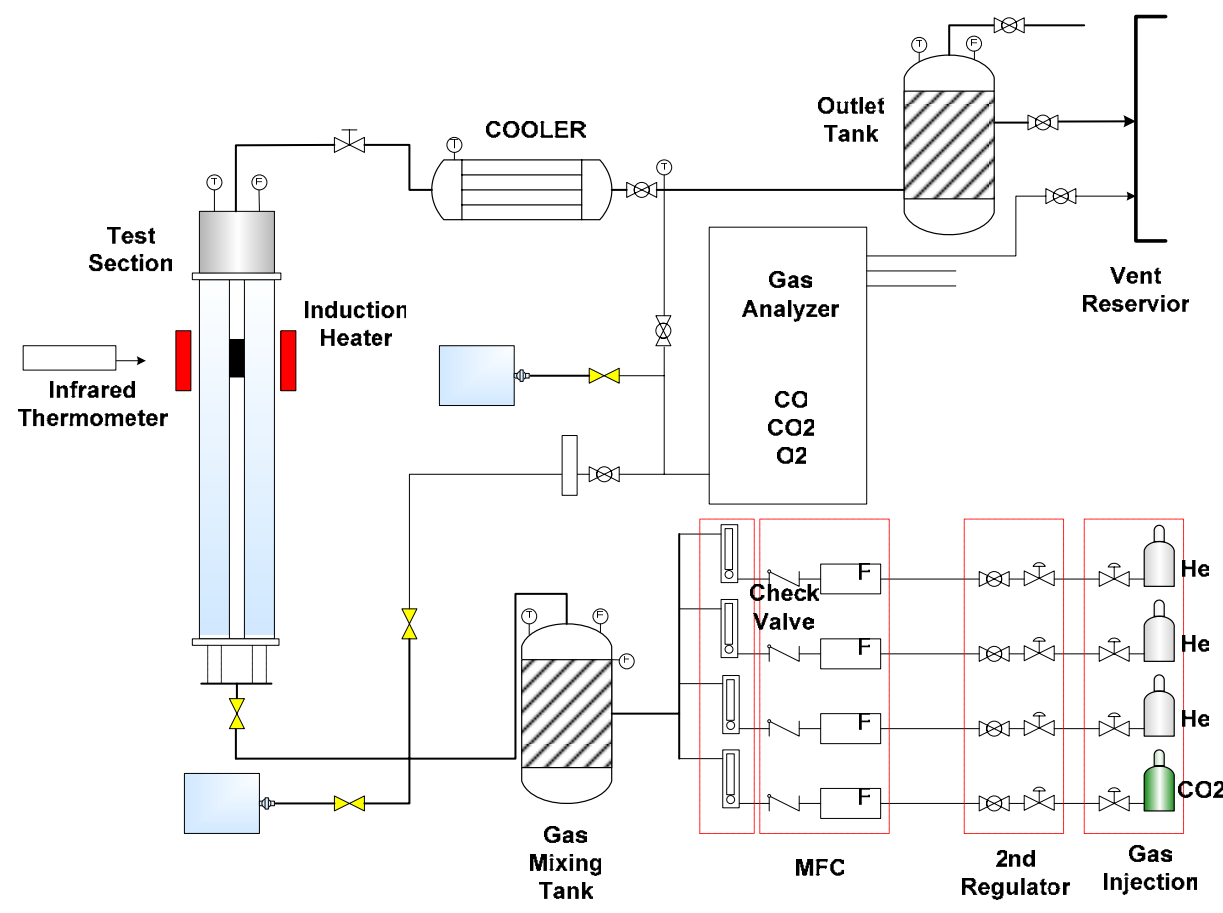

Figure 3-14. Test facility for $\mathrm{C} / \mathrm{CO}_{2}$ reaction. 

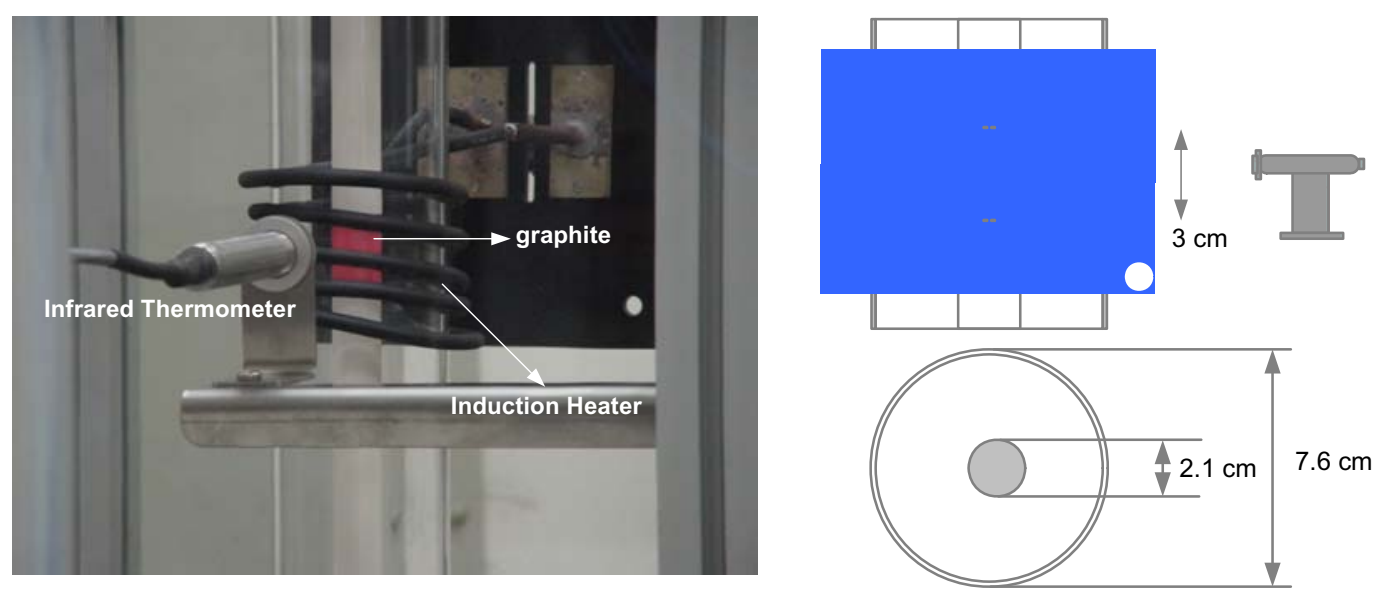

Figure 3-15. Test section for $\mathrm{C} / \mathrm{CO}_{2}$ reaction.

To investigate the reaction of $\mathrm{C} / \mathrm{CO}_{2}$, we measured kinetic parameters: an activation energy (Ea) and an order of reaction (n). Figure 3-16 illustrates the effect of temperature on the reaction rate. In this graph, which is generally called as Arrhenius plot, the $\mathrm{x}$-axis represents 1000/T and y-axis represents the logarithm of the reaction rate. This figure shows a linear trend of the data between the two main parameters: 1000/T and a log of the reaction rates, and it confirms that the Arrhenius model globally well represents the reaction of $\mathrm{C} / \mathrm{CO}_{2}$ in our conditions. The activation energy can be obtained from the slope of this graph and we repeated the same tests 7 times for more confidence. By applying a statistical method, we determined the value of activation energy as $295 \pm 8 \mathrm{~kJ} / \mathrm{mol}$ within $95 \%$ confidence level.

Although we tried to measure the reaction from $600^{\circ} \mathrm{C}$, we could not detect it below $1000^{\circ} \mathrm{C}$ due to its slow rate of reaction. Figure 3-16 illustrates the rates of reaction at the temperature between $1000{ }^{\circ} \mathrm{C}$ and $1400{ }^{\circ} \mathrm{C}$ at the mole fraction of $\mathrm{CO}_{2}$ between 5 and 15 percent. This figure shows that the effect of $\mathrm{CO}_{2}$ concentration is much smaller than the effect of temperature. On the basis of the experimental data, the value of the order of reaction was calculated as 0.9 . Figure 4 also shows that there is no transition in the reaction rate data, and it confirms that the rate of the $\mathrm{C} / \mathrm{CO}_{2}$ reaction is not affected by mass diffusion in our experimental conditions. We expect that the mass diffusion effect would occur at higher temperature.

Figure 3-17 compares the rates of reactions between the $\mathrm{C} / \mathrm{CO}_{2}$ and the $\mathrm{C} / \mathrm{O}_{2}$, which is the dominant reaction in HTGR air-ingress. The experimental temperature ranged between $700^{\circ} \mathrm{C}$ and $1500{ }^{\circ} \mathrm{C}$, and the $\mathrm{CO}_{2}$ mole fraction was 2.5 percent to 20 percent. This figure shows that the rate of the $\mathrm{C} / \mathrm{CO}_{2}$ reaction is much smaller than that of the $\mathrm{C} / \mathrm{O}_{2}$ reaction. The differences between them are very large at low temperature, but the differences are reduced as the temperature increases due to the limitation of the $\mathrm{C} / \mathrm{O}_{2}$ reaction by mass diffusion effect. Based on the trend of Figure 3-17, we deduce that both of the reaction rates would be comparable around $2000^{\circ} \mathrm{C}$. For the situation where the portion of $\mathrm{O}_{2}$ gas is very small, on the basis of our experimental data, we propose the following rate equation:

$$
r_{g}\left(\mathrm{~kg} / \mathrm{m}^{3} \mathrm{~s}\right)=5.7 \times 10^{-7} \exp \left(-\frac{295000}{R \cdot T}\right) \cdot\left(p_{\mathrm{CO} 2}\right)^{0.9},
$$

where $r_{g}$ is a volumetric rate of $\mathrm{C} / \mathrm{CO}_{2}$ reaction, $\mathrm{R}$ is a gas constant, $\mathrm{T}$ is temperature $(\mathrm{K})$, and $\mathrm{p}_{\mathrm{CO} 2}$ is a partial pressure $(\mathrm{Pa})$ of $\mathrm{CO}_{2}$. This equation is a general type of Arrhenius equation and it agrees well with our experimental data with RMS error of $\pm 5 \%$. 


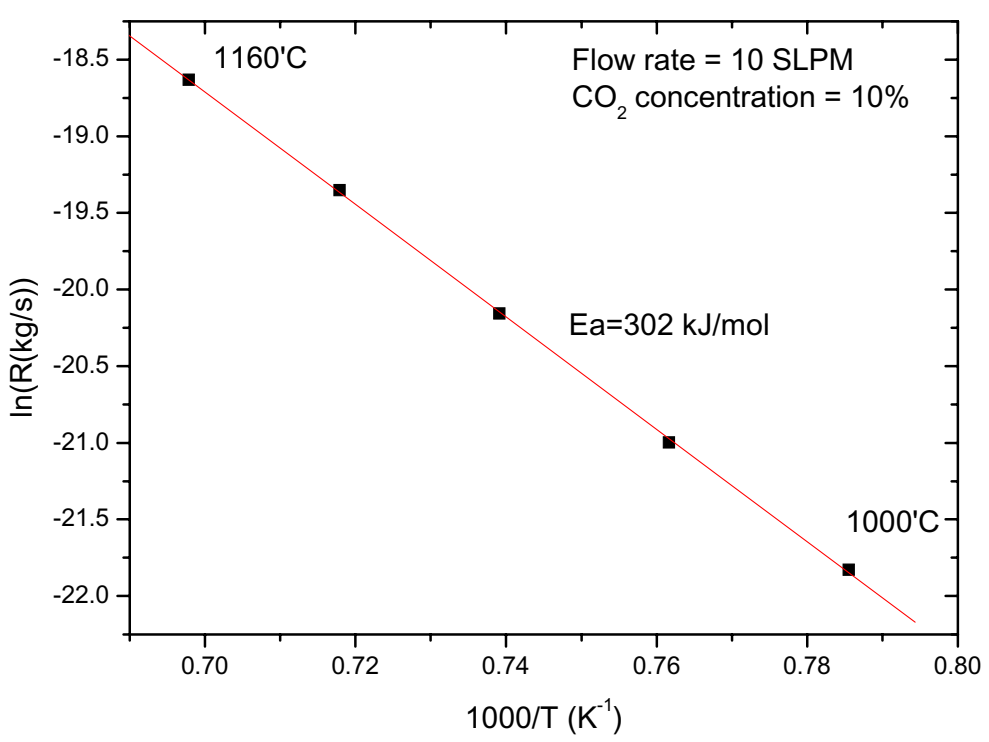

Figure 3-15. Arrehinus curve for $\mathrm{C} / \mathrm{CO}_{2}$ reaction.

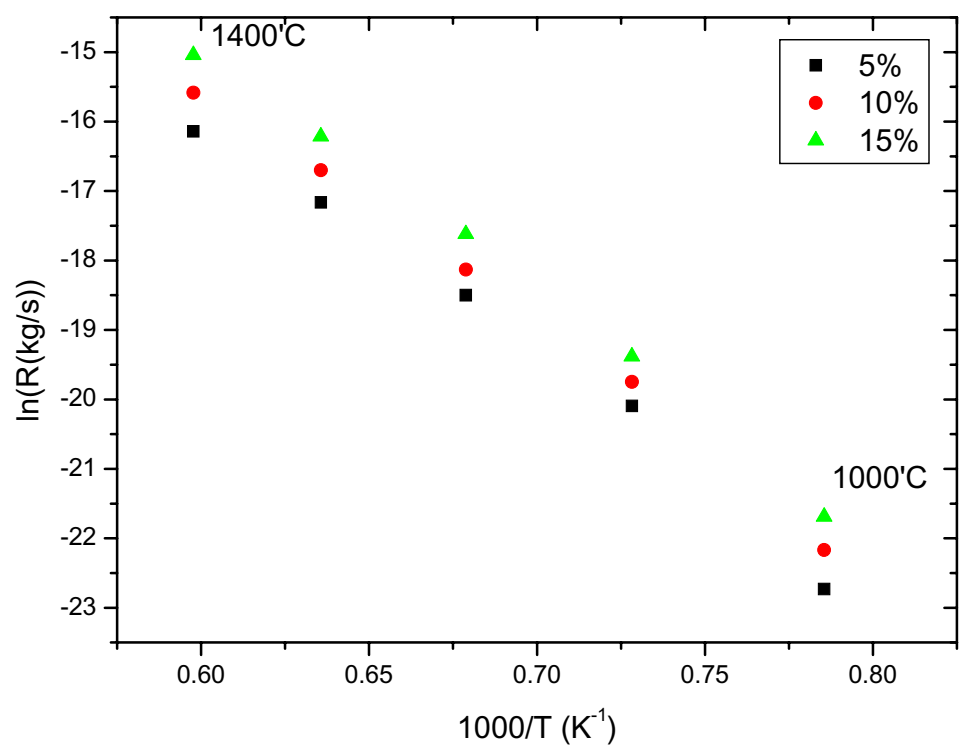

Figure 3-16. Experimental results for the rate of $\mathrm{C} / \mathrm{CO}_{2}$ reaction. 


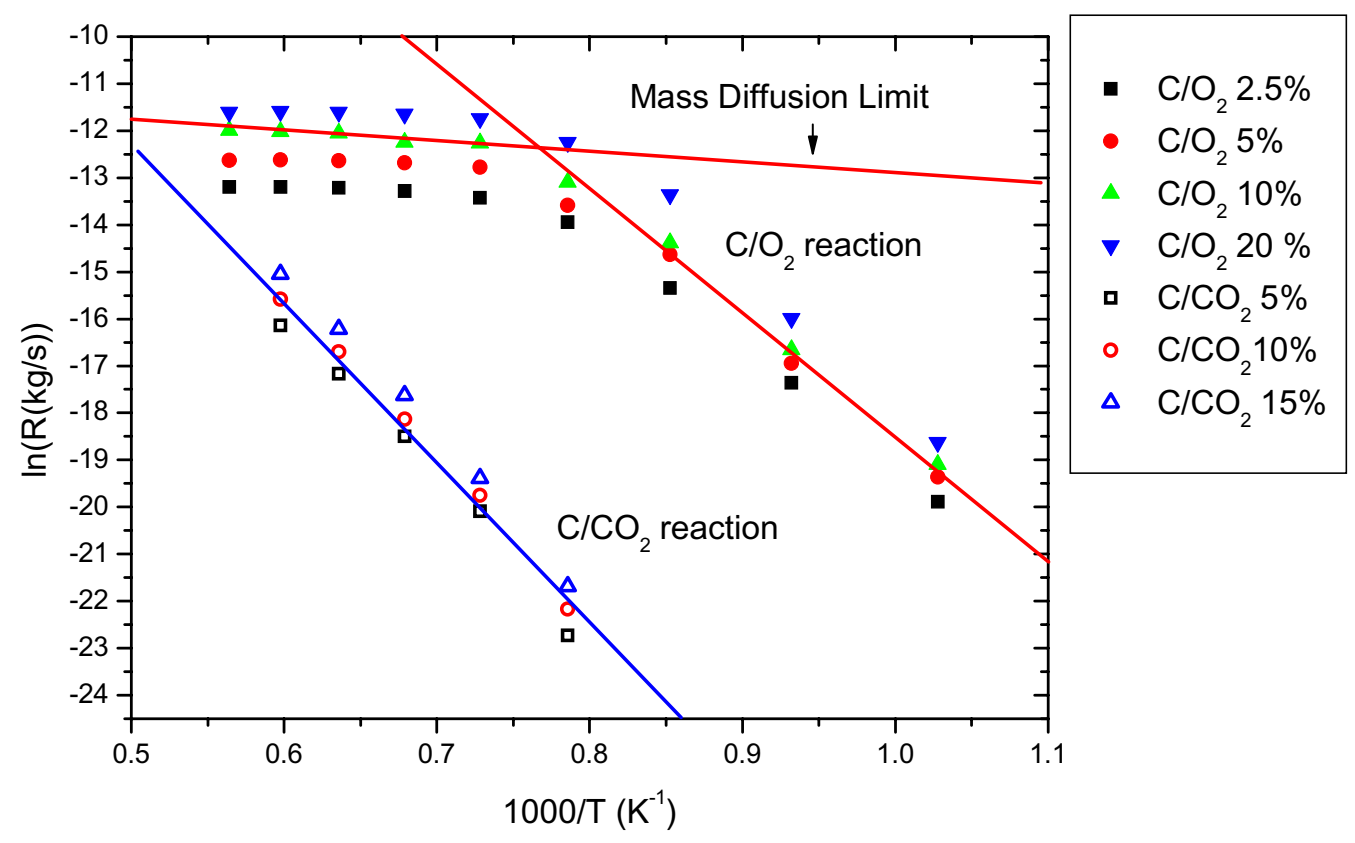

Figure 3-17. Comparisons on the rate of reaction between $\mathrm{C} / \mathrm{O}_{2}$ reaction and $\mathrm{C} / \mathrm{CO}_{2}$ reaction.

\section{Task 4: Improvement of System Codes (INL)}

The RELAP5/ATHENA code (RELAP5-3D 2002) was extended to model the molecular diffusion of several species of gas through a system represented by a general network of control volumes wherein any control volume can be connected to several other control volumes on its inlet and outlet sides. Previously, the molecular diffusion modeling was applicable only to a gas mixture with two species of gas and only to gas mixture in a pipe wherein each control volume was connected only to one other control volume at each of its two ends. In the extended modeling, the molecular diffusion modeling can be applied to gas mixtures containing up to five species of gas $\left(\mathrm{He}, \mathrm{N}_{2}, \mathrm{O}_{2}, \mathrm{CO}_{2}\right.$, and $\left.\mathrm{CO}\right)$ and any individual control volume may be connected up to twelve other control volumes on either its inlet or outlet sides.

Extensions Made to RELAP5/ATHENNA for Modeling the Diffusion of Multiple Species of Gas in a General Network of Control Volumes and Assessement

For a general network of control volumes with several species of gas, the transient concentrations of the various species of gas in the RELAP5/ATHENA code is calculated by the equation (Press et al. 1986)

$$
\frac{C_{j i}^{n+1}-C_{j i}^{n}}{\Delta t}=\left[\frac{\sum_{k=1}^{k \max } D_{j i k} A_{i k}\left(\frac{C_{j k}^{n}-C_{j i}^{n}}{\Delta x_{i k}}\right)-\sum_{m=1}^{m \max } D_{j i m} A_{i m}\left(\frac{C_{j i}^{n}-C_{j m}^{n}}{\Delta x_{i m}}\right)}{\Delta x_{i} A_{i}}\right]
$$


where

$C_{j i}^{n}=$ mole-fraction of $\mathrm{j}$-th species of gas in control volume " $\mathrm{i}$ " at time step " $\mathrm{n}$ " (unitless),

$\mathrm{k}=$ index identifying one of the RELAP5 control volumes on outlet side of control volume " $\mathrm{i}$ ", $\mathrm{kmax}=$ total number of RELAP5 control volumes connected to outlet side of control volume "i", $\mathrm{m}=$ index identifying one of the RELAP5 control volumes on inlet side of control volume " $\mathrm{i}$ ", $\operatorname{mmax}=$ total number of RELAP5 control volumes connected to inlet side of control volume "i", $D_{j i k}=$ effective binary diffusivity of the $\mathrm{j}$-th species of gas and the gas mixture in the diffusion path between control volumes "i" and " $\mathrm{k}$ " $\left(\mathrm{m}^{2} / \mathrm{s}\right)$,

$D_{j i k}=\left(\Delta x_{i} D_{j i}+\Delta x_{k} D_{j k}\right) /\left(\Delta x_{i}+\Delta x_{k}\right)$,

$D_{j i m}=\left(\Delta x_{i} D_{j i}+\Delta x_{m} D_{j m}\right) /\left(\Delta x_{i}+\Delta x_{m}\right)$,

$D_{j i}=$ effective binary diffusivity of the $\mathrm{j}$-th species of gas and the gas mixture in control volume " $\mathrm{i}$ ",

$A_{i k}=$ cross-sectional area for diffusion path between control volumes "i" and " $\mathrm{k}$ " $\left(\mathrm{m}^{2}\right)$,

$A_{i k}=\min \left(A_{i}, A_{k}\right)$,

$A_{\text {im }}=\min \left(A_{i}, A_{m}\right)$,

$A_{i}=$ cross-sectional area for diffusion path in control volume "i",

$\Delta x_{i k}=$ length of diffusion path between control volumes "i" and " $\mathrm{k}$ " (m),

$\Delta x_{i k}=0.5\left(\Delta x_{i}+\Delta x_{k}\right)$,

$\Delta x_{i m}=0.5\left(\Delta x_{i}+\Delta x_{m}\right)$,

$x_{i}=$ length of diffusion path in control volume "i".

The effective binary diffusivity of the $\mathrm{j}$-th species of gas and the gas mixture in control volume "i" can be calculated by the equation (Reid et al. 1986)

$$
D_{j i}=\left(\sum_{n=1, n \neq j}^{n \max } \frac{y_{n i}}{D_{j n i}}\right)^{-1}
$$

where

$D_{j i}=$ effective binary diffusivity of the $\mathrm{j}$-th species of gas and the gas mixture in control volume "i" $\left(\mathrm{m}^{2} / \mathrm{s}\right)$,

nmax $=$ number of species of gas in the gas mixture (unitless),

$y_{n i}=$ mole-fraction of $\mathrm{n}$-th species of gas in the gas mixture in control volume "i" (unitless),

$D_{j n i}=$ binary diffusivity of the $\mathrm{j}$-th and $\mathrm{n}$-th species of gas in control volume "i" $\left(\mathrm{m}^{2} / \mathrm{s}\right)$.

The binary diffusivity for the $\mathrm{j}$-th and $\mathrm{n}$-th species of gas is calculated by the correlation (Reid et al. 1986, RELAP5-3D 2002, Davis 2003)

$D_{j n}=\frac{0.0101\left(\frac{1 .}{w_{j}}+\frac{1 .}{w_{n}}\right)^{0.5} T_{i}^{1.75}}{\left[P_{i}\left\{a_{d j}^{0.333}+a_{d n}^{0.333}\right\}^{2.0}\right]}$ 
where

$T_{i}=$ temperature of gas mixture in control volume with index " $\mathrm{i}$ " $(\mathrm{K})$,

$P_{i}=$ pressure of gas mixture in control volume with index "i”" $(\mathrm{Pa})$,

$w_{j}=$ molecular weight of $\mathbf{j}$-th species of gas in gas mixture,

$w_{n}=$ molecular weight of $\mathrm{n}$-th species of gas in gas mixture,

$a_{d j}=$ atomic diffusion volume for $\mathrm{j}$-th species of gas in gas mixture,

$a_{d n}=$ atomic diffusion volume for $\mathrm{n}$-th species of gas in gas mixture.

The atomic diffusion volumes for each species of gas are defined as shown in Table 4-1 (Davis 2003).

Table 4-1. Atomic diffusion volumes of various species of gas.

\begin{tabular}{|l|l|}
\hline Species of gas & Atomic diffusion volume \\
\hline \hline helium & 2.67 \\
\hline nitrogen & 18.5 \\
\hline oxygen & 16.3 \\
\hline carbon dioxide & 26.9 \\
\hline carbon monoxide & 18.0 \\
\hline
\end{tabular}

Two simple but rigorous test problems were used to assess the modeling of the diffusion of several species of gas in a general network of control volumes. The first test problem, named the Multiple Junction Test Problem, compares the diffusion calculated in a pipe for two different nodalizations of the pipe. One of the nodalizations represents the pipe by a series of in-line control volumes, while the other nodalization represents the middle of the pipe with a series of separate but parallel control volumes. This test problem focuses on assessing the modeling of diffusion in a system with control volumes with multiple inlet and outlet junctions. The test problem also assesses for internal consistency the modeling of a gas mixture consisting of four species of gas. The second test problem, named the Bulb Experiment Test Problem, compares the calculated and measured mole-fractions of gases in a system consisting of two bulbs connected by a diffusion path and with initially different compositions of in each bulb.

The Multiple Junction Test Problem involved the calculation of the transient mixing in a pipe of four species of gas originally separated from each other. The calculation was performed with two different nodalizations that should produce identical results for correct modeling of a general network of control volumes. In the first nodalization, the gas mixture in the pipe is represented by a single row of four equally sized control volumes. This nodalization is shown in Figure 4-1. In the second nodalization, multiple connections were applied to the outlet side of control volume 101 and to the inlet side of control volume 104 shown in Figure 4-1. This nodalization is shown in Figure 4-2. For the nodalization shown in Figure 4-1, control volumes with identification numbers of 101 and 102 initially contain a mixture of $\mathrm{N}_{2}, \mathrm{O}_{2}$, and $\mathrm{CO}_{2}$ at a pressure of $0.1 \mathrm{MPa}$ and a temperature of $291 \mathrm{~K}$. The initial mass fractions of $\mathrm{N}_{2}, \mathrm{O}_{2}$, and $\mathrm{CO}_{2}$ in these control volumes were $0.769,0.1$, and 0.131 , respectively. These gases are the "non-working" fluid. The control volumes with identification numbers of 103 and 104 initially contain He (the working fluid) at a pressure of $0.1 \mathrm{MPa}$ and a temperature of $291 \mathrm{~K}$. The length of each of the four control volume is $0.1 \mathrm{~m}$ and the control volumes are equal in cross-sectional area. At the time of zero seconds, the valve isolating control volumes 101 and 102 from control volumes 103 and 104 is fully opened (cross-sectional area of opened valve equal to the cross-sectional area of the four control volumes) and diffusion results in the gradual mixing of the various species of gas. In the second nodalization of the pipe, control volumes 102 and 103 in Figure 4-1 were each split into two equally sized control volumes with the sum of the cross-sectional area of each of these two pairs equal to the cross-sectional area of the pipe shown in Figure 4-1. For this nodalization, 
control volumes 102 and 104 represent one half of the middle section of the pipe and control volumes 103 and 105 the other half. The outlet side of control volume 101 is connected to both control volumes 102 and 103 and the inlet side of control volume 106 is connected to both control volumes 104 and 105 . The crosssectional area of the pipe is everywhere the same as for the pipe shown in Figure 4-1. Control volumes 101, 102, and 103 initially contain the same mixture of $\mathrm{N}_{2}, \mathrm{O}_{2}$, and $\mathrm{CO}_{2}$ as the control volumes 101 and 102 in Figure 4-1, and control volumes 104, 105, and 106 initially contain $\mathrm{He}$ at the same conditions as that in control volumes 103 and 104 in Figure 4-1.

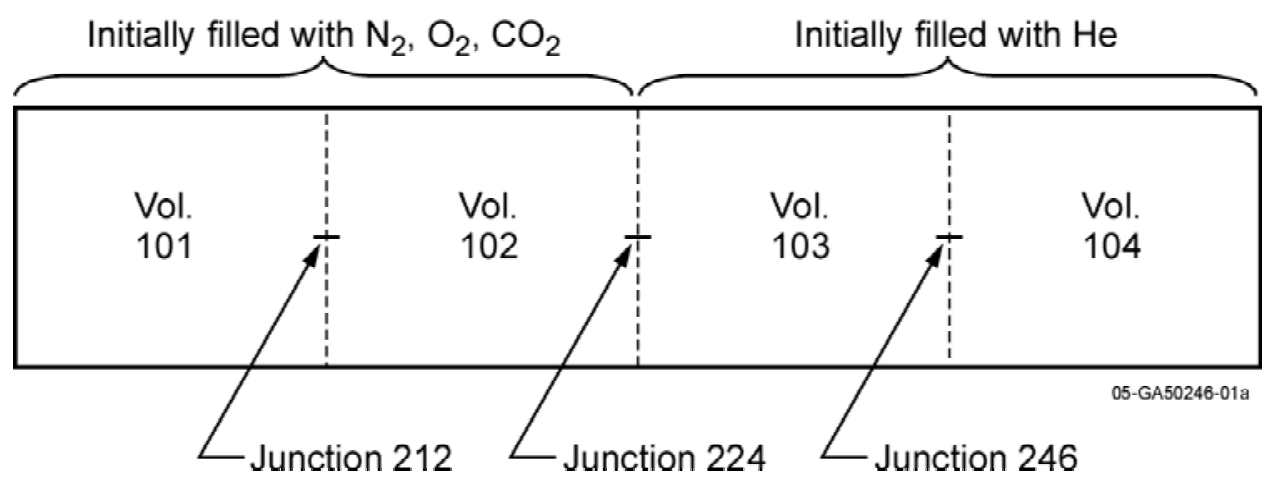

Figure 4- 1. Nodalization of pipe containing a mixture of gases as a single row of four equally sized control volumes.

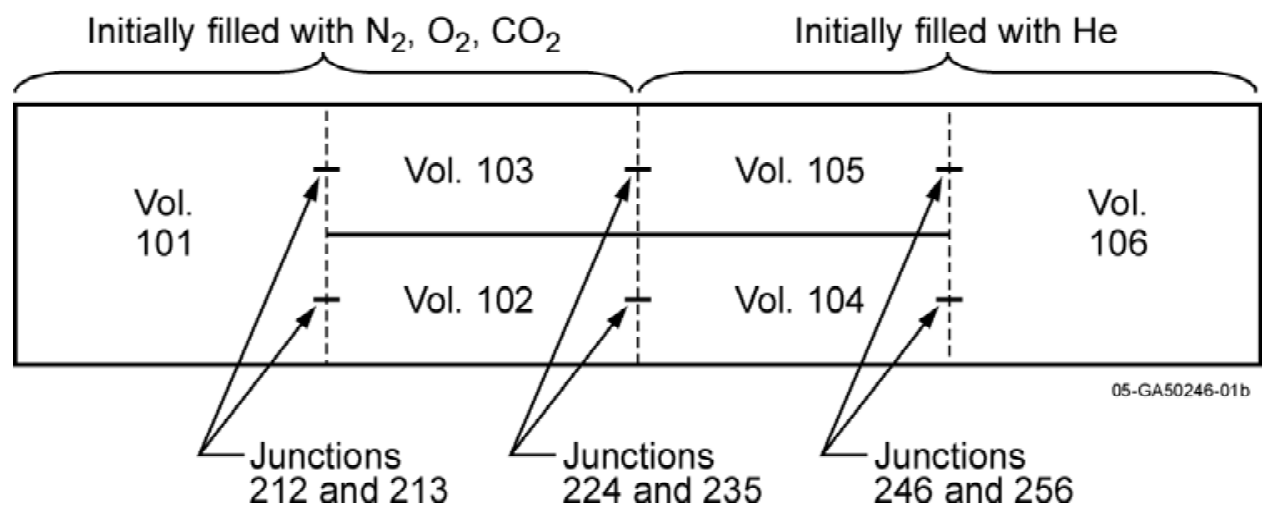

Figure 4-2. Nodalization of pipe with control volumes at ends of pipe having multiple connections to inlet or outlet side.

The calculations performed with the nodalization shown in Figure 4-1 were found to be identical with the calculations performed using the nodalization shown in Figure 4-2. Figure 4-3 compares the transient mass fraction of the non-working gases $\left(\mathrm{N}_{2}, \mathrm{O}_{2}\right.$, and $\left.\mathrm{CO}_{2}\right)$ at the two ends of the pipe as calculated for the case with single connections in the control volumes at the two ends of the pipe and for the case with multiple connections in the control volumes at the two ends of the pipe. As shown in this figure, the results for the two nodalizations are identical. For internally consistent modeling, the calculations should predict that the mass fractions of each species of gas in each control volume asymptotically approach the same value. Figure 4-3 shows that this requirement is also satisfied by the modeling. In summary, the results shown in Figure 43 indicate that the extensions made to the RELAP5/ATHENA code for modeling a generalized network of control volumes and gas mixtures with several species of gas have been correctly implemented. 


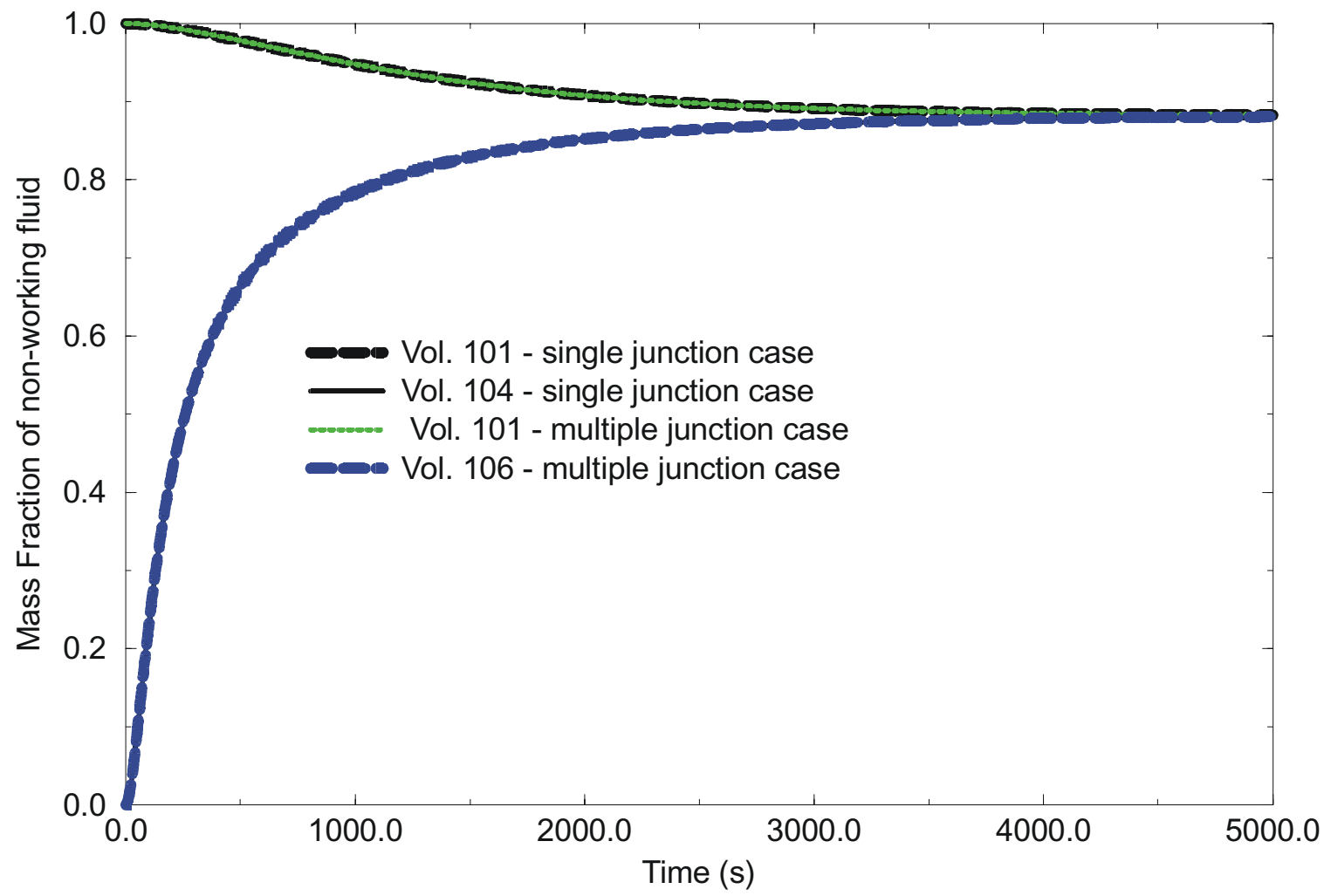

Figure 4-3. Transient concentration of non-working fluid gases $\left(\mathrm{N}_{2}, \mathrm{O}_{2}\right.$, and $\left.\mathrm{CO}_{2}\right)$ at the two ends of pipe.

The calculated transient mole-fractions of gas show that the diffusion modeling in RELAP5/ATHENA is conserving the moles of gas in a system being modeled. For the four control volume system shown in Figure 4-1, the left half of the system contained only helium before opening of the valve isolating the two halves of the system and the right half contained 0.8181 mole-fractions of $\mathrm{N}_{2}, 0.0932$ molefractions of $\mathrm{O}_{2}$, and 0.0887 mole fractions of $\mathrm{CO}_{2}$. Each half of the system contained the same moles of gas. Figure 4-4 shows the calculated transient mole-fractions of helium and oxygen in control volumes 101 (left most control volume) and 104 (right most control volume). After the valve has been open for $5000 \mathrm{~s}$, the calculated mole-fractions of gas in the system approach their asymptotic values. The mole-fractions of helium in control volumes 101 and 104 are calculated to approach 0.5, which is the correct value for conserving the moles of helium in the system. The mole-fractions of $\mathrm{O}_{2}$ in control volumes 101 and 104 are calculated to approach 0.0466 , which is the correct value for conserving $\mathrm{O}_{2}$ in the system. 


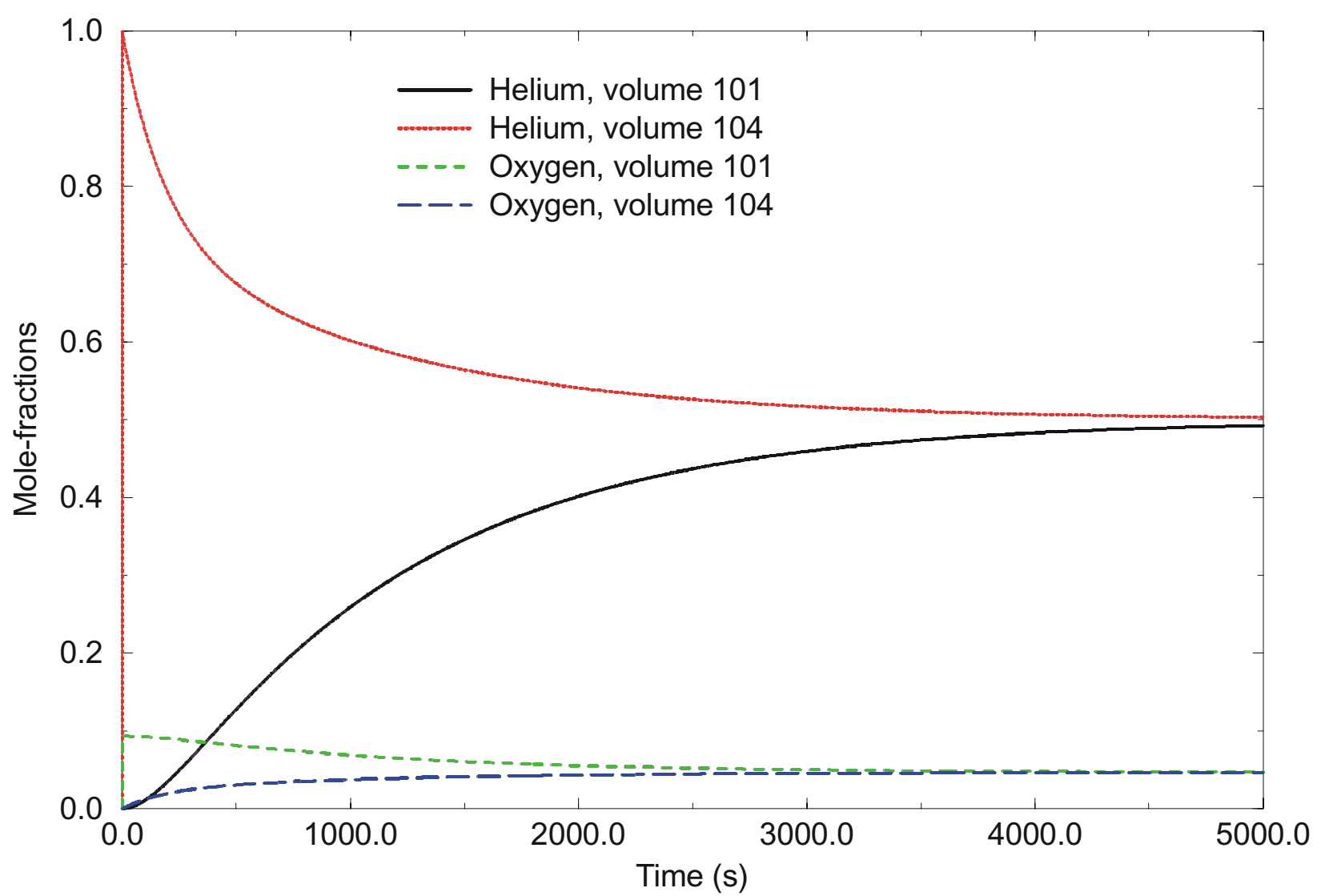

Figure 4-4. Calculated transient mole-fractions of helium and oxygen for four volume control system shown in Figure 4-1.

The presence of helium was calculated to cause the effective binary diffusivities of the three nonworking gases $\left(\mathrm{N}_{2}, \mathrm{O}_{2}\right.$, and $\left.\mathrm{CO}_{2}\right)$ to increase by about a factor of two. The effective binary diffusivities of each species of gas in the gas mixture in control volume 101 at the times of $0.0 \mathrm{~s}$ and $5000 \mathrm{~s}$ are shown in Table 4-2. At the time of $0.0 \mathrm{~s}$, no helium was present in control volume 101 and at the time of $5000 \mathrm{~s}$ about half the moles of gas in the control volume was helium. The effective binary diffusivities of $\mathrm{O}_{2}$ and the gas mixture at the times of $0.0 \mathrm{~s}$ and $5000 \mathrm{~s}$ are $0.1002 \times 10^{-4} \mathrm{~m}^{2} / \mathrm{s}$ and $0.1696 \times 10^{-4} \mathrm{~m}^{2} / \mathrm{s}$, respectively. For $\mathrm{N}_{2}$ and $\mathrm{CO}_{2}$, the effective binary coefficients also increased by similar amounts between $0.0 \mathrm{~s}$ and $5000.0 \mathrm{~s}$.

Table 4-2. Effective binary diffusivities of each gas species in mixture in control volume 101.

\begin{tabular}{|c|c|c|c|c|}
\hline \multirow{2}{*}{$\begin{array}{c}\text { Gas } \\
\text { species }\end{array}$} & \multicolumn{2}{|c|}{ Time of $0.0 \mathrm{~s}$} & \multicolumn{2}{c|}{ Time of $5000 \mathrm{~s}$} \\
\cline { 2 - 5 } & Mole fractions & Diffusivity $\left(\mathrm{m}^{2} / \mathrm{s}\right)$ & Mole fractions & Diffusivity $\left(\mathrm{m}^{2} / \mathrm{s}\right)$ \\
\hline \hline $\mathrm{N}_{2}$ & 0.8181 & $0.1080 \times 10^{-4}$ & 0.4113 & $0.1808 \times 10^{-4}$ \\
\hline $\mathrm{O}_{2}$ & 0.09314 & $0.1002 \times 10^{-4}$ & 0.04691 & $0.1696 \times 10^{-4}$ \\
\hline $\mathrm{CO}_{2}$ & 0.08872 & $0.9715 \times 10^{-4}$ & 0.04473 & $0.1652 \times 10^{-4}$ \\
\hline $\mathrm{He}$ & 0.0 & - & 0.4971 & - \\
\hline
\end{tabular}

The Bulb Experiment Test Problem assessed the RELAP5 modeling of diffusion against experimental data. The experiment was performed by Duncan and Toor (Duncan and Toor 1962) using a two-bulb diffusion cell. The apparatus for the experiment consisted of bulbs on the left and right ends of a diffusion path $85.9 \mathrm{~mm}$ long and $2.08 \mathrm{~mm}$ in diameter. The volume of the left bulb was $77.99 \times 10^{-6} \mathrm{~m}^{3}$ and the volume of the right bulb was $78.63 \times 10^{-6} \mathrm{~m}^{3}$. The left bulb was filled with a gas mixture consisting of 0.5 
mole fractions of $\mathrm{N}_{2}$ and 0.5 mole fractions of $\mathrm{CO}_{2}$. The right bulb was filled with a gas mixture consisting of 0.499 mole-fractions of $\mathrm{N}_{2}$ and 0.501 mole-fractions of $\mathrm{H}_{2}$. The gases in the bulbs and the diffusion path were at a pressure of $0.1 \mathrm{MPa}$ and a temperature of $308 \mathrm{~K}$ through out the experiment. A stopcock was located in the middle of the diffusion path and opened at the experiment time of zero seconds to start the experiment. A measurement was performed of the transient mole-fractions of each species of gas in the left and right bulbs.

RELAP5/ATHENA calculations of the bulb experiment were performed using a network of twelve equal length control volumes in a horizontal line. The left and right control volumes in the network represented the left and right bulbs in the experiment; their volumes were equal to the volumes of the left and right bulbs in the experiment, respectively. The ten control volumes between the left and right control volumes had cross sectional areas corresponding with a diffusion path with a diameter of $2.08 \mathrm{~mm}$ and the combined lengths of these ten control volumes was equal to $85.9 \mathrm{~mm}$.

The RELAP5/ATHENA calculations of the bulb experiment are generally in fair to good agreement with the measured results. Comparisons of the RELAP5/ATHENA calculations of the mole-fractions of gas in the left and right bulbs with the measured results are shown in Figures 5-7. The figures show the transient mole-fractions calculated by the RELAP5/ATHENA code and the measured results at the earliest time at which measurements were made, namely 14,400 s (4 hours). The gas species $\mathrm{H}_{2}$ is the fastest diffusing of the three species of gas in the experiment. As shown in Figure 4-5, the calculated and measured values of the mole-fractions of $\mathrm{H}_{2}$ in the left and right bulbs at the time of $14,400 \mathrm{~s}$ are in good agreement. As shown in Figure 4-6, the calculated and measured values of $\mathrm{CO}_{2}$ in the left bulb at the time of $14,400 \mathrm{~s}$ are in good agreement, while the calculated value of $\mathrm{CO}_{2}$ for the right bulb under-predicts the measured value by a factor of two. As shown in Figure 4-7, the calculated and measured values of $\mathrm{N}_{2}$ for the right bulb at the time of $14,400 \mathrm{~s}$ are in good agreement, while the calculated value for the left bulb under-predicts the measured value by about $30 \%$.

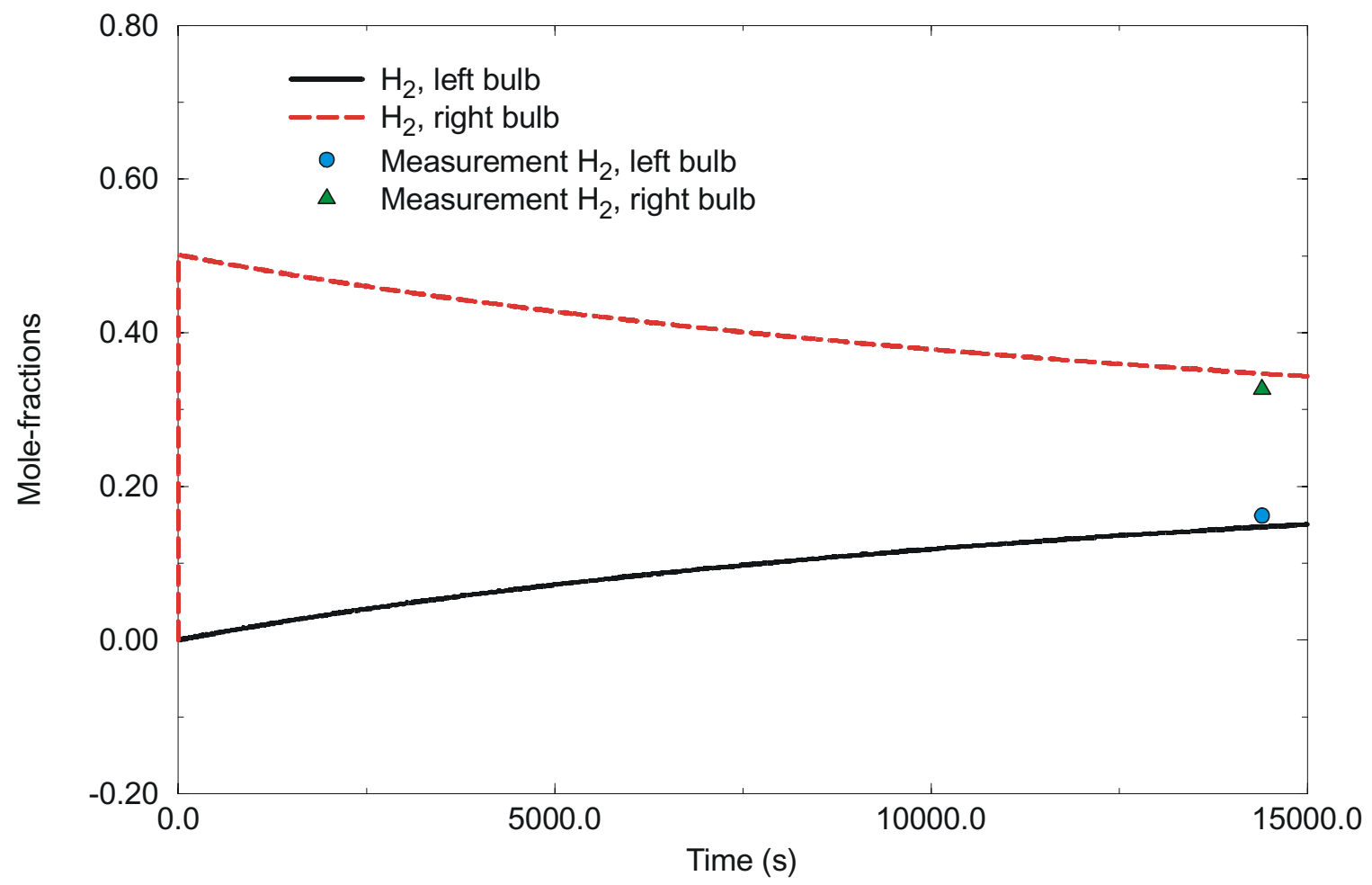

Figure 4-5. Comparison of calculated and measured mole-fractions of $\mathrm{H}_{2}$ in left and right bulbs of the bulb experiment. 


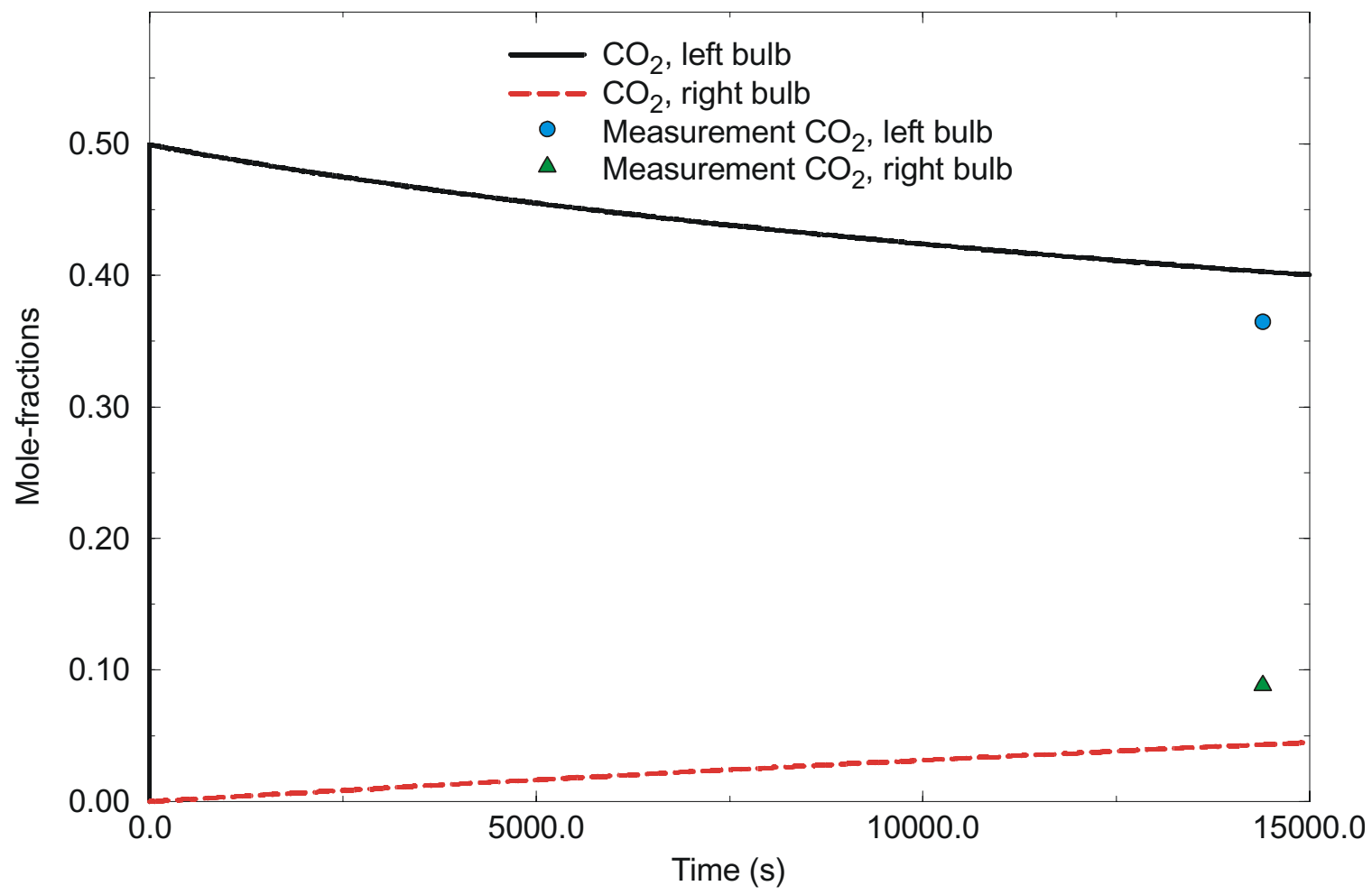

Figure 4-6. Comparison of calculated and measured mole-fractions of $\mathrm{CO}_{2}$ in left and right bulbs of the bulb experiment.

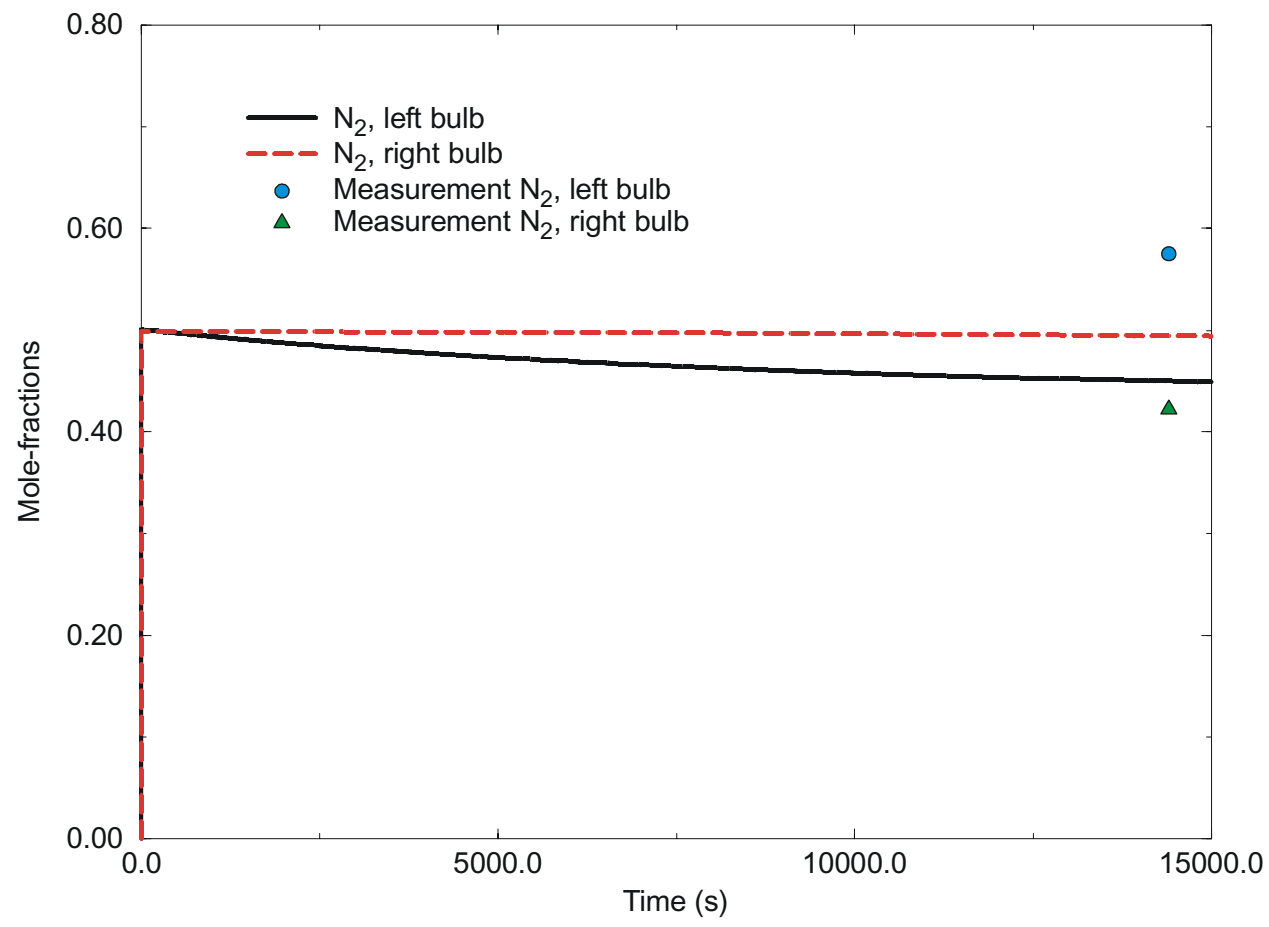

Figure 4-7. Comparison of calculated and measured mole-fractions of $\mathrm{N}_{2}$ in left and right bulbs of the bulb experiment. 
The under-prediction of the concentration of $\mathrm{N}_{2}$ in the left bulb and the under-prediction of the amount of $\mathrm{CO}_{2}$ in the right bulb were due to the special case of reverse diffusion occurring for a period of time in the vicinity of the left bulb (Duncan and Toors 1962). RELAP5/ATHENA is not capable of modeling reverse diffusion, which requires the calculation of a negative value of the effective diffusion coefficient so as to calculate diffusion against the concentration gradient.

In summary, the assessment of the diffusion modeling in the RELAP5/ATHENA code indicates correct modeling for a general system containing several species of gases. The Multiple Junction Test Problem showed correct modeling of diffusion in a network of control volumes with multiple inlet and outlet junctions. The Bulb Experiment Test Problem showed calculated and measured results to be in fair to good agreement for diffusion in a system with three species of gas and involving for a period of time the special case of diffusion against the concentration gradient.

\section{Additional Assessment of the Molecular Diffusion model in MELCOR}

The MELCOR computer code (version 1.8.5) was assessed using natural circulation data generated in the NACOK experimental apparatus (Kuhlmann 2002). This is the same data that was assessed using the RELAP5-3D computer code as reported in the 2004 annual INERI report INEEL/EXT-04-02459 (November 2004).The MELCOR model contained the same number of control volumes and heat structures as used in the RELAP5 model as shown in Figure 4-8, thus a direct comparison of the RELAP5 and MELCOR 1.8.5 results could be made. A description of the geometry and boundary conditions used in the model are contained in INEEL/EXT-04-02459.

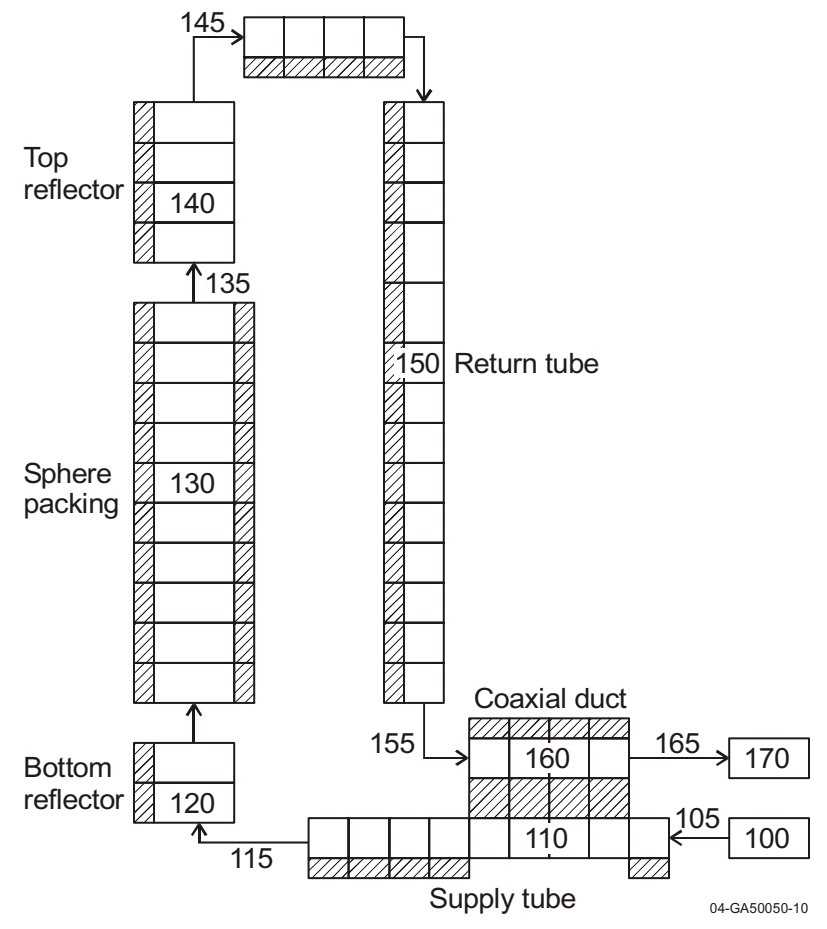

Figure 4-8. MELCOR model of the NACOK experiment.

The model represents all the thermal hydraulic components of the experimental apparatus, including the coaxial duct, supply tube, bottom reflector, packed spheres, top reflector, and return tube. Boundary conditions of atmospheric pressure and $20^{\circ} \mathrm{C}$ were applied in Component 100 and 170, which are timedependent volumes. 
Preliminary results of the comparison are show in Fig. 4-9.

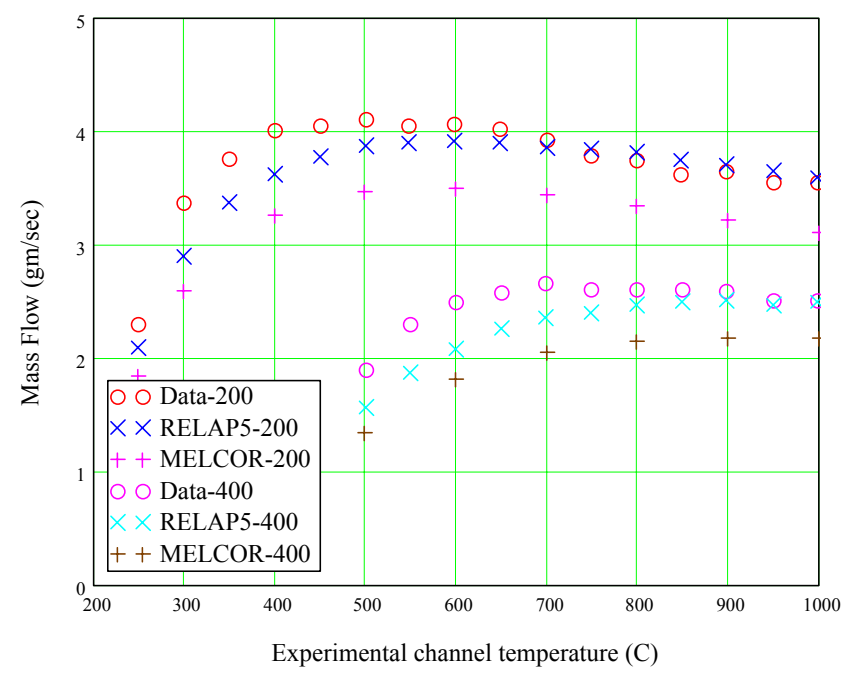

Figure 4-9. Measured and calculated air flow rates for the NACOK natural circulation experiment corresponding to return tube temperatures of $200 \mathrm{C}$ and $400 \mathrm{C}$.

Preliminary assessment of the results indicate that the convective heat transfer coefficients calculated by MELCOR in the return tube are slightly low than the ones calculated by the RELAP5 code thus, resulting in lower mass flow rates as seen in the figure. The lower heat transfer coefficients result in less heat loss from the air, resulting in higher gas temperatures in the return tube which in turn affects the net buoyancy force driving the experimental flow rate.

\section{Publication in 2005:}

H. No, C. Oh, J. Kim, G. Park, J. Lee, W. Martin, M. Kim, J. Conlin, and W. Ji, "Very-High-Temperature Gas-Cooled Reactors: Progress and Challenges," Proc. International Congress on Advances in Nuclear Power Plants, ICAPP 2005, Seoul, Korea, May 15-19, 2005.

R. Moore and C. Oh, "Assessment of a Molecular Diffusion Model in Melcor," 2005 ANS Transactions, Vol. 92. pp.215-216,Annual Meeting, San Diego, CA. June 5-9, 2005

C.Davis, L. Siefken, and C. Oh, “Assessment of RELAP5-3D for Analysis of Very High Temperasture GasCooled Reactors," NURETH-11, Avignon, France, October 1-8, 2005.

C. Davis, L. Siefken, and C.H. Oh, "Assessment of a Molecular Diffusion Model in RELAP5," submitted to 2005 ANS Winter Meeting, Washington DC, November 13-17,2005. 


\section{Task 5: Neutronic Modeling (University of Michigan)}

\section{Task Status and Significant Results}

During this year, progress has been made in the following areas: (1) modeling of double heterogeneities of the particle fuel, (2) neutronic analysis with temperature feedback, and (3) fuel depletion calculations. These efforts are described below.

\subsection{Analysis of Double Heterogeneity}

Stochastic fuel geometry

Previous results have shown that the 2-region model (fuel kernel; fuel coatings and graphite matrix) yields acceptable results compared with the 6-region model when the microspheres are located on a lattice. We have extended this analysis to geometries with microspheres randomly placed in a fuel compact cell, consisting of a fuel compact (a right circular cylinder of length $4.928 \mathrm{~cm}$ and diameter $1.245 \mathrm{~cm}$ ) surrounded by its share of the graphite portion of a fuel block, as depicted in Figure 5-1 below. The following cases were analyzed:

Case 1 - The fuel region consists of 5-region microspheres randomly placed in a fuel compact (graphite matrix) using random sequential addition (RSA) in each of 50 layers. This "stratified RSA" method results in 129 heterogeneous microspheres (fuel kernel and 4 coatings) being inserted into each of the 50 layers in the fuel compact. This is a "6-region" fuel configuration, including the graphite matrix. See Figure 5-1.

Case 2 - Same as Case 1 except the microsphere coatings are mixed with the graphite matrix and the fuel kernels are placed at the identical points as the full microspheres. This is a "2-region" fuel configuration.

Case 3 - Same as Case 1 except RSA is performed in 10 layers rather than 50 layers, resulting in more random placement of the microspheres. See Figure 5-2.

Case 4 - Same as Case 3 except with 2-region microsphere cells.

The results for Cases 1-4 are given in Table 5-1. These results confirm that the 2-region microsphere cell yields acceptable results for particle fuel where the microspheres are randomly located within a finite geometry as well as located on a lattice as we had previously reported. The effect of implementing RSA in 50 layers versus 10 layers appears to be negligible, but this is still under examination.

Table 5-1. MCNP5 Simulations of Fuel Compact Cells

\begin{tabular}{|r|c|c|c|c|c|}
\hline Case & \# regions & \# layers & \# realizations & $k_{\text {eff }}$ & Sigma \\
\hline 1 & 2 & 50 & 2 & 1.34237 & .00022 \\
\hline 2 & 6 & 50 & 2 & 1.34268 & .00022 \\
\hline 3 & 2 & 10 & 19 & 1.34228 & .00019 \\
\hline 4 & 6 & 10 & 2 & 1.34258 & .00022 \\
\hline
\end{tabular}



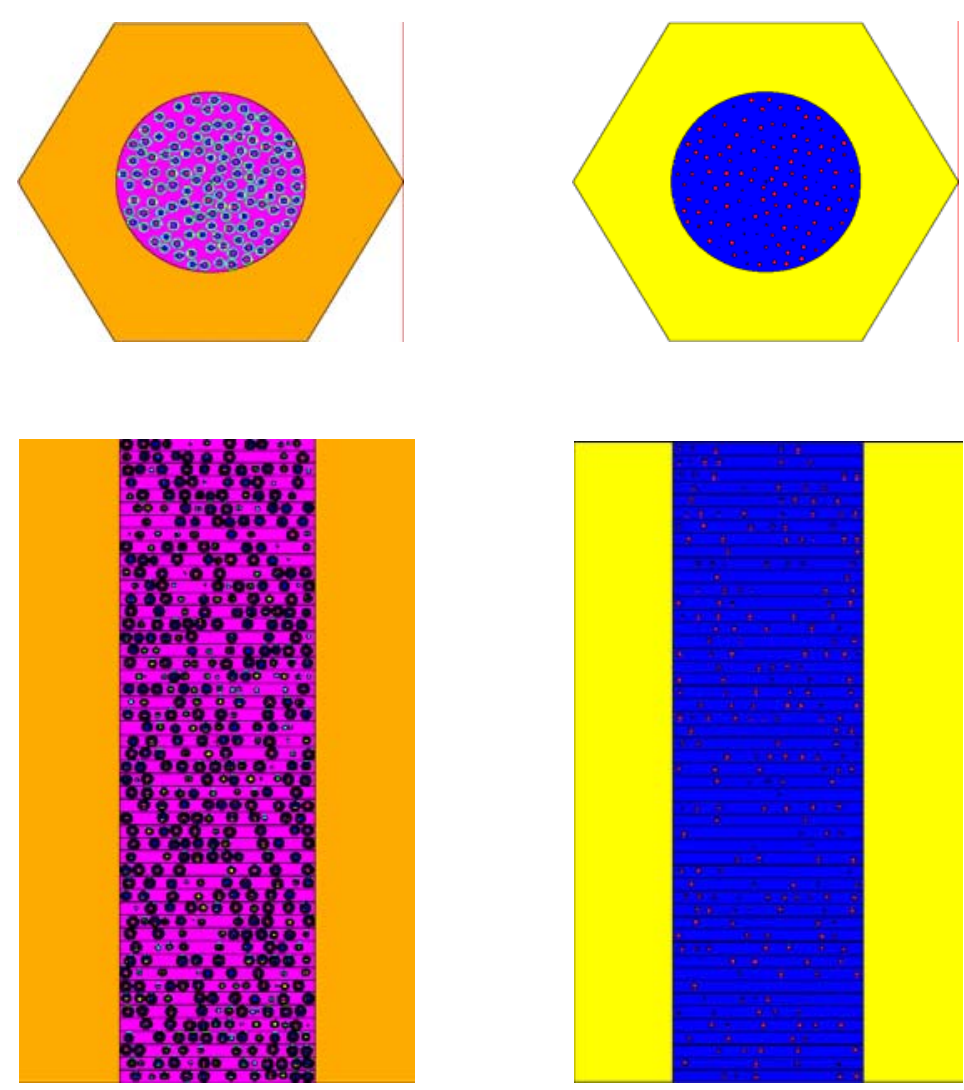

Figure 5-1. MCNP5 Fuel Compact Geometries:

Six-region (left) and Two-region (right) RSA Configurations
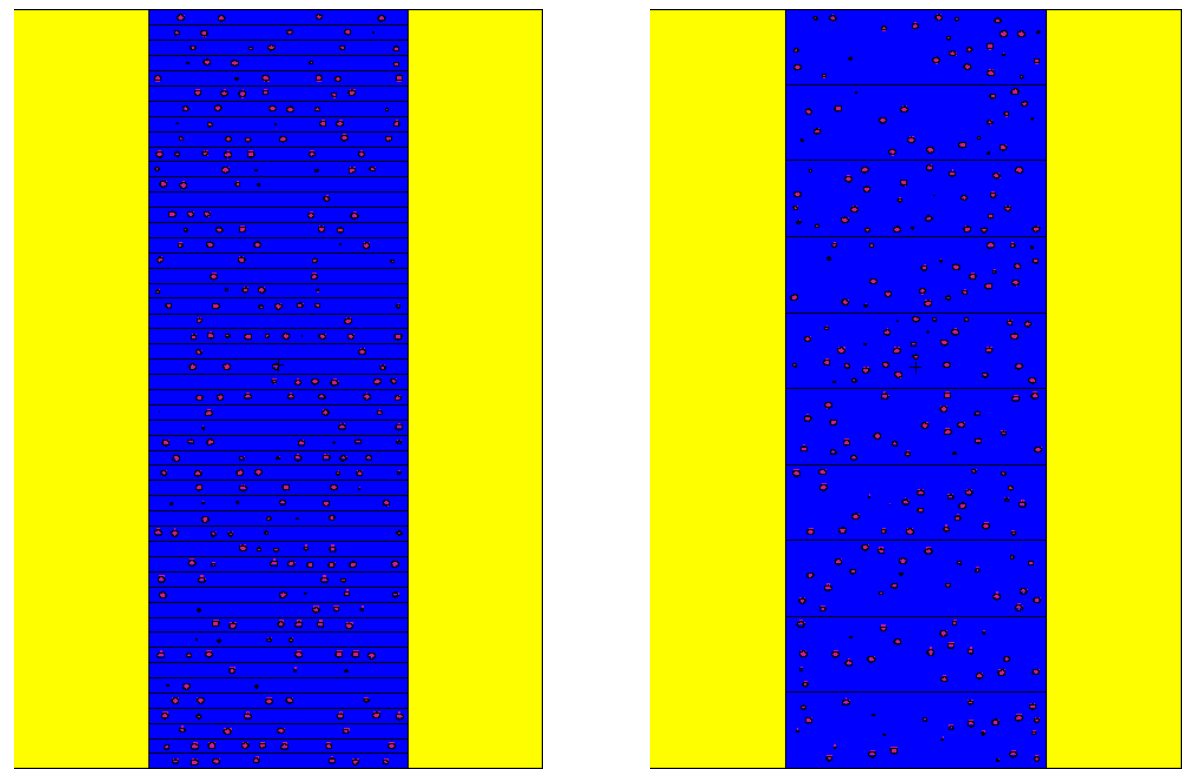

Figure 5-2. MCNP5 Fuel Compact Geometries:

Fifty-layer (left) and Ten-layer (right) RSA Configurations 


\section{Eliminating clipped cells}

We have already demonstrated that the stochastic mixture of fuel particles can be modeled as a simple cubic lattice of microspheres. However, if this lattice is then inserted into the fuel compact region of a fuel element, MCNP5 will "clip" the microspheres that are on the boundary of the fuel compact, resulting in partial fuel kernels on the boundary, as depicted in Figure 5-3. This is clearly unphysical and an artifact of an incomplete model with MCNP5. This has a substantial impact on the neutronic analysis, resulting in changes in keff on the order of $0.4 \%$ for fuel compact cells.

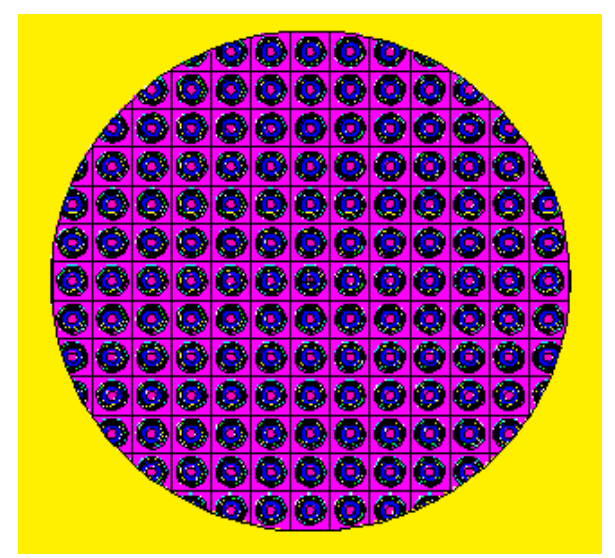

Figure 5-3. Clipped Model

Two approaches were examined to eliminate clipped cells while maintaining the packing fraction. The partial fuel kernels are removed in both approaches, meaning that the effective packing fraction of the remaining fuel is too high, since there is less fuel in the fuel compact region. To correct this, the first approach (\#1) squeezed the fuel in the $\mathrm{z}$ direction while keeping the planar (x-y) lattice the same, until the original packing fraction was obtained (see Figure 5-4a). This results in 121 fuel particles in the $x-y$ plane. However, this approach results in non-cubical cells. The second approach (\#2) kept the cells cubical but reduced the edge of the cube until the effective packing fraction of the fuel region was the desired value. This gave a denser planar distribution, with 129 fuel kernels in the plane versus 121 with the original lattice after partial fuel particles were removed.

The results for these configurations are shown in Table 5-2 for a fuel compact cell. The reference calculation is taken from Table 5-1 and is an RSA model with fully heterogeneous microspheres placed randomly in each of ten layers in a fuel compact as described above. As can be seen, the effect of clipping is substantial $(\sim-.25 \%)$ but the unclipped models overcompensate and are high by $\sim .2 \%$. Table 5-3 gives the results for full core although we do not have a reference calculation to compare with. As can be seen, the effect for full core calculations are consistent with the fuel compact cases, with the eigenvalues consistent with the clipped case the lowest, followed by unclipped models \#1 and \#2 in that order. However, the effect of clipped cells is somewhat less for the full core configuration than the fuel compact configuration, reflecting the decreased importance of the double heterogeneity in a full core configuration due to the softer spectra with the increased graphite in the full core configuration. 


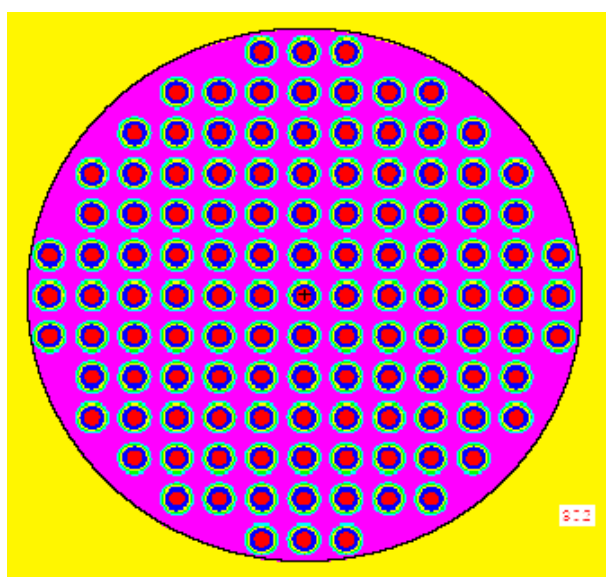

Figure 5-4a. Unclipped Model \#1

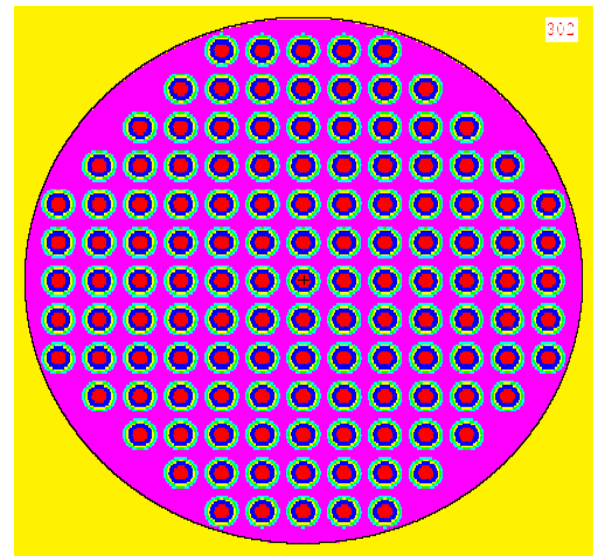

Figure 5-4b. Unclipped Model \#2

Table 5-2. MCNP5 Simulations of Fuel Compact Cells

\begin{tabular}{|l|l|l|}
\hline Fuel region modeled as & $k_{\text {eff }}$ & Sigma \\
\hline Six-region microsphere cells (clipped) & 1.3401 & .0004 \\
\hline Six-region microsphere cells (unclipped Model \#1) & 1.3438 & .0002 \\
\hline Six-region microsphere cells (unclipped Model \#2) & 1.3445 & .0002 \\
\hline Six-region microsphere cells RSA (Table 5-1) & 1.3426 & .0002 \\
\hline
\end{tabular}

Table 5-3. MCNP5 Simulations of Full Core

\begin{tabular}{|c|c|c|}
\hline Full core modeled with & $k_{\text {eff }}$ & Sigma \\
\hline Six-region microsphere cells (clipped) & 1.0946 & .0002 \\
\hline Six-region microsphere cells (unclipped Model \#1) & 1.0957 & .0002 \\
\hline Six-region microsphere cells (unclipped Model \#2) & 1.0966 & .0002 \\
\hline
\end{tabular}

\subsection{Temperature feedback}

We have completed calculations representing the effects of temperature feedback on global power distributions. This was done by coupling nuclear and thermal/hydraulic calculations performed by MCNP5 and RELAP5. The MCNP5 calculation used 103 homogenized prismatic fuel assemblies. These were grouped into three (inner, middle, and outer) rings comprising of 30, 37, and 36 assemblies each. The height of the core is $7.93 \mathrm{~m}$, discretized axially into 12 equal segments. The 36 regions ( 3 rings, 12 axial segments each) each had a different temperature.

The coupling of MCNP5 and RELAP5 was achieved through the use of a Python script. RELAP5 outputs a temperature distribution which is read by the Python script. The script creates an MCNP5 input file with the 36 different regions, achieving a temperature distribution in MCNP5. MCNP5 outputs a power distribution which is then input into RELAP5 and the iteration is repeated.

Previously we reported our difficulty in achieving convergence in coupled neutronic- $\mathrm{T} / \mathrm{H}$ calculations. The slow convergence of the power distribution is due to poorly converged point-wise power distribution in each MCNP run. We have run more particles in our MCNP simulations and corrected the number densities of the materials and have achieved convergence as shown in the Figure 5-5. 


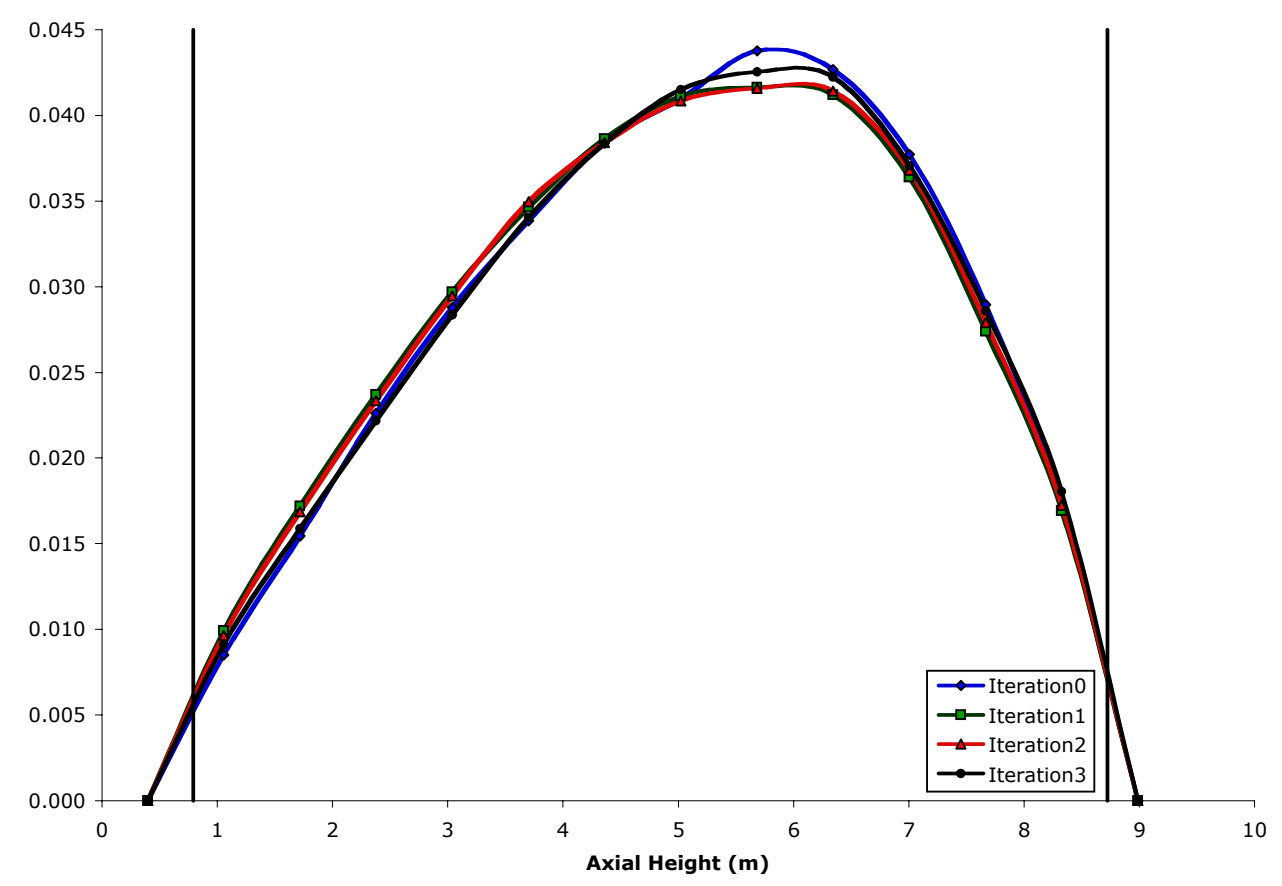

Figure 5-5. Iterations on Axial Power Distribution in the Middle Core Ring.

Between iteration 2 and 3 there is virtually no difference in the power distribution. The points on the plot were calculated at 14 axial regions, the lines are included to guide the eye. The temperature convergence is shown in Figure 5-6.

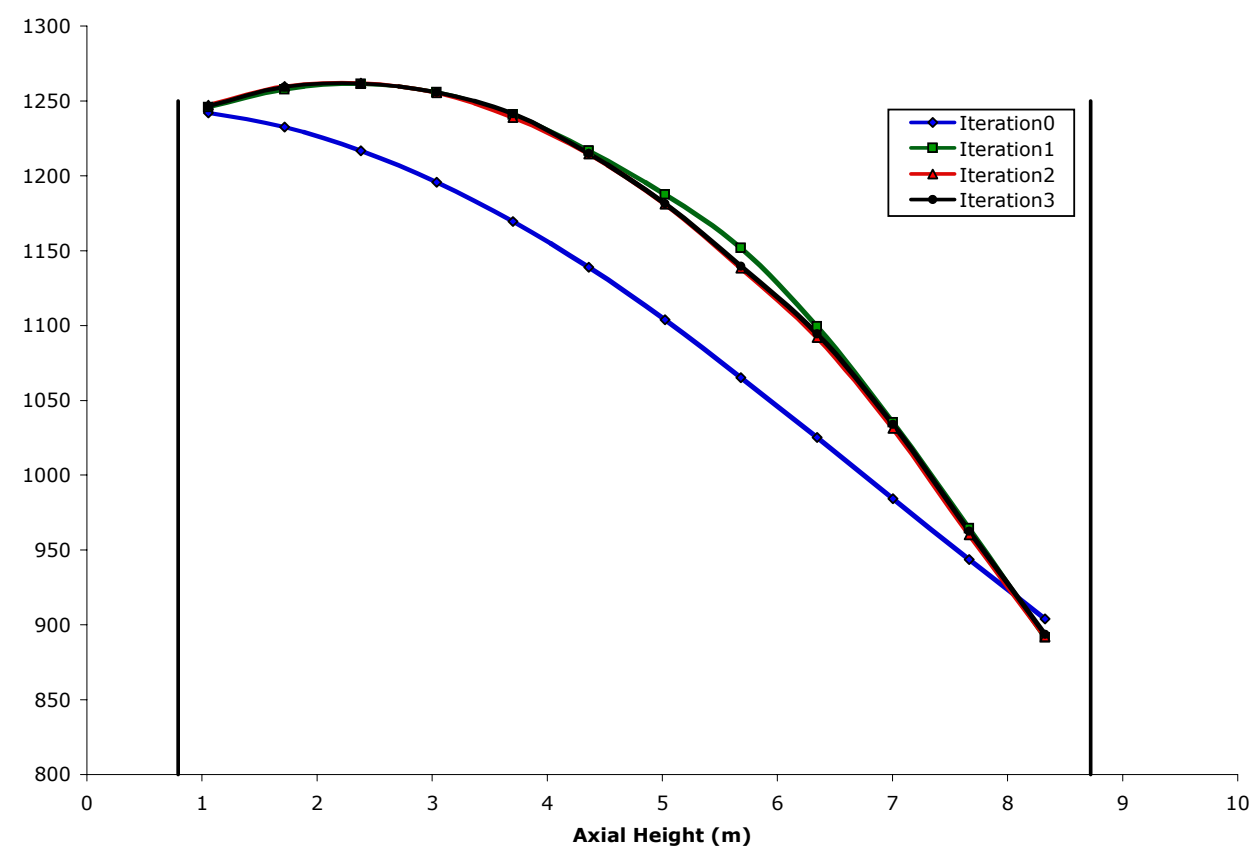

Figure 5-6. Iterations on Temperature Distribution in the Middle Core Ring 
More work has been done to ensure correct temperature dependent cross section libraries. Our past work has included using Pseudo Materials to approximate correct temperatures of the cross section libraries. A new tool has been created while at Los Alamos, facilitating the creation of new libraries and the use of Pseudo Materials.

\subsection{Fuel Depletion Calculations for the VHTGR Core}

As a key step in determining decay heat production rates in post-shutdown accident analyses for the VHTGR core, we focused significant effort over the past several months to perform fuel depletion calculations. Following the general approach we have taken for using the MCNP5 Monte Carlo code for all of our reactor physics calculations for the VHTGR core, we have used the MONTEBURNS code, which originally combined MCNP4C with the ORIGEN2.2 fuel depletion code, for all of our fuel cycle calculations. In order to allow consistent analyses with depletion, we modified the MONTEBURNS code to use MCNP5 and we also adapted it to run in parallel on our Apple G5 cluster.

For the MONTEBURNS calculations, the reactor core is divided into three radial rings, each of which consists of 10 homogenized hexagonal fuel blocks. To perform realistic fuel cycle analysis, we have represented 13 fuel nuclides, 25 fission products, and 5 structural materials listed in Table 5-4, where we include the MCNP5 material number ZAID for each nuclide. As the first step in accounting for temperature feedback in fuel depletion calculations, we used the DOPPLER code to generate MCNP5 cross section libraries for the 43 nuclides of Table 5-4 at a temperature of 900K.

Table 5-4. Fuel nuclides, fission products, and structural materials represented in the coupled MCNP5-ORIGEN2.2 fuel cycle analysis

\begin{tabular}{|c|c|c|c|c|c|}
\hline \multicolumn{2}{|c|}{ Fuel Nuclides } & \multicolumn{2}{|c|}{ Fission Products } & \multicolumn{2}{|c|}{ Structural Materials } \\
\hline Nuclide & ZAID Number & Nuclide & ZAID Number & Nuclide & $\begin{array}{c}\text { ZAID } \\
\text { Number }\end{array}$ \\
\hline $\mathrm{U}-234$ & $92234.00 \mathrm{c}$ & Kr-83 & $36083.00 \mathrm{c}$ & $\mathrm{C}-12$ & $6000.00 \mathrm{c}$ \\
\hline U-235 & $92234.16 \mathrm{c}$ & Zr-93 & $40093.00 \mathrm{c}$ & B-10 & $5010.00 \mathrm{c}$ \\
\hline $\mathrm{U}-238$ & $92238.16 \mathrm{c}$ & Tc-99 & $43099.00 \mathrm{c}$ & B-11 & $5011.00 \mathrm{c}$ \\
\hline Np-237 & $93237.00 \mathrm{c}$ & Rh-103 & $45103.00 \mathrm{c}$ & $\mathrm{O}-16$ & $8016.00 \mathrm{c}$ \\
\hline Pu-239 & $94239.00 \mathrm{c}$ & Rh-105 & $45105.00 \mathrm{c}$ & S-28 & $14028.00 \mathrm{c}$ \\
\hline $\mathrm{Pu}-240$ & $94240.00 \mathrm{c}$ & Pd-108 & $46108.00 \mathrm{c}$ & & \\
\hline $\mathrm{Pu}-241$ & $94241.00 \mathrm{c}$ & Ag-109 & $47109.00 \mathrm{c}$ & & \\
\hline $\mathrm{Pu}-242$ & $94242.00 \mathrm{c}$ & Xe-131 & $54131.00 \mathrm{c}$ & & \\
\hline $\mathrm{Pu}-243$ & $94243.00 \mathrm{c}$ & Xe-134 & $54134.00 \mathrm{c}$ & & \\
\hline $\mathrm{Pu}-244$ & $94244.00 \mathrm{c}$ & Xe135 & $54135.00 \mathrm{c}$ & & \\
\hline Am-241 & $95241.00 \mathrm{c}$ & Cs-133 & $55133.00 \mathrm{c}$ & & \\
\hline Am-242 & $95242.00 \mathrm{c}$ & Cs-137 & $55137.00 \mathrm{c}$ & & \\
\hline Am-243 & $95243.00 \mathrm{c}$ & Ba-138 & $56138.00 \mathrm{c}$ & & \\
\hline & & Nd-143 & $60143.00 \mathrm{c}$ & & \\
\hline & & Nd-145 & $60145.00 \mathrm{c}$ & & \\
\hline & & Pm-147 & $61147.00 \mathrm{c}$ & & \\
\hline & & Pm-148 & $61148.00 \mathrm{c}$ & & \\
\hline & & Sm-147 & $62147.00 \mathrm{c}$ & & \\
\hline & & Sm-149 & $62149.00 \mathrm{c}$ & & \\
\hline & & Sm-150 & $62150.00 \mathrm{c}$ & & \\
\hline & & Sm-151 & $62151.00 \mathrm{c}$ & & \\
\hline & & Sm-152 & $62152.00 \mathrm{c}$ & & \\
\hline & & Eu-153 & $63153.00 \mathrm{c}$ & & \\
\hline & & Eu-154 & $63154.00 \mathrm{c}$ & & \\
\hline & & Eu-155 & $63155.00 \mathrm{c}$ & & \\
\hline
\end{tabular}


Using a uniform temperature of $900 \mathrm{~K}$ for the entire core and reflector regions, we performed fuel depletion calculations for a one-year fuel cycle, using MONTEBURNS time steps of one month each. We plot in Figure 5-7 the axial fuel burnup distribution for the 10 axial zones in the middle fuel ring at the end of first burnup step of 30 days into the fuel cycle and at the end of the 12th time step corresponding to the end of cycle (EOC). We note significant flattening of the axial burnup distribution over the year-long cycle, which results from a preferential depletion of the fuel in high-power regions of the core over the cycle. Figure 5-8 shows the evolution of the effective multiplication factor as a function of time.

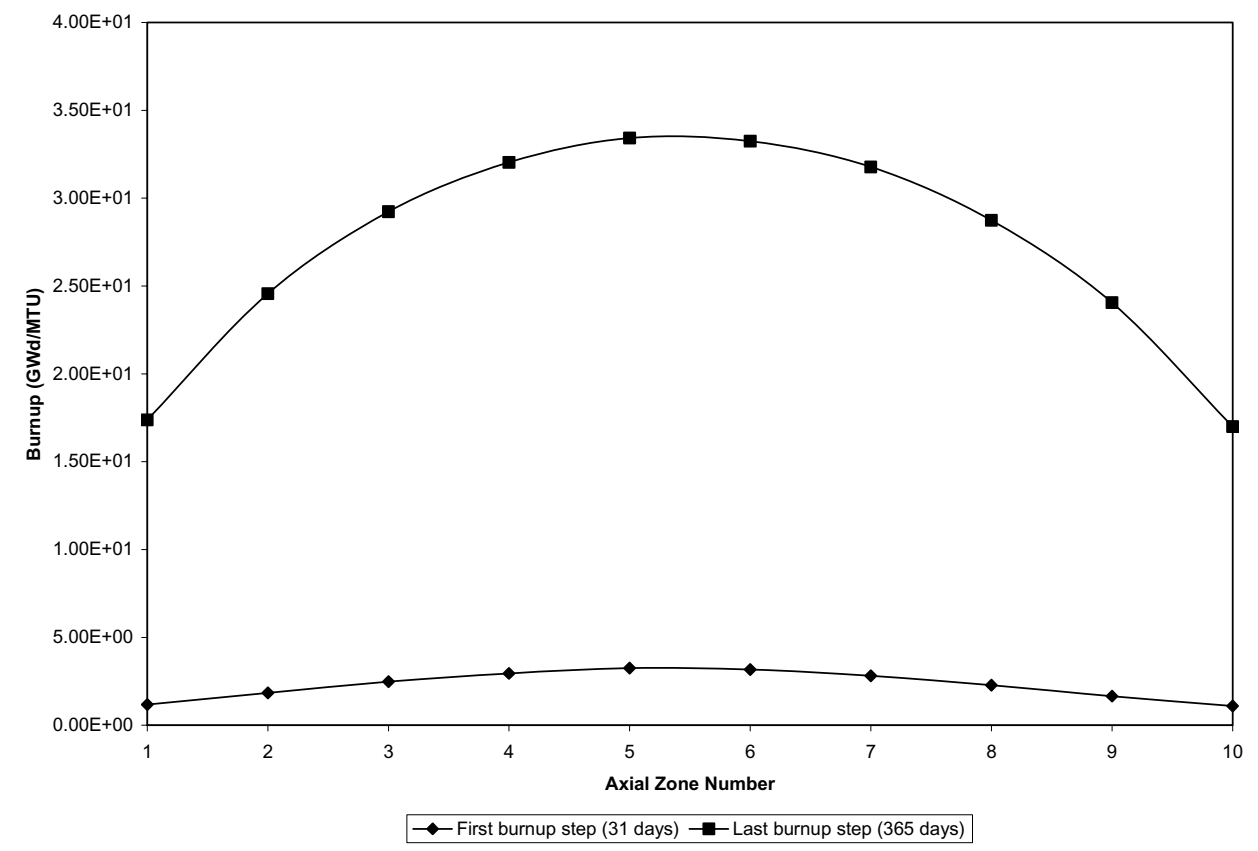

Figure 5-7. Axial burnup distributions over 10 axial fuel blocks of the middle fuel ring.

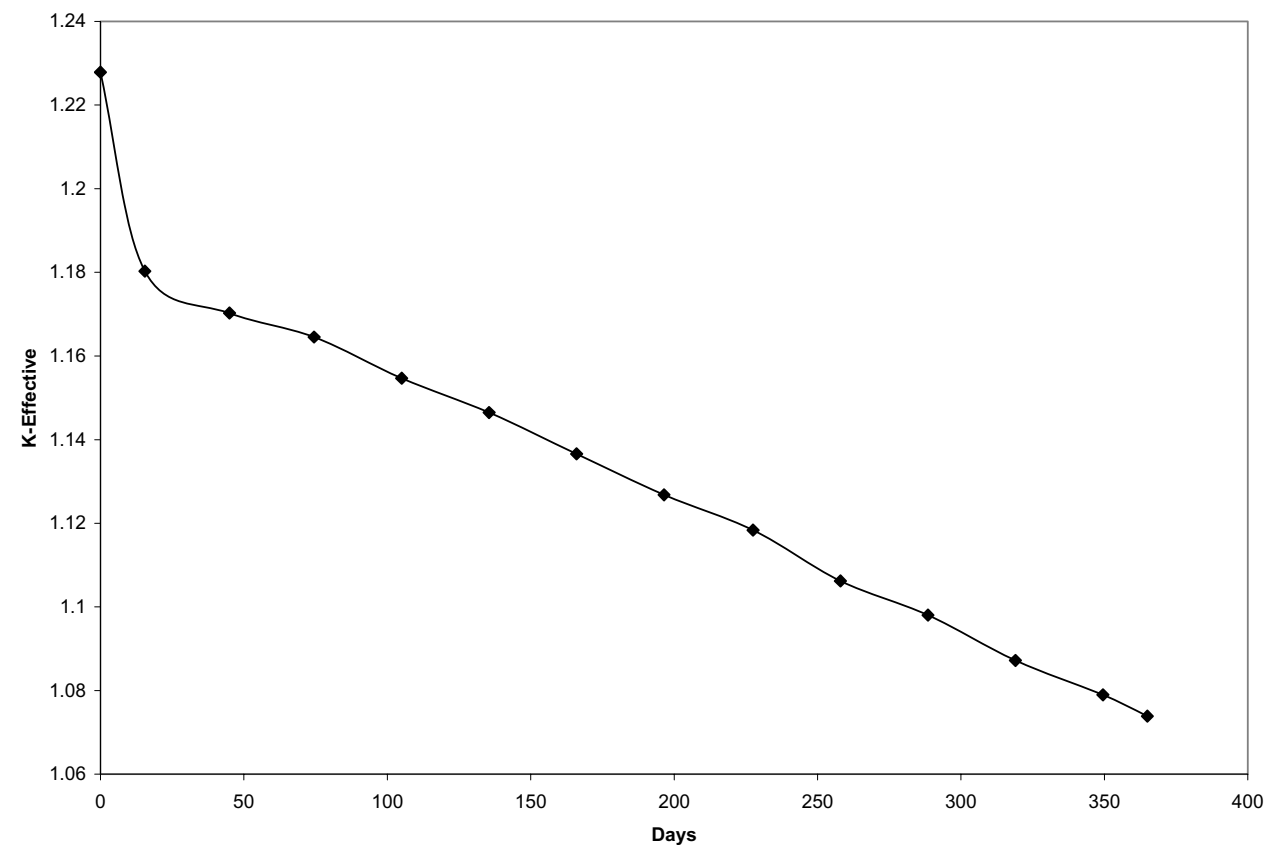

Figure 5-8. Effective multiplication factor as a function of time during the fuel cycle. 
We also continued the ORIGEN2.2 calculations following the shutdown of the reactor at the end of the yearlong cycle. The calculations yield fission product decay heat production rates, representing the EOC burnup distribution, as a function of time after the shutdown. We are in the process of analyzing the ORIGEN2.2 post-shutdown decay heat production rates and will also implement, in stand-alone MCNP5 gamma transport calculations, post-shutdown radioactivity and decay energy data for each of the 25 MONTEBURNS fission products of Table 4-1.

Remaining activities

Detailed fuel depletion calculations will be performed to allow the use of power distributions that account for temperature feedback. Gamma transport calculations will be performed to obtain decay heat deposit rates as a function of time after reactor shutdown for a discrete representation of 30 fuel blocks.

Issues/Concerns

None.

\section{Publication in 2005:}

1. F. B. Brown, W. R. Martin, W. Ji, J. L. Conlin, and J. C. Lee, "Stochastic Geometry and HTGR Modeling with MCNP5," Proc. Monte Carlo 2005 Topical Meeting, American Nuclear Society, Chattanooga, TN, April 17-21, 2005, on CD-ROM, American Nuclear Society, LaGrange Park, IL (2005).

2. W. Ji, J. L. Conlin, W. R. Martin, J. C. Lee, and F. B. Brown, "Explicit Modeling of Particle Fuel for the Very-High Temperature Gas-Cooled Reactor," Trans. Am. Nucl. Soc. 92, 236-238, San Diego, CA (2005).

3. J. L. Conlin, W. Ji, J. C. Lee, and W. R. Martin, "Pseudo Material Construct for Coupled NeutronicThermal-Hydraulic Analysis of VHTGR," Trans. Am. Nucl. Soc. 92, 225-227, San Diego, CA (2005).

4. H.-C. No, C. H. Oh, J. H. Kim, G.-C. Park, J. C. Lee, W. R. Martin, M. O. Kim, J. L. Conlin, and W. Ji, "Very-High-Temperature Gas-Cooled Reactors: Progress and Challenges," Proc. International Congress on Advances in Nuclear Power Plants, ICAPP 2005, Seoul, Korea.

5. W. Ji, J. L. Conlin, G. Yesilyurt, W. R. Martin, J. C. Lee, and F. B. Brown, "Neutronic Analysis to Support Validation of Safety Analysis Codes for the VHTR," submitted to the American Nuclear Society Annual Conference, Washington, DC (November 2005).

\section{Task 6: V\&V Simulation (All)}

Most of results in all tasks, $1,2,3,4$, and 5 are $V \& V$ simulation. 


\section{APPENDIX-A}

\section{References}

\section{Task 1}

1. J. Roes, "Experimental Investigations of Graphite Corrosion and Aerosol Formation during Air Ingress into the Core of a High Temperature Pebble Bed Reactor," Juel-2956 (1994)

2. F. Reitsma, et. al., "The PBMR Steady State and Coupled Kinetics Core Thermal-Hydraulics Benchmark Test Problems," $2^{\text {nd }}$ international Topical Meeting on High Temperature Reactor Technology, Paper C17, Beijing, China, September 2004.

3. General Atomics, "GT-MHR Conceptual Design Description Report," GA/NRC-337-02, August 2002.

4. "Heat Transport and Afterheat Removal for Gas Cooled Reactors Under Accident Conditions," IAEATECDOC-1163, International Atomic Energy Agency (2000).

\section{Task 2}

1. IAEA-TECDOC-757, "Decay heat removal and heat transfer under normal and accident conditions in gas cooled reactors," IAEA, VIENNA (1994).

2. N. Kuzavkov, "Heat transport and afterheat removal for gas cooled reactors under accident conditions," IAEA, Vienna, pp.19-27, 2000.

3. Aleksander sala, Radiant Properties of Materials, ELSEVIER SCIENCE PUBLISHING CO., INC. New york, pp. 341-354 (1986).

4. D.Especel, S.Mattei, "Total emissivity measurement without use of an absolute reference," Infrared Physics \& Technology 37, pp.777-784, 1996.

5. Michael F. Modest, Radiative heat Transfer, Academic Press, USA (1993).

6. Frank P. Incopera, Introduction to heat transfer, John Wiley \& Sons, USA (1996).

7. KAERI (Korea Atomic Energy Research Institute), MARS3.0 code manual, KAERI, Korea, pp. 239-240 (2004).

8. TAC Technologies, "NEVADA Software Package Quick Reference Series", TAC Technologies, USA, 2000 .

9. W.J. Lee et al., "Development of MARS-GCR for Gas-Cooled Reactor Analysis - Incorporation of Gas Properties,” Proceeding of NURETH-10, Seoul, Korea, October 5-9, 2003.

10. M. Moshfeghian and K.J. Bell, "Local heat transfer measurements in and downstream from a U-bend," ASME paper No. 79-HT-82, 1979.

11. B. J. Yun et al., Measurement of the Two-phase Mass Flow Rate Using an Average Bidirectional Flow Tube, Proceeding of Two-Phase Flow Modeling and Experimentation, Pisa, Italy, September, 2004.

12. R.K. MacGregor et al., Free Convection Through Vertical Plane Layers: Moderate and High Pradtl Number Fluids, J. Heat Transfer, Vol. 91, pp. 391, 1969.

13. Y. Mori and W. Nakayama, "Study on Forced convective Heat Transfer in Curved Pipes", Int. J. Mass Transfer, 10, pp. 37-59, 1967. 


\section{Task 3}

1. P.L. Walker, Jr., F. Rusinko, Jr., and L. G. Austin, 1958, Gas Reactions of Carbon, Advan. Catalysis, Vol. 11,133

2. E.L. Fuller, O.C. Kopp and A.D. Underwood, 1991, Kinetics and mechanisms of graphite oxidation: A microgravimetric system for evaluation of chemical and structural effects, Proc. 20th Conf. Carbon , 604 , ORNL-TN-37831

3. E.L. Fuller, Joseph M. Okoh, 1997, Kinetics and mechanisms of the reaction of air with nuclear grade graphites: IG-110, J. Nuclear Materials, Vol. 240, pp. 241-250

4. Masuro Ogawa, 1993, Mass transfer with graphite oxidation in gas mixture laminar flow through circular tube, JEARI, Vol. 35, No. 3, pp. 245- 252

5. M. Ogawa, 1987, Mass transfer of mixed gas flow crossing a high temperature graphite cylinder with chemical reactions and in-pore diffusion, Int. J. Heat Mass Transfer, Vol. 30, No. 5, pp. 1017-1026

6. Haruo Kawakami, 1986, Air oxidation behavior of carbon and graphite materials for HTGR, JEARI, No. 124, pp. 26-33

7. O'Brien, M.H. Merrill, S.N. Ugaki, 1988, Combustion testing and thermal modeling of proposed CIT graphite tile materials, EGG-FSP-2855, Eg\&G Idaho

8. Luo Xiaowei, Robin Jean-Charles, Yu Suyuan, 2003, Effect of temperature on graphite oxidation behavior, Nuclear Engineering and Design Revised

9. H.K. Hinsen, W. Katscher, R. Moorman, 1983, Kinetics of the graphite/oxygen reaction in the in-pore diffusion controlled regime

\section{Task 4}

1. C. B. Davis, The Addition of Oxygen, Carbon Dioxide, and Carbon Monoxide

NoncondensableGases into RELAP5-3D, INL Report R5/3D-03-05, April, 2003.

2. J. B. Duncan and H. L. Toors, "An Experimental Study of Three Component Gas Diffusion,"

A. I. Ch. E. Journal, March, 1962, pages 38-41.

3. W. H. Press et al., Numerical Recipes, Cambridge University Press, New York, NY, 1986.

4. R. C. Reid, J. M. Prausnitz, and B. E. Poling, The Properties of Gases and Liquids, Fourth

Edition, McGraw-Hill Book Company, New York, 1986.

5. The RELAP5-3D-3D Development Team, RELAP5-3D-3D Code Manual, INEEL-EXT-98-00834, Revision 2.0, July 2002.

\section{Task 5}

1. F. B. Brown, "MCNP - A General Monte Carlo N-Particle Transport Code, Version 5", LA-UR-03-1987, Los Alamos National Laboratory (2003).

2. F. B. Brown and W. R. Martin, "Stochastic Geometry for MCNP5," Trans. Am. Nucl. Soc. 91, 171-173, Washington, DC (November 2004). 
3. F. B. Brown and W. R. Martin, "Stochastic Geometry Capability in MCNP5 for the Analysis of Particle Fuel," Annals of Nuclear Energy 31, (November 2004).

4. F. B. Brown, W. R. Martin, W. Ji, J. L. Conlin, and J. C. Lee, "Stochastic Geometry and HTGR Modeling with MCNP5," Proc. Monte Carlo 2005 Topical Meeting, American Nuclear Society, Chattanooga, TN, April 17-21, 2005, on CD-ROM, American Nuclear Society, LaGrange Park, IL (2005).

5. J. L. Conlin, W. Ji, J. C. Lee, W. R. Martin, Pseudo-Material construct for Coupled Neutronic-ThermalHydraulic Analysis of VHTGR, Trans. Am. Nuc. Soc. 92, 225 (2005).

6. J. L. Conlin, F. B. Brown, R. D. Mosteller, "Temperature Corrections in MCNP for Calculating the Doppler Defect," LA-UR-05-6225, Los Alamos National Laboratory, (2005).

7. W. Ji, J. L. Conlin, W. R. Martin, and J. C. Lee, "Reactor Physics Analysis of the VHTGR Core," Trans. Am. Nucl. Soc. 91, 556-558, Washington, DC (November 2004).

8. W. Ji, J. L. Conlin, W. R. Martin, J. C. Lee, and F. B. Brown, "Explicit Modeling of Particle Fuel for the Very-High Temperature Gas-Cooled Reactor," Trans. Am. Nucl. Soc. 92, 236-238, San Diego, CA (2005).

9. W. Ji, J. L. Conlin, G. Yesilyurt, W. R. Martin, J. C. Lee, and F. B. Brown, "Neutronic Analysis to Support Validation of Safety Analysis Codes for the VHTR," submitted to the American Nuclear Society Annual Conference, Washington, DC (November 2005).

10. P. E. MacDonald, et al., "NGNP Preliminary Point Design - Results of the Initial Neutronics and Thermal-Hydraulic Assessments During FY-03", INEEL/EXT-03-00870 Rev. 1, Idaho National Engineering and Environmental Laboratory (2003).

11. R. E. MacFarlane and P. Talou, "DOPPLER: A Utility Code for Preparing Customized Temperature-Dependent Data Libraries for the MCNP Monte Carlo Transport Code," Internal Memorandum, Los Alamos National Laboratory (2003).

12. D. L. Poston and H. R. Trellue, "User's Manual, Version 2.0 for MONTEBURNS Version 1.0," LA-UR-99-4999, Los Alamos National Laboratory (1999).

13. The RELAP5-3D Code Development Team, "ATHENA Code Manual," INEEL-EXT-98-00834, Rev. 2.2, Idaho National Engineering and Environmental Laboratory (2003). 


\section{APPENDIX -B}

\section{Project Milestone / Deliverable Summary}

\begin{tabular}{|c|c|c|}
\hline Milestone/Deliverable Description & $\begin{array}{l}\text { Planned } \\
\text { Completion }\end{array}$ & Actual Completion \\
\hline 1. CFD TH Code Development & 30 June 2005 & Completed \\
\hline 1-1 CFD TH model & 31 December 2004 & Completed \\
\hline 1-2 Diffusion model & 31 December 2003 & Completed \\
\hline 1-3 Chemical reaction model & 30 June 2005 & Completed \\
\hline 1-4 Particle model & 30 June 2005 & Completed \\
\hline 2. $\quad$ RCCS Separate Experiment & 30 June 2005 & Completed \\
\hline $\begin{array}{l}\text { 2-1. Development of water-pool } \\
\text { RCCS }\end{array}$ & 31 December 2003 & Completed \\
\hline 2-2. Scaling of water-pool RCCS & 30 June 2005 & Completed \\
\hline 2-3 Heat transfer coefficients & 30 June 2005 & Completed \\
\hline 3. Air Ingress Separate Experiment & 30 June 2005 & Completed \\
\hline $\begin{array}{l}\text { 3-1. Measurement technique } \\
\text { development }\end{array}$ & 30 June 2004 & Completed \\
\hline 3-2. Diffusion-limited model & 30 June 2005 & Completed \\
\hline $\begin{array}{l}\text { 4-1. Implementation of Diffusion } \\
\text { model }\end{array}$ & 31 March 2005 & Completed \\
\hline $\begin{array}{l}\text { 4-1-A. Noncondensable gas } \\
\text { implementation }\end{array}$ & 30 April 2003 & Completed \\
\hline 4-1-B Diffusion model & 31 December 2003 & Completed \\
\hline 4-1-C Simulation & 31 March 2006 & On going \\
\hline $\begin{array}{l}\text { 4-2. Implementation of Chemical } \\
\text { Equilibrium Model }\end{array}$ & 31 December 2003 & Completed \\
\hline 4-2-A Extended work to task 4 & January 2006 & On going \\
\hline 4-2-B. Simulation & 31 March 2006 & On going \\
\hline 5. $\quad$ Neutronic Modeling & 31 December 2005 & On going \\
\hline 6. $\quad$ V\&V Simulation & 31 March 2006 & On going \\
\hline 6-1. RCCS validation & 31 December 2005 & On going \\
\hline 6-2. System code vs. CFD code & 31 December 2006 & On going \\
\hline 6-3. Large-scale air ingress analysis & 31 March 2006 & On going \\
\hline 6-4. System scale simulation & 31 march 2006 & On going \\
\hline Final report & 30 April 2006 & Scheduled \\
\hline
\end{tabular}




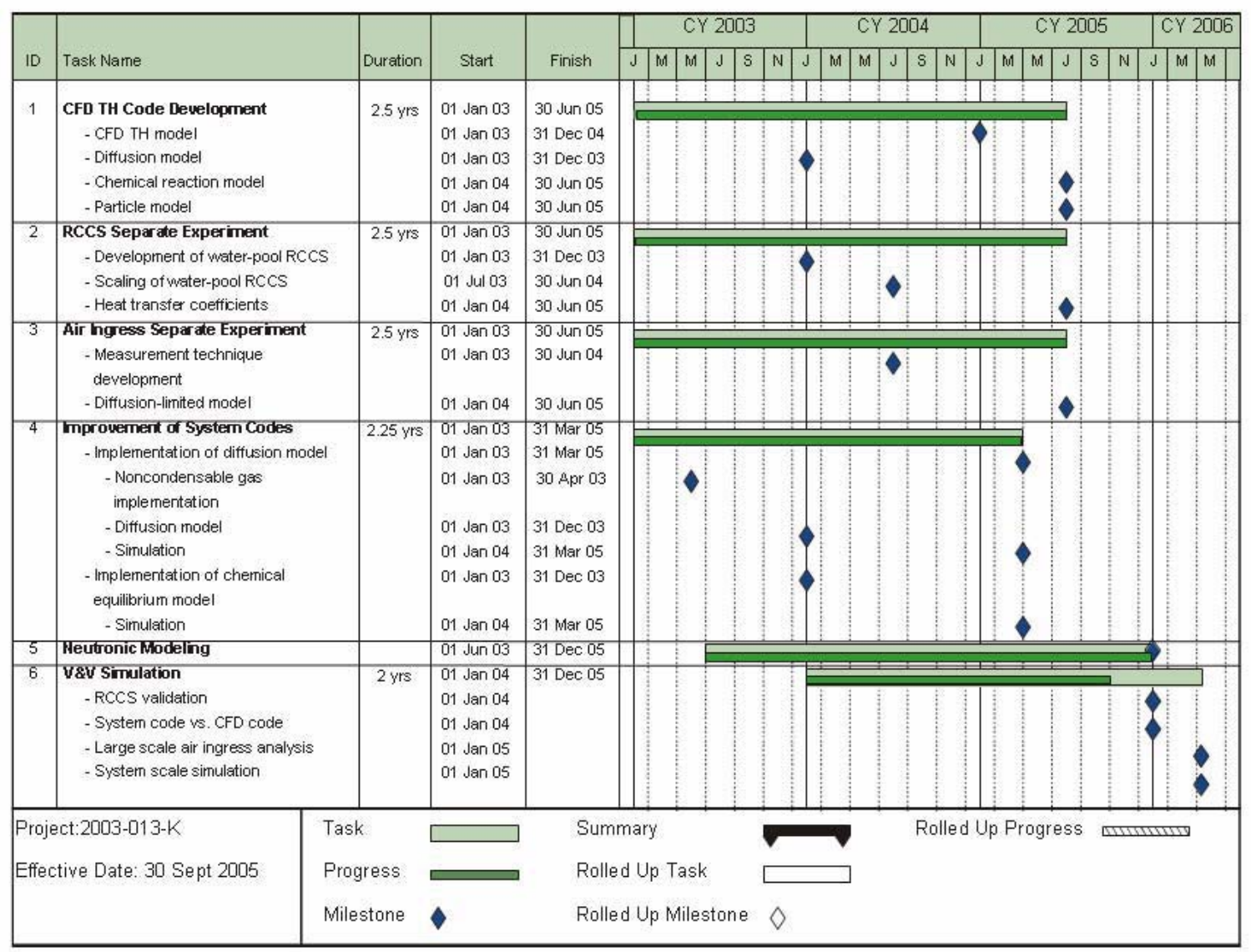

[5-6950365-05 